\title{
Magnetic Properties and Kinetic Roughening Study of Prepared Polyaniline- Lead Ferrite, Cobalt Ferrite and Nickel Ferrite Nanocomposites Electrodeposited Thin Films
}

\section{Leila Abbasi}

Arak University of Technology

Kambiz Hedayati ( $\sim$ kambiz.hedayati@gmail.com )

Arak University of Technology https://orcid.org/0000-0002-2875-0255

Davood Ghanbari

Arak University of Technology

Original Research

Keywords: Nanocomposite, Polyaniline, Electrodeposition

Posted Date: February 12th, 2021

DOl: https://doi.org/10.21203/rs.3.rs-190312/v1

License: (c) (1) This work is licensed under a Creative Commons Attribution 4.0 International License.

Read Full License 


\title{
Magnetic properties and kinetic roughening study of prepared polyaniline- lead ferrite, cobalt ferrite and nickel ferrite nanocomposites electrodeposited thin films
}

\author{
Leila Abbasi, Kambiz Hedayati*, Davood Ghanbari \\ Department of Science, Arak University of Technology, Arak, 3818141167, Iran \\ *K-hedayati@arakut.ac.ir
}

\begin{abstract}
:
The purpose of this study was to prepare polyaniline-lead ferrite, polyaniline-cobalt ferrite and polyaniline / nickel ferrite thin layers. The preparation process consists of two steps :First, ferrites are synthesized using a microwave irradiated hydrothermal method. The ferrites were then added separately to $0.1 \mathrm{M}$ aniline electrolyte solution and $0.2 \mathrm{M}$ sulfuric acid. The accumulation of polyaniline and ferrite composites was carried out in an electrochemical cell by electrodeposition method. The surface morphology of the composite layers was investigated by scanning electron microscopy and the percentage of the constituents was studied by X-ray energy scattering (EDX) analysis. Also, surface roughness analysis and kinetic roughening of thin films was performed using atomic force microscopy (AFM). Hysteresis loop of magnetic samples were investigated by vibrating sample magnetometer (VSM). The structure and crystalline size of samples studied by X-ray diffraction analyze.
\end{abstract}

Keywords: Nanocomposite, Polyaniline, Electrodeposition 


\section{Introduction}

The electromagnetic pollution has been arising from mobile phones, radar systems, computers another electronic devices. It has become electromagnetic pollution where can be compared with other pollution like water and air pollution and it is necessary to dissolve this problem [1]. Since the use of electromagnetic devices has quickly increased and publications of electromagnetic energy have grown in the frequency span used via another users, electromagnetic interposition (EMI) has become an important trouble in urban society. Electromagnetic waves can peril health similar nervousness and headaches. Therefore, different EMI shielding procedures have been expanded for decrease the possibility of incidence of the aforesaid dangers [2].

At first, metallic components were utilized for shielding aim [3]. Newly, carbon-based nanostructures shielding materials have expand considerable attractive due to good flexibility, small density and high electrical conductivity. The carbon materials in any matrix may reason decreasing EMI shielding efficiency and make them excellent materials for commercial shielding usage. Between the conducting polymers (CPs), polyaniline (PANI) is charming causes because easy synthesis, easy doping, high chemical stability and high electrical conductivity [4].

The addition of nanoparticles to polymers allows the modification of the polymer's physical and mechanical virtues [5]. The properties of nanomaterials are various from bulk because of surface efficacy and quantum confined size [6]. Magnetic materials have many applications in data storage and magnetic devices like patterned media and random access. Magnetic iron oxide nanoparticles or ferrites are effective magnetic materials for the uses in sensors, catalysis and other magnetic devices $[7,8]$. Ferrites can be classified in spinel ferrites, hexagonal ferrites and garnet ferrites categories between these, spinel ferrites have substantial significance for researchers because of their high saturation magnetization, small coercivity, large magneto crystalline anisotropy and high 
Curie temperature. Spinel ferrites in the total formula of $\mathrm{AFe}_{2} \mathrm{O}_{4}$ (A is a divalent metal cation) have newly possessed a big amount of consideration. Nickel ferrite $\left(\mathrm{NiFe}_{2} \mathrm{O}_{4}\right)$ and cobalt ferrite $\left(\mathrm{CoFe}_{2} \mathrm{O}_{4}\right)$ are the superlative significant functional ferrites which have a vast span of applications [9-12]. Hexagonal ferrites $\mathrm{MFe}_{12} \mathrm{O}_{19}(\mathrm{M}=\mathrm{Pb}, \mathrm{Sr}$ and $\mathrm{Ba})$ are good known as permanent magnetic materials with powerful anisotropy concomitant the c-axis. Furthermore, hexagonal ferrites are technologically a very helpful materials in sector because of their application in permanent constant magnets and microwave devices. [13].

Due to the widespread applicability of ferrites, different synthesis path has been expanded since their fabrication. These contain the sol-gel, coprecipitation, hydrothermal and microemulsion, microwave treatment [14-16]. Between the different techniques reported, microwave combustion the method is maybe chosen for homogeneity, high purity and reformed specifications. The microwave energy is an inner one equipment of heat energy generation and transformation. In result, the morphology, shape, crystallite size, and other properties are almost variation by changed microwave energy as heating source [14].

Electrodeposition is an interesting technique for deposition of conductive and semi conductive layers. Electrodeposited films can be produced by controlling either the deposition potential or current density in electrolyte. Three electrodes used in electrodeposition: (1) a working electrode (WE) on substrate is deposited, (2) a secondary electrode (SE) to complete the electrical circuit and (3) a reference electrode (RE) to control the potential between the WE and the electrolyte $[17,18]$.

The Superlative efficient method to fabrication conducting polymers is via electrochemical polymerization. Electrochemical polymerization technique has well control on the morphology and thickness of the coatings via controlling current density and potential. In addition, 
Electrochemical is an economical method [19]. Electrodeposition of polyaniline is an economical and environmental technique. Electrodeposition process can be environmental because no toxic oxidant or surfactant is needed to polymerization of solution. The electrodeposition of polyaniline is forcefully dependent on different factors similar $\mathrm{pH}$, temperature, solution concentration and substrate material texture [20-22].

\section{Experimental}

The materials used to synthesized of nanocomposites are lead acetate $\left(\mathrm{Pb}\left(\mathrm{C}_{2} \mathrm{H}_{3} \mathrm{O}_{2}\right)_{2}\right)$, cobaltsulfate hydrate $\left(\mathrm{CoSO}_{4} \cdot\left(\mathrm{H}_{2} \mathrm{O}\right)_{7}\right)$, nickel sulfate $\left(\mathrm{NiSO}_{4} \cdot 6 \mathrm{H}_{2} \mathrm{O}\right)$, sodium hydroxide $(\mathrm{NaOH})$ and iron nitrate.9aq a.r. $\left(\mathrm{Fe}\left(\mathrm{NO}_{3}\right)_{3} .9 \mathrm{H}_{2} \mathrm{O}\right)$ were purchased from Aldrich or Merck (Germany, Berlin). Aniline $\left(\mathrm{C}_{6} \mathrm{H}_{5} \mathrm{NH}_{2}\right)$ that distilled before use was purchased from Merck.

The structure of the samples was analyzed by X-ray diffraction (Philips, X'PertPro), with CuK $\alpha$ radiation $(\lambda=0.154 \mathrm{~nm})$. The percentage of ingredients was studied by X-ray energy scattering analysis (EDX). The surface morphology of the thin films was examined by scanning electron microscope equipped with EDX detector by LEO model VP 1450 (Germany). The surface roughness analysis of the layers was studied by atomic force microscopy manufactured by Ara Research Company (Iran). The room temperature hysteresis magnetic loop was investigated using the VSM device (Meghnatis Kavir Kashan Company, Iran).

\section{Preparation of ferrite nanoparticles:}

In this study, nanoparticles of cobalt, lead and nickel ferrite were synthesized by microwave irradiation. The process steps for each of these are as follows: 


\section{Preparation of cobalt ferrite nanoparticles}

For synthesized cobalt ferrite $0.2 \mathrm{~g}$ of cobalt-sulfate hydrate and $1 \mathrm{~g}$ of iron nitrate $9 \mathrm{H}_{2} \mathrm{O}$ were combined into $200 \mathrm{ml}$ of deionized water. The solution was stirred for 30 mins with a magnetic stirrer at temperature of $100{ }^{\circ} \mathrm{C}$. Then the $\mathrm{pH}$ of the prepared solution was increased to 10 by incorporate $20 \mathrm{ml}$ of $1 \mathrm{M}$ sodium hydroxide solution. The solution was cooled to room temperature for 10 mins. After than solution to be microwave irradiated for 10 mins. The cobalt ferrite precipitate was washed and separated by centrifugation and completely dried at $80^{\circ} \mathrm{C}$.

\section{Synthesis of lead hexa-ferrite nanoparticles}

$0.1 \mathrm{~g}$ of $\mathrm{Pb}\left(\mathrm{C}_{2} \mathrm{H}_{3} \mathrm{O}_{2}\right)_{2}$ and $1.5 \mathrm{~g}$ of $\mathrm{Fe}\left(\mathrm{NO}_{3}\right)_{3} .9 \mathrm{H}_{2} \mathrm{O}$ were mixed together into $50 \mathrm{ml}$ of deionized water. The solution was stirred for 5 mins with a magnetic stirrer. The $\mathrm{pH}$ of the solution by adding $15 \mathrm{ml}$ of $1 \mathrm{M} \mathrm{NaOH}$ solution was increased to 10 . The solution was then microwave irradiated for 5 mins. The $\mathrm{PbFe}_{12} \mathrm{O}_{19}$ precipitate was washed and centrifugation and completely dried at $80{ }^{\circ} \mathrm{C}$. The powder was then placed in the electronic furnace for $2 \mathrm{~h}$ at $800{ }^{\circ} \mathrm{C}$.

\section{Preparation of nickel ferrite}

Nickel ferrite nanoparticles were prepared by combine $0.1 \mathrm{~g}$ of nickel sulfate and $0.31 \mathrm{~g}$ of iron nitrate $\left(9 \mathrm{H}_{2} \mathrm{O}\right)$ into $50 \mathrm{ml}$ of deionized water. The mixed solution was stirred for $5 \mathrm{mins}$. The $\mathrm{pH}$ of the resulted solution was increased to 10 by adding $10 \mathrm{ml}$ of one molar sodium hydroxide solution. The final solution was then microwave irradiated for 5 mins. The nickel ferrite precipitate was separated by centrifugation and dried completely at $80{ }^{\circ} \mathrm{C}$. The nickel ferrite powder was then calcinated for 2 hours at $500{ }^{\circ} \mathrm{C}$. 


\section{Electrodeposition of polyaniline}

In this experiment, of aniline thin films deposition on copper substrate by cyclic voltammetry technique. For electrodeposition of polyaniline thin layers, $0.2 \mathrm{M}$ of sulfuric acid solution and 0.1 $\mathrm{M}$ of aniline were used as electrolyte. The deposition was performed using cyclic voltammetry for the number of cycles 10 and 5. The voltage applied at this stage ranged from -0.2 to $1.2 \mathrm{~V}$.

\section{Polyaniline / lead ferrite, nickel ferrite and cobalt ferrite nanocomposites}

In this study, electrodeposition was used to prepare polyaniline - lead ferrite, polyaniline-nickel ferrite and polyaniline- cobalt ferrite composites. For this purpose, a copper layer was used as the substrate. The substrates were prepared by two-step mechanical and electrochemical polishing. Electroporation is performed in an electrochemical cell containing working electrode, secondary electrode and reference electrode. To do this, $1 \mathrm{~g}$ of each ferrite was added to $100 \mathrm{ml}$ electrolyte include $0.1 \mathrm{M}$ of aniline and $0.2 \mathrm{M}$ of sulfuric acid solution separately. The deposition was performed for five cycles and by cyclic voltammetry $(\mathrm{C}-\mathrm{V})$ for the voltage of -0.2 to 1.2 volts.

For investigation of nanoparticles concentration in electrolyte polyaniline- cobalt ferrite nanocomposites prepared with to different $0.1 \mathrm{~g}-1 \mathrm{~g}$ cobalt ferrite in the same electrolyte.

\section{Results and discussion}

\section{Morphology study of nanoparticles and thin films}

Fig. 1 shows the surface morphology of polyaniline thin films for the 5 cycles deposition numbers that was investigated by scanning electron microscopy and Fig. 2 illustrates the surface 
morphology of polyaniline thin layer for the number of deposition 10 cycles. As depicted in Figs. 1 and 2, the grain of layers increases with increasing number of deposition cycles and thus the thickness of the layer.

Fig. 3 indicate the morphology of cobalt ferrite nanoparticles, images approve formation of nanoparticles with average diameter about $40 \mathrm{~nm}$ Fig. 4 shows scanning electron microscopy images of lead hexa-ferrite nanoparticles, the results confirm synthesis of magnetic nanostructures with size less than $50 \mathrm{~nm}$. Fig. 5 illustrate SEM images of nickel ferrite, these outcomes also show all ferrites nanoparticles have the average size around $50 \mathrm{~nm}$.

Fig. 6 shows the surface morphology of the polyaniline-cobalt ferrite thin layer nanocomposite with a value of $0.1 \mathrm{~g}$ of cobalt ferrite and Fig. 7 shows the same nanocomposite with a of $1 \mathrm{~g}$ cobalt ferrite. In these images, as we expected nanocomposite with $1 \mathrm{~g}$ cobalt ferrite have more nanoparticles in comparison to nanocomposite with $0.1 \mathrm{~g}$ cobalt ferrite.

Fig. 8 and Fig. 9 indicate the morphology of the polyaniline/lead ferrite nanoparticles and polyaniline/ nickel ferrite thin layer nanocomposite with addition of $1 \mathrm{~g}$ nano-fillers respectively. According to SEM analysis, the ferrite nanoparticles were dispersed homogeneously in the polyaniline thin layer and the larger nanoparticles make the larger grains in the polymer matrix.

\section{Elemental map and energy dispersive X-ray spectroscopy}

Fig. 10 illustrate elemental map of polyaniline thin layer with the 10 cycles deposition. This analyze shows the Nitrogen, Oxygen and Carbon elements uniformity distribution in polyaniline layer. 
Energy dispersive X-ray (EDX) analysis determined the elements of electrodeposited films. Fig. 11, Fig. 12 and Fig. 13 show elemental EDX analysis for cobalt ferrite, nickel ferrite and lead ferrite nanopowder respectively. $K_{a}, K_{B}, L_{a}$ of iron element is shown in all spectra, for cobalt ferrite also $\mathrm{K}_{\mathrm{a}}, \mathrm{K}_{\mathrm{B}}, \mathrm{L}_{\mathrm{a}}$ peaks of cobalt element was approved. $\mathrm{M}_{\mathrm{a}}, \mathrm{M}_{\mathrm{B}}, \mathrm{L}_{\mathrm{a}}$ peaks are related to lead element and finally spectra confirm presence of nickel with obvious related $K_{a}, K_{B}, L_{a}$ peaks. As we expected $K_{a}$ peak of oxygen exist in all analyses and there are no major peaks related to impurities.

Fig. 14, Fig. 15 and Fig. 16 indicate EDX analysis for polyaniline / cobalt ferrite, nickel ferrite and lead ferrite thin layer composite respectively. The $\mathrm{K}_{\mathrm{a}}$ of $\mathrm{N}$ and $\mathrm{C}$ peaks belong to the polyaniline thin layer. All the peaks are as same as of the pure nanoparticles with this point that all nanocomposites are on the copper substrate that observe in the all thin films spectra. In Fig. 14 Co, $\mathrm{O}$ and $\mathrm{Fe}$ peaks are related to cobalt ferrite in composite. The $\mathrm{Ni}, \mathrm{Fe}$, and $\mathrm{O}$ peaks indicate nickel ferrite formation in Fig. 15. Finally, in Fig. 16 display the peaks of $\mathrm{Pb}, \mathrm{Fe}$ and $\mathrm{O}$ for of lead ferrite nanoparticles in composite.

\section{X-ray diffraction}

Fig. 17 shows the $\mathrm{X}$-ray diffraction pattern of cobalt ferrite nanostructures in the range of $2 \Theta$ to 10-80 ${ }^{\circ}$. The X-ray diffraction pattern shows the $\mathrm{CoFe}_{2} \mathrm{O}_{4}$ nanoparticles peaks that have a suitable estimate with standard peaks [23]. The results have appropriate agreement with cubic standards (JCPDS:01-1121, space group: Fd-3m, space group number:227, a=b=c: 8.39 A )

Fig. 18 indicate the of nickel ferrite nanoparticles respectively. The results have suitable accordance with cubic standards (JCPDS: 74-1913, FCC, space group:Fd-3m, space group number:227, $a=b=c: 8.258$ A). XRD pattern of lead hexa ferrite have agreeable estimate via 
standard samples [24-25]. The results have suitable accordance with hexagonal standards (JCPDS:17-0660, space group:P63/mmc, space group number:194, a,b:5.88, c: 23.02 A). The polyaniline/ nano ferrite thin layer nanocomposite was not observed because the high elevation substrate peaks.

The general technique for calculated the crystallite size of particles by XRD patterns are the method. The Debye-Scherrer formula indicate in equation (1).

$$
D=\frac{0.9 \lambda}{\beta \cos \theta}
$$

That $\beta$ is full width half maximum, $\lambda$ is the $X$-ray wavelength (1. $54 \AA$ ), $\Theta$ is diffraction angle and $\mathrm{D}$ is crystallite size [25].

The crystallite size of cobalt ferrite, nickel ferrite and lead hexa-ferrite nanoparticles via DebbieScherrer formula calculated, 16, 21 and $42 \mathrm{~nm}$ respectively.

The Williamson-Hall method permits to specify the magnitude of the crystallite size and strain of the crystal lattice. The Williamson-Hall can be written like the equation (2):

$$
\beta \cos \theta=4 \varepsilon \sin \theta+\frac{0.9 \lambda}{D}
$$

That $\square$ is lattice strain and other parameters are like equation (1) [26]. The $\square$ and $D$ can be computed from the slope and intercept of the $\beta \cos \theta$ and $4 \sin \theta$ plots, respectively. The crystallite size of $\mathrm{CoFe}_{2} \mathrm{O}_{4}, \mathrm{NiFe}_{2} \mathrm{O}_{4}$ and $\mathrm{PbFe}_{12} \mathrm{O}_{19}$ nanoparticles via Williamson-Hall method calculated, 11, 23 and $46 \mathrm{~nm}$ respectively. Also, the strain of lattice for $\mathrm{CoFe}_{2} \mathrm{O}_{4}, \mathrm{NiFe}_{2} \mathrm{O}_{4}$ and $\mathrm{PbFe}_{12} \mathrm{O}_{19}$ nanoparticles obtained $0.004,0.012$ and 0.009 respectively. 


\section{Kinetic roughening of Surface}

Kinetic roughening happens in systems when matter is removed from or added to a surface. The study of material in atomic scale ranges in thin films to the macroscopic scales as known kinetic roughening [27].

The roughness of a thin film depended to thickness of layer. The roughness (w) is expressed by equation (3).

$$
w(l, t)=\sqrt{\left\langle[h(t)-\langle h(t)\rangle]^{2}\right\rangle}
$$

that $h$ is each point height the surface of layers, $l$ is the length of area that roughness is measured and finally $\mathrm{t}$ is the deposition time or film thickness. In some systems, kinetic roughening is explained via Family-Vicsek or normal scaling. In normal scaling suppose where roughness depended to 1 and $t$ in small and large scales by equations (4) and (5).

$$
\begin{aligned}
& w(l, t) \propto l^{H} \quad \text { for } l \ll l_{c} \\
& w(l, t) \propto t^{\beta} \quad \text { for } l \gg l_{c}
\end{aligned}
$$

In equations (4) and (5) $\mathrm{H}$ : Hurst coefficient, $\beta$ : growth exponent and $\mathrm{l}_{\mathrm{c}}$ : crossover length. For some other systems kinetic roughening explained via anomalous scaling rules that depended by following equations:

$$
\begin{aligned}
& w(l, t) \propto l^{H} t^{\beta_{l o c}} \quad \text { for } l \ll l_{c} \\
& w(l, t) \propto t^{\beta+\beta_{l o c}} \quad \text { for } l \gg l_{c}
\end{aligned}
$$


In These equations $\beta_{\text {loc }}$ is known as the local roughness exponent. In anomalous scaling roughness in small length depended to thickness of layers but in normal scaling not depended and when $\beta_{\text {loc }}$ is zero anomalous scaling changed to normal scaling. [28].

The surface roughness of thin films studied by AFM. Images of the AFM for a polyaniline thin layer for the number of deposition cycles 5 and 10 are shown in Fig. 20.

Fig. 21 shows diagram of roughness-scan length in logarithmic scale of deposited polyaniline thin films with 5 and 10 cycles. This diagram describes polyaniline thin films have an anomalous scaling behavior.

Fig. 22 related to the results of AFM analysis for polyaniline/ cobalt ferrite thin layer composite with $0 / 1 \mathrm{~g}$ and $1 \mathrm{~g}$ cobalt ferrite nanoparticles. According to these images with increases of cobalt ferrite nanoparticles density the roughness of deposited films cycles increased, which is consistent with the SEM results.

\section{Magnetic properties}

The magnetic properties and hysteresis loop of samples investigated via vibrating sample magnetometer at room temperature. Figs. 23, 24 and 25 illustrate the vibrating sample manetometer VSM analysis for cobalt ferrite, nickel ferrite and lead ferrite nanoparticles respectively. The remanence magnetization $(\mathrm{Mr})$, saturation magnetization $(\mathrm{Ms})$ and magnetic coercivity $\left(\mathrm{H}_{\mathrm{c}}\right)$ each of nanoparticles explain in table 1.

Examining these results and observing the lead ferrite and cobalt ferrite are ferromagnetic materials, also lead ferrite is harder than cobalt ferrite, but nickel ferrite nanoparticles have a superparamagnetic behavior. 
Magnetic properties of polyaniline-cobalt ferrite (1 $\mathrm{g}$ nanoparticles) thin layer composite investigated in parallel and vertical field. The hysteresis loop of this thin film indicated in Fig. 26 and Fig. 27 for in parallel and vertical field respectively. Comparing the results of hysteresis loop analysis for cobalt ferrite and the thin film composite shows that the amount of $\mathrm{M}_{\mathrm{s}}$ and $\mathrm{H}_{\mathrm{c}}$ with the presence of polyaniline in the composite is greatly reduced. For above thin films in the parallel field state, the saturated magnetic field is less than the vertical field state. Easy axis in vertical field mode and hard axis in parallel field mode.

\section{Conclusions}

The lead ferrite, cobalt ferrite and ferrite nickel nanoparticles fabricated by microwave irradiated. The polyaniline/ nano ferrites thin film composites growth by electrodeposition method. The SEM analysis found that the grains size has increased with increasing layer thickness. The EDX analysis has been shown the peaks related to the polyaniline each of ferrites. XRD analysis show the structure of samples, also crystallite size and strain of lattice calculated using the Debbye-Scherrer method and the Williamson-Hall method. The crystallite size of the nanoparticles calculated by these methods consisted the grain size of samples observed by SEM. Kinetic roughening of polyaniline thin films have an anomalous scaling behavior.

The results of the VSM indicated lead ferrite and cobalt ferrite are ferromagnetic and nickel ferrite is superparamagnetic. Also, in composite polymer $\mathrm{M}_{\mathrm{s}}$ and $\mathrm{H}_{\mathrm{c}}$ reduced by adding nanoparticles to polyaniline.

\section{References}


[1] Y. Huangfu, K. Ruan, H. Qiu, Y. Lu, Ch. Liang, J. Kong, J. Gu, "Fabrication and investigation on the PANI/MWCNT/thermally annealed graphene aerogel/epoxy electromagnetic interference shielding nanocomposites", Journal of Composites Part A, 121 (2019) 265.

[2] B.R. Kim, H.K. Lee, S.H. Park, H.K. Kim, "Electromagnetic interference shielding characteristics and shielding effectiveness of polyaniline-coated films", Journal of Thin Solid Films, 519 (2011) 3492.

[3] A.P. Sobha, P.S. Sreekala, S.K. Narayanankutty, "Electrical, thermal, mechanical and electromagnetic interference shielding properties of PANI/FMWCNT/TPU composites", Journal of Progress in Organic Coatings, 113 (2017) 168.

[4] M. Saini, R. Shukla, A. Kumar, " $\mathrm{Cd}^{2+}$ substituted nickel ferrite doped polyaniline nanocomposites as effective shield against electromagnetic radiation in X-band frequency", Journal of Magnetism and Magnetic Materials, 491 (2019) 165549.

[5] R. Arora, U. K. Mandal, P. Sharma, A. Srivastav,” TiO2 and PVA based Polyaniline Composite materials-A Review", Journal of Materials Today: Proceedings, 2 (2015) 2767.

[6] S. M. Rathod, P. S. Khandelwal, R. S. Rajuskar,” Influence of Gadolinium Doped in Nickel Nano Ferrite on Magnetic and optical Properties Prepared by Sol-Gel Technique", Journal of Materials Today: Proceedings, 15 (2019) 560.

[7] S. S. Dunn, D. R. B. Vera, S. R. Benhabbour, M. C. Parrott, "Rapid microwave-assisted synthesis of sub-30 nm lipid nanoparticles", Journal of Colloid and Interface Science, 488 (2017) 240 . 
[8] W. Zheng, P. Li, Z. Wang, N. H. Golshan, K. S. Ziemer, M. Su,” High-yield large scale laser patterning of magnetic nanoparticles”, Journal of Magnetism and Magnetic Materials, 489 (2019) 165419.

[9] K. Pubby, S.S. Meena, S.M. Yusuf, S. B. Narang, "Cobalt substituted nickel ferrites via Pechini's sol-gel citrate route: X-band electromagnetic characterization", Journal of Magnetism and Magnetic Materials, 466 (2018) 430.

[10] P. Klumdoung, A. Hassadee, P. Pankaew, "Effect of Nickel Ferrite Addition on Characteristics of Nanostructured Nickel Ferrite/Hydroxyapatite Ceramic", Journal of Materials Today: Proceedings, 17 (2019) 1752.

[11] J. A. C. Arango, A. A. Cristobal, C. P. Ramos, P. G. Bercoff, P. M. Botta, "Mechanochemical synthesis and characterization of nanocrystalline Ni1-xCoxFe2O4 $(0 \leq \mathrm{x} \leq 1)$ ferrites", Journal of Alloys and Compounds, 811 (2019) 152044.

[12] Ch. Lin, Y. Siao, M. Hsieh, "Magnetic properties of lead ferrite nanoparticles prepared by the polymerized complex method", Journal of Alloys and Compounds, 462 (2008) 315.

[13] S. M. Hashemi, S. Hasani, Kh. Jahanbani Ardakani, F. Davar, "The effect of simultaneous addition of ethylene glycol and agarose on the structural and magnetic properties of $\mathrm{CoFe} 2 \mathrm{O} 4$ nanoparticles prepared by the sol-gel auto-combustion method”, Journal of Magnetism and Magnetic Materials, 492 (2019) 165714.

[14] M. Sundararajan, L. J. Kennedy, U. Aruldoss, Sk. Kh. Pasha, J. J. Vijaya, Steve Dunn, "Microwave combustion synthesis of zinc substituted nanocrystalline spinel cobalt ferrite: Structural and magnetic studies”, Journal of Materials Sciencein Semiconductor Processing, $40(2015) 1$. 
[15] A. P. Herrera, L. Polo-Corrales, E. Chavez, J. Cabarcas-Bolivar, Oswald N. C. Uwakweh, Carlos Rinaldi, "Influence of aging time of oleate precursor on the magnetic relaxation of cobalt ferrite nanoparticles synthesized by the thermal decomposition method", Journal of Magnetism and Magnetic Materials, 328 (2013) 41.

[16] S. Mandizadeh, A. Salehabadi, O. Amiri, M. Salavati-Niasari, "Amino acids assisted hydrothermal synthesis of W-type SrFe18027 nanostructures; a potential hydrodesulfurization catalyst”, international journal of hydrogen energy, 44 (2019) 15017.

[17] C. T. Fleaca, F. Dumitrache, I. Morjan, A. M. Niculescu, I. Sandu, A. Ilie, I. Stamatin, A. Iordached, E. Vasile, G. Prodan, "Synthesis and characterization of polyaniline-Fe@C magnetic nanocomposite powder”, Applied Surface Science, 374 (2016) 213.

[18] Y. Song, S. Liu, B. Wang, M. Shang, L. Lin, Y. Su, “Continuous and controllable preparation of polyaniline with different reaction media in microreactors for supercapacitor applications", Journal of Chemical Engineering Science, 207 (2019) 820.

[19] M. M. Sadeghi, A. Shokuhi Rad, M. Ardjmand, A. Mirabi, "Preparation of magnetic nanocomposite based on polyaniline/Fe3O4 towards removal of lead (II) ions from real samples”, Journal of Synthetic Metals, 245 (2018) 1.

[20] A. Abdelraheem, A. H. El-Shazly, M. F. Elkady, "Characterization of atypical polyaniline nano-structures prepared via advanced techniques", Journal of Alexandria Engineering Journal, 57 (2018) 3291.

[21] A. Nautiyal, S. Parida, "Comparison of polyaniline electrodeposition on carbon steelfrom oxalic acid and salicylate medium”, Journal of Progress in Organic Coatings, 94 (2016) 28. 
[22] M. Yusairie, I. Ruhani, M. Farhan Zainal," Electrodeposition and Characterization of Polyaniline Films", IEEE Symposium on Humanities, Science and Engineering Research, (2012) 1301.

[23] K. Hedayati, S. Azarakhsh, J. Saffari, D. Ghanbari, "Magnetic and Photo-catalyst $\mathrm{CoFe}_{2} \mathrm{O}_{4}-$ CdS nanocomposites: Simple preparation of $\mathrm{Ni}, \mathrm{Co}, \mathrm{Zn}$ or Ag-doped CdS nanoparticles" Journal of Materials Science: Materials in Electronics, 28 (2017) 5472.

[24] A. Naseri, M. Goodarzi, D. Ghanbari, "Green synthesis and characterization of magnetic and effective photocatalyst $\mathrm{NiFe} 2 \mathrm{O} 4-\mathrm{NiO}$ nanocomposites" Journal of Materials Science: Materials in Electronics, 28 (2017) 17635.

[25] B. Lahijani, K. Hedayati, M. Goodarzi, "Magnetic $\mathrm{PbFe}_{12} \mathrm{O}_{19}-\mathrm{TiO}_{2}$ nanocomposites and their photocatalytic performance in the removal of toxic pollutants" Main Group Metal Chemistry, $41(2018) 53$.

[26] W. Kwak, J. M. Kim, "Random deposition model with surface relaxation in higher dimensions", journal of Physica A, 520 (2019) 87.

[27] K. Hedayati, "Structural and magnetic characterization of electrodeposited $\mathrm{Ni}-\mathrm{Cu} / \mathrm{Cu}$ and $\mathrm{Fe}-$ Ni-Cu/Cu multilayer"”, journal of Applied Physics A,118 (2015) 975.

[28] K. Hedayati, G. Nabiyouni, "Surface roughness analysis and magnetic property studies of nickel thin films electrodeposited onto rotating disc electrodes", journal of Applied Physics A,116 (2014) 1605. 


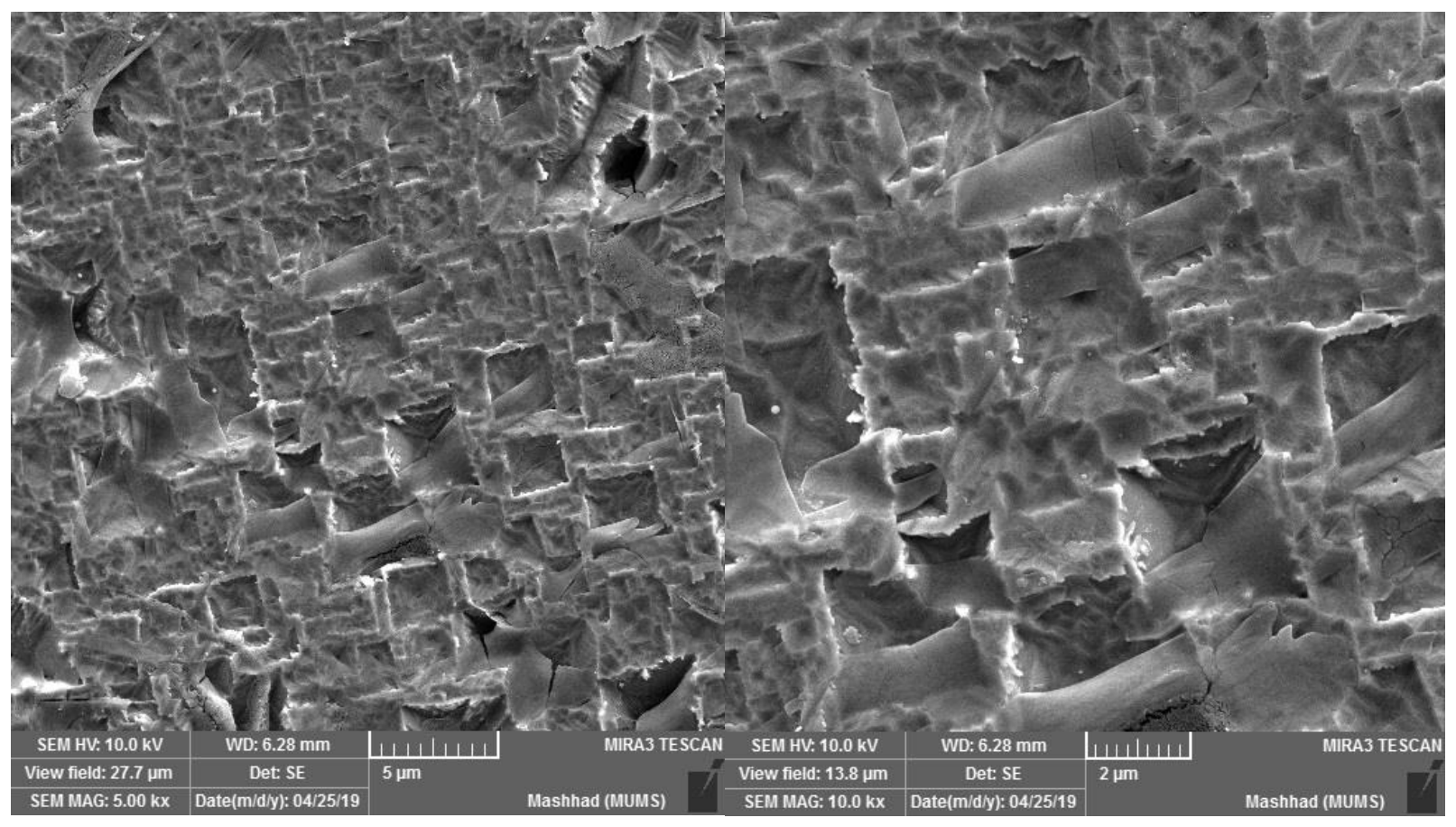

Fig. 1. FESEM images of thin layer of Polyaniline with 5 cycles of electrodeposition. 


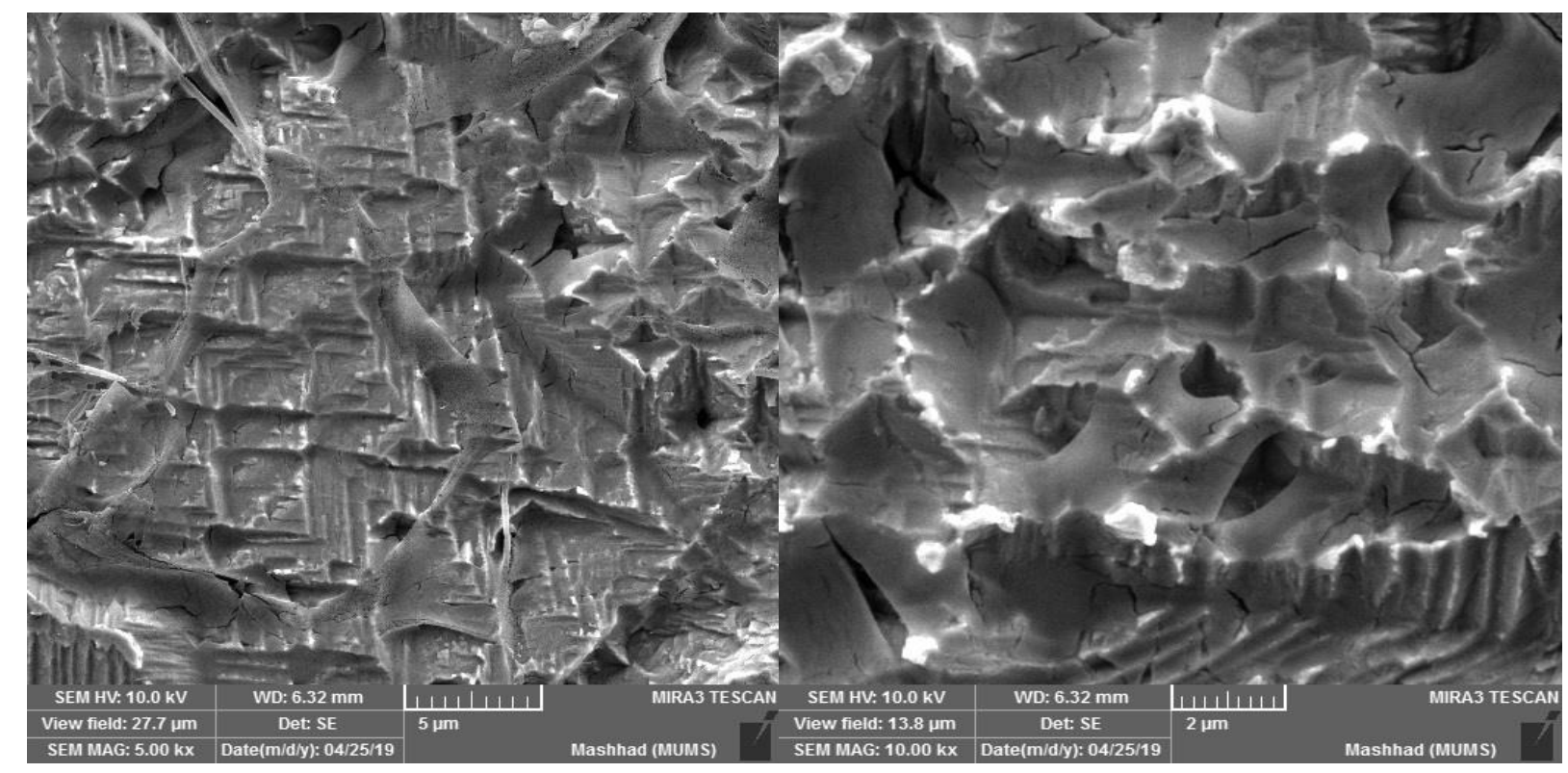

Fig. 2. SEM images of thin layer of Polyaniline with 10 cycles of electrodeposition. 


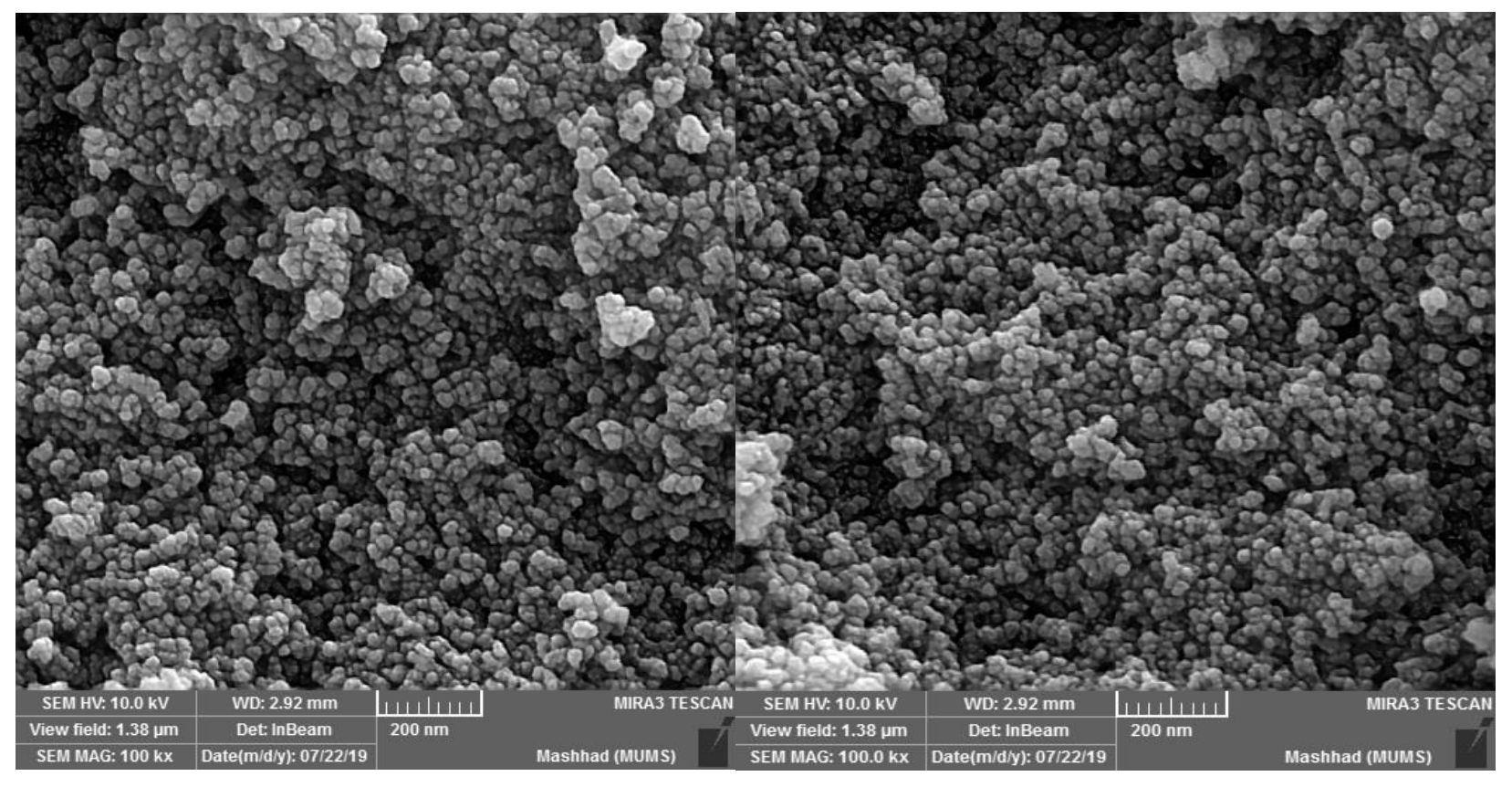

Fig. 3. SEM images of cobalt ferrite nanoparticles. 


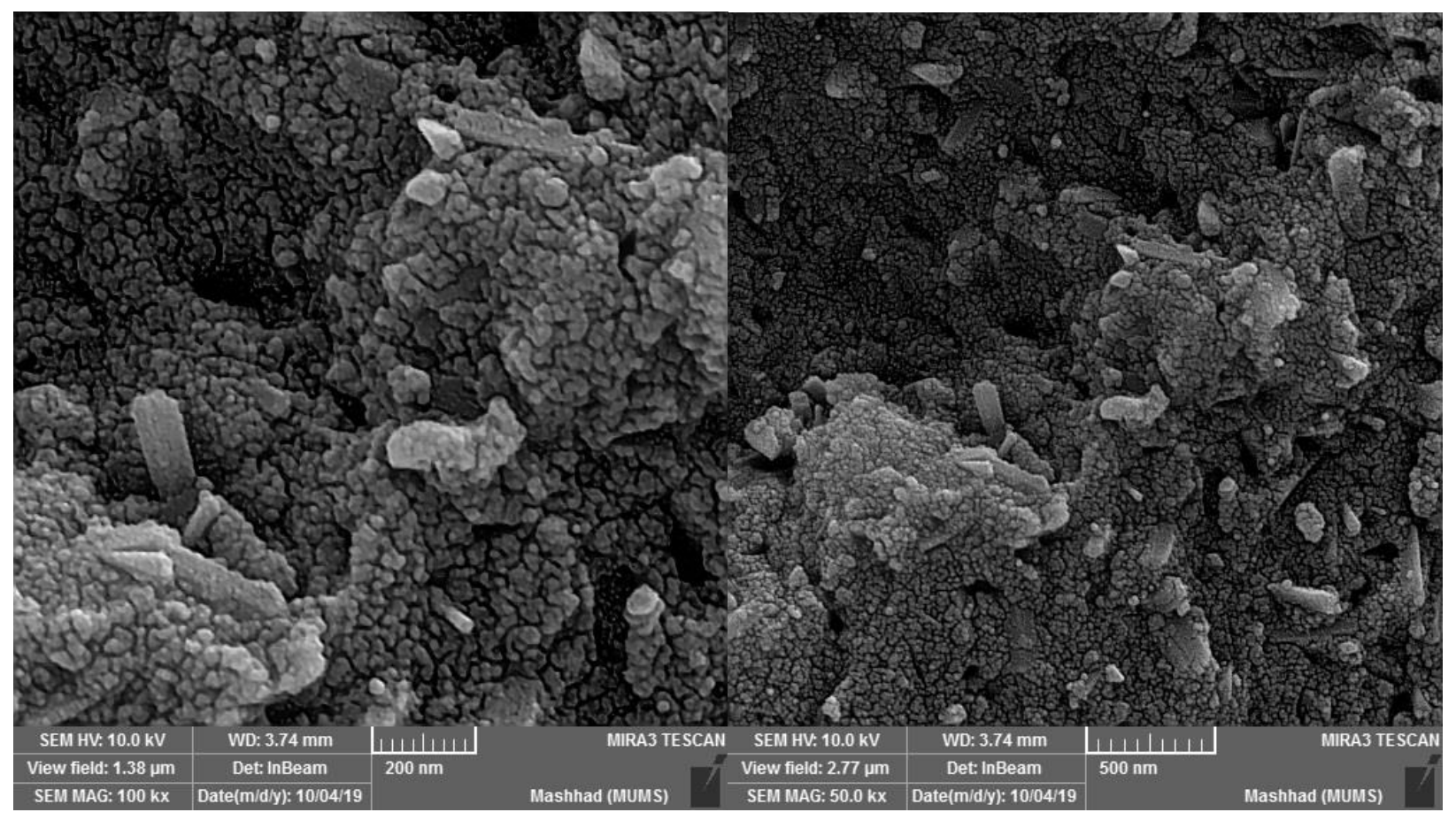

Fig. 4. SEM images of lead ferrite nanoparticles. 


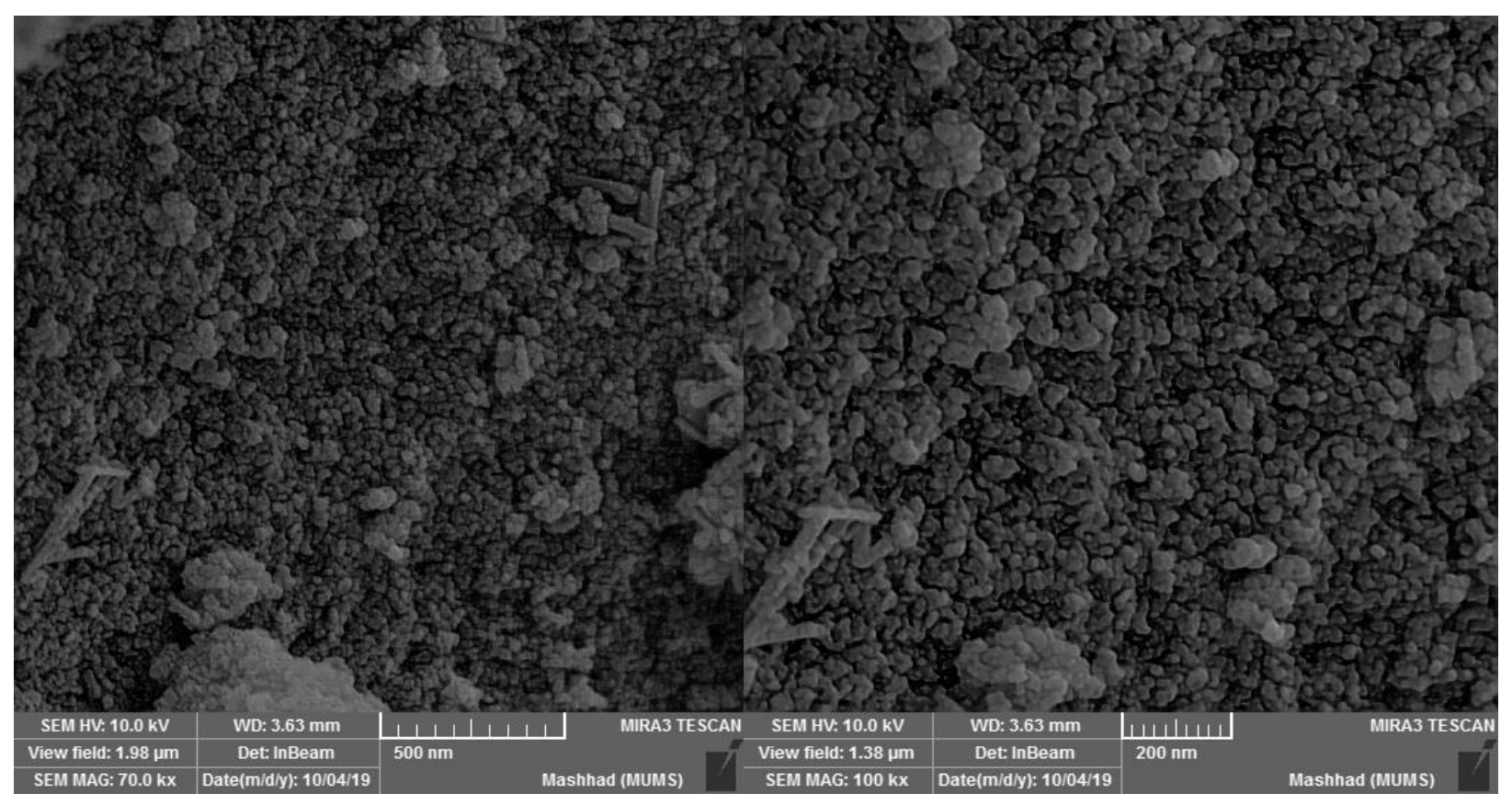

Fig. 5. SEM images of nickel ferrite nanoparticles. 

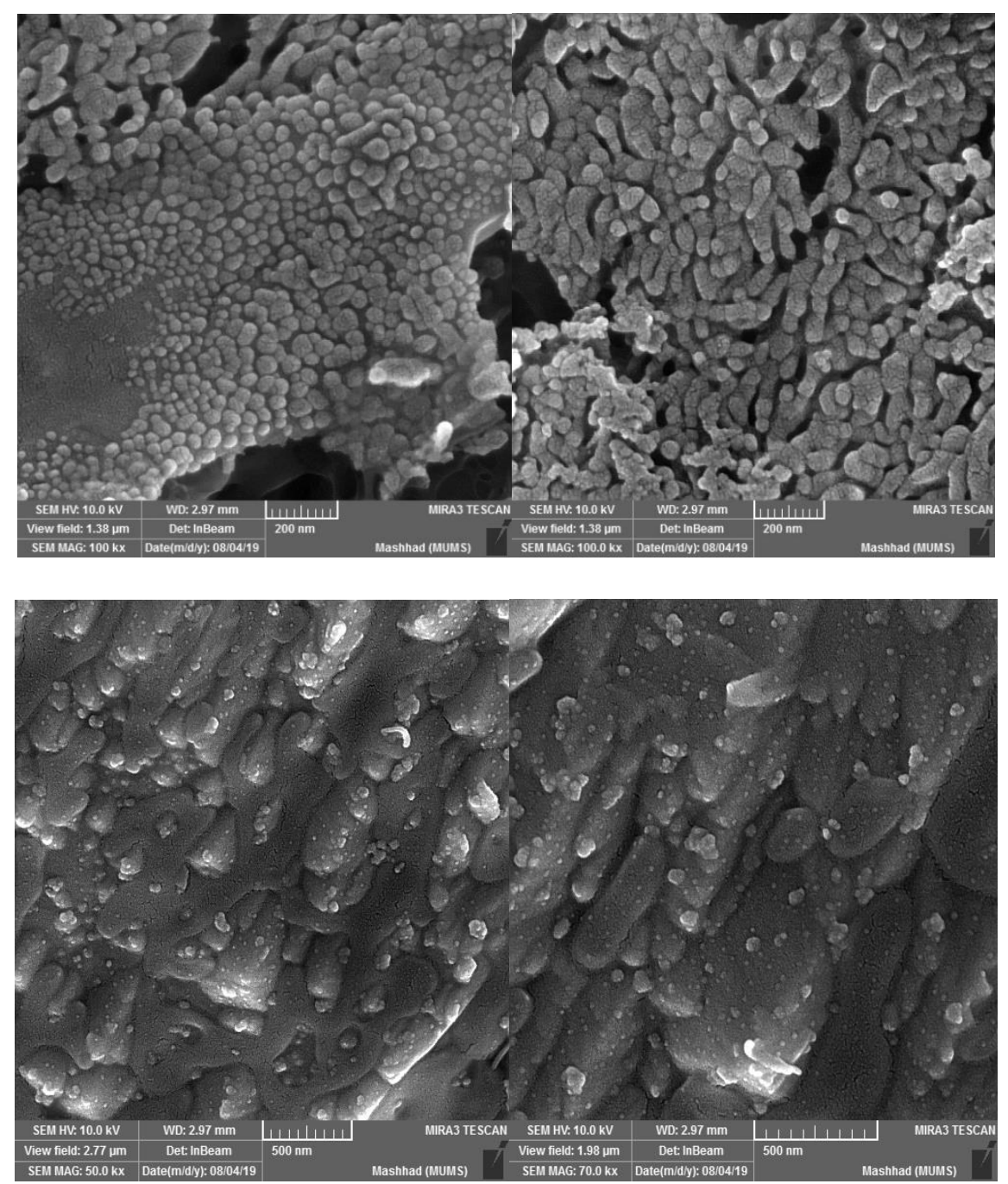

Fig. 6. SEM images of polyaniline/ cobalt ferrite thin layer composite

(with $0.1 \mathrm{~g}$ of cobalt ferrite ). 


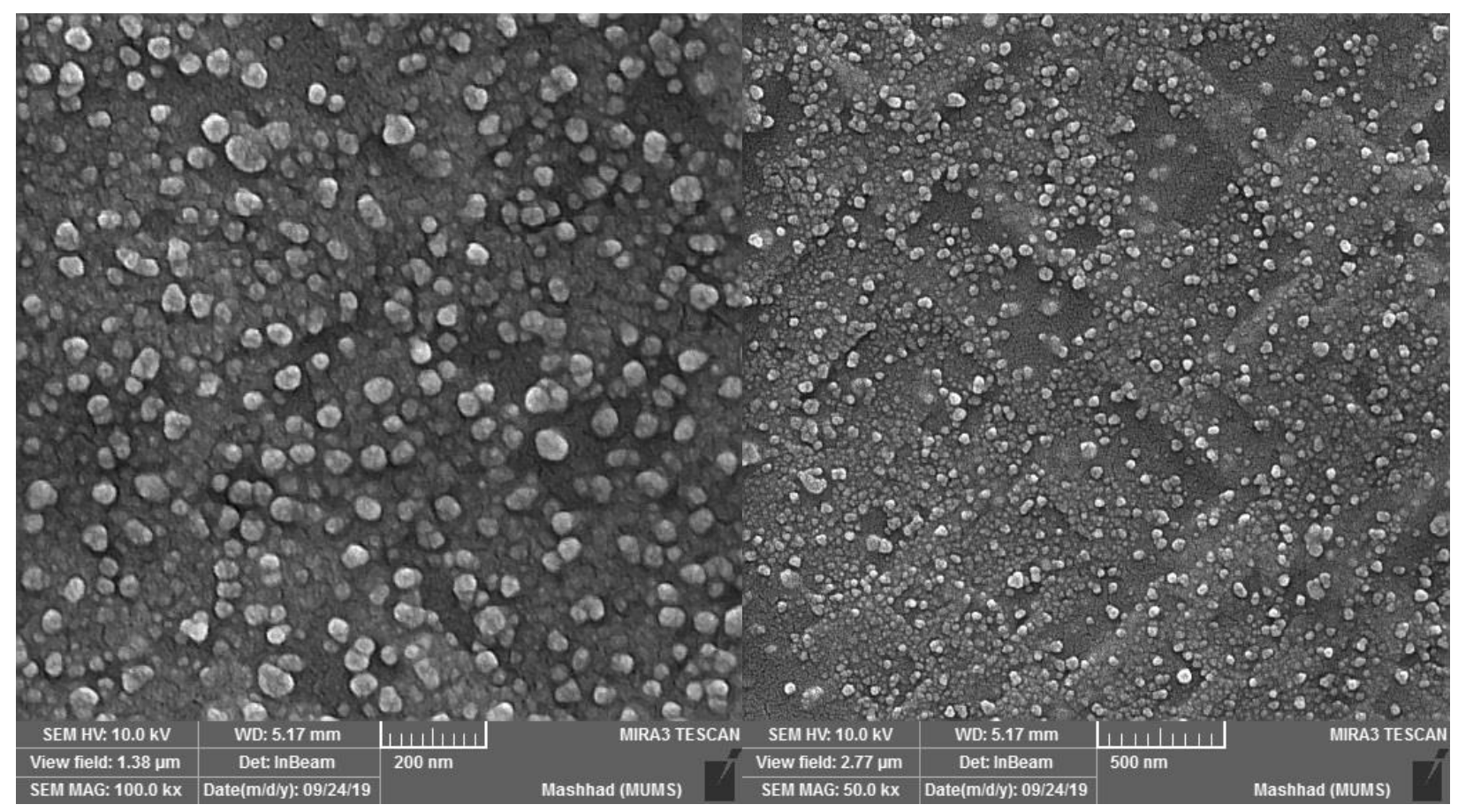

Fig. 7. SEM images of polyaniline/ cobalt ferrite thin layer composite ( $1 \mathrm{~g}$ of cobalt ferrite $)$ 


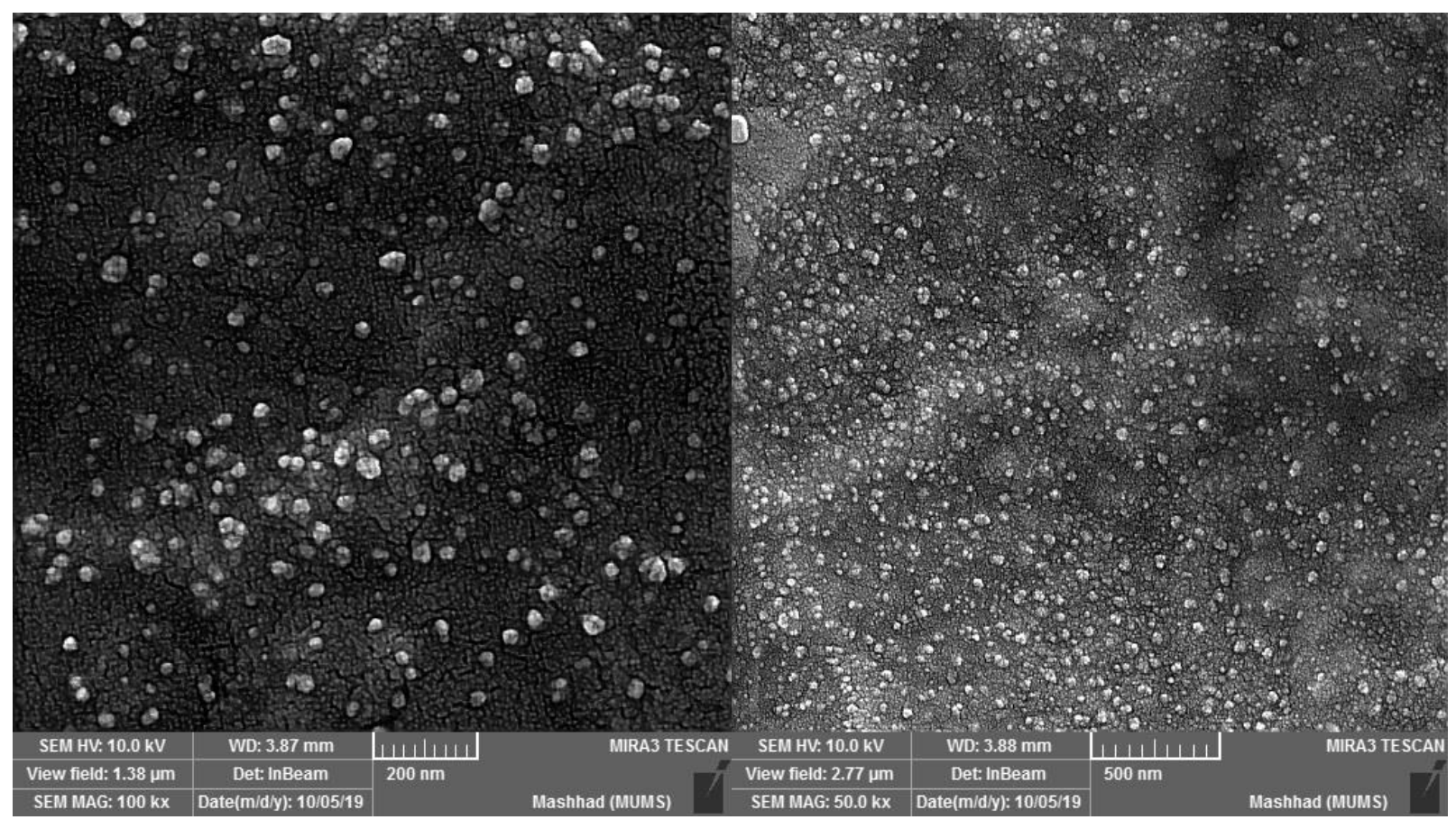

Fig. 8. SEM images of polyaniline/ lead ferrite thin layer composite (with $1 \mathrm{~g}$ of lead ferrite ). 


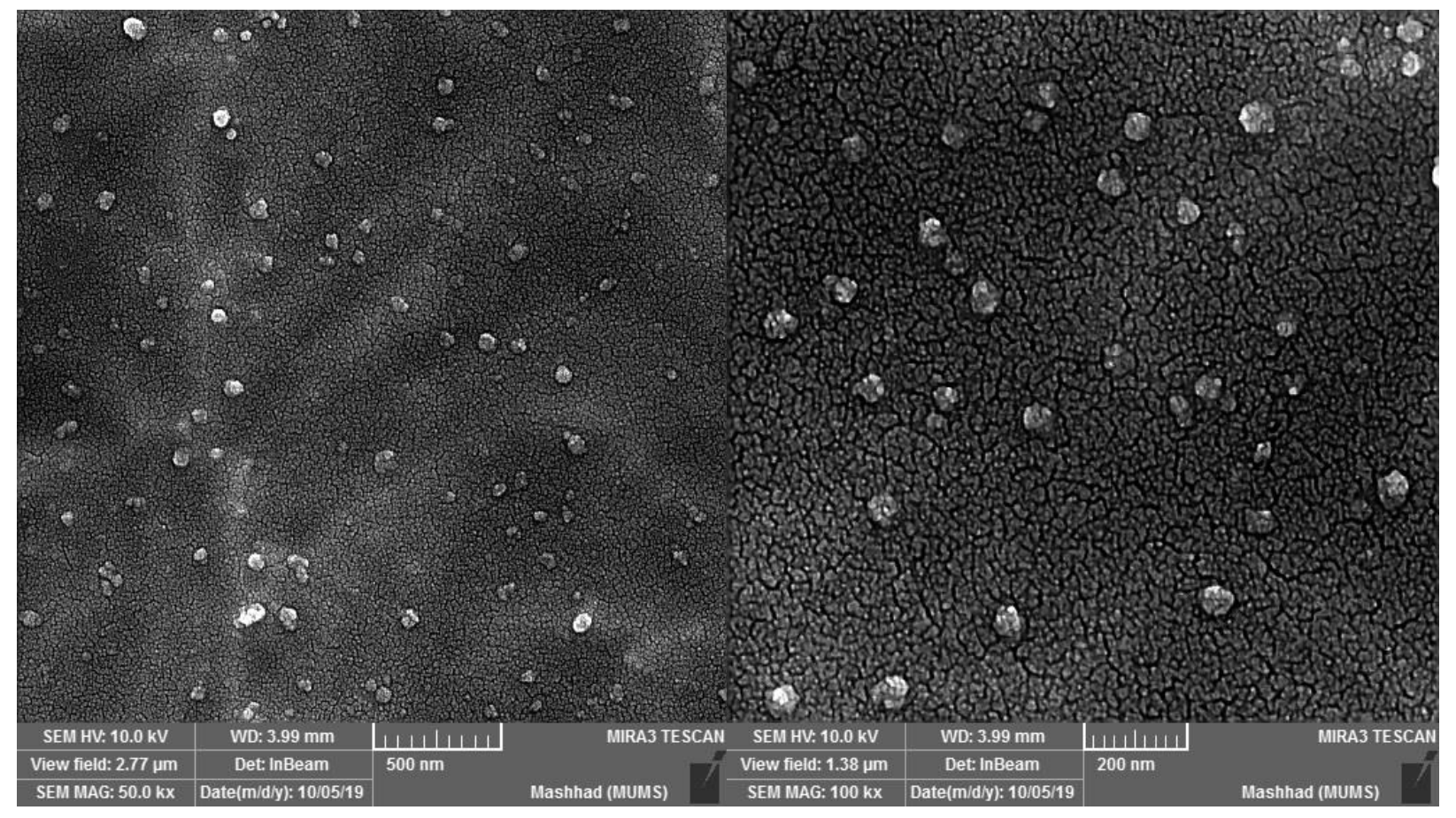

Fig. 9. SEM images of polyaniline/ nickel ferrite thin layer composite (with $1 \mathrm{~g}$ of nickel ferrite ). 

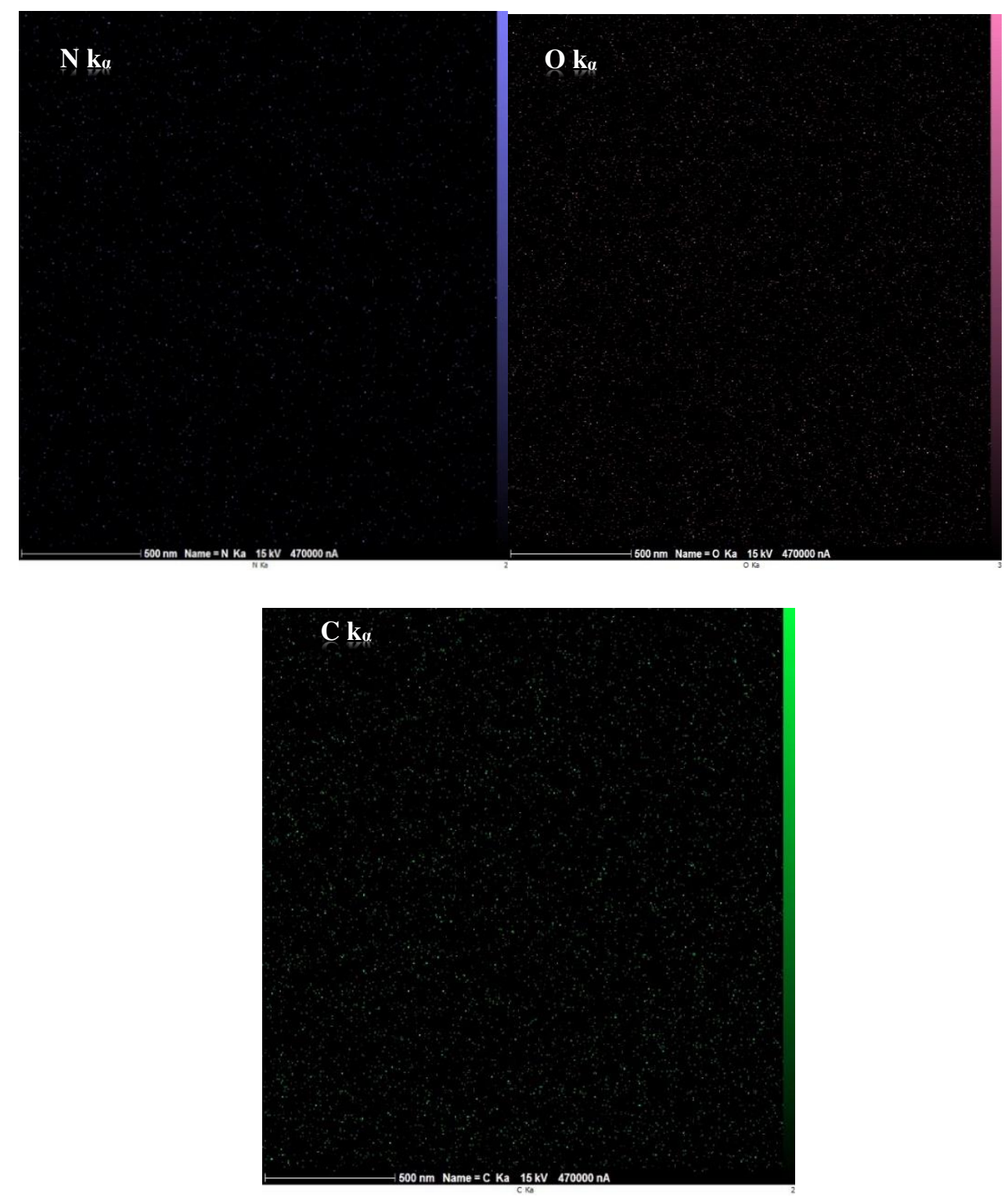

Fig. 10. Elemental map of the detected elements in EDX of the polyaniline thin layer with the number of 10 deposition cycles. 


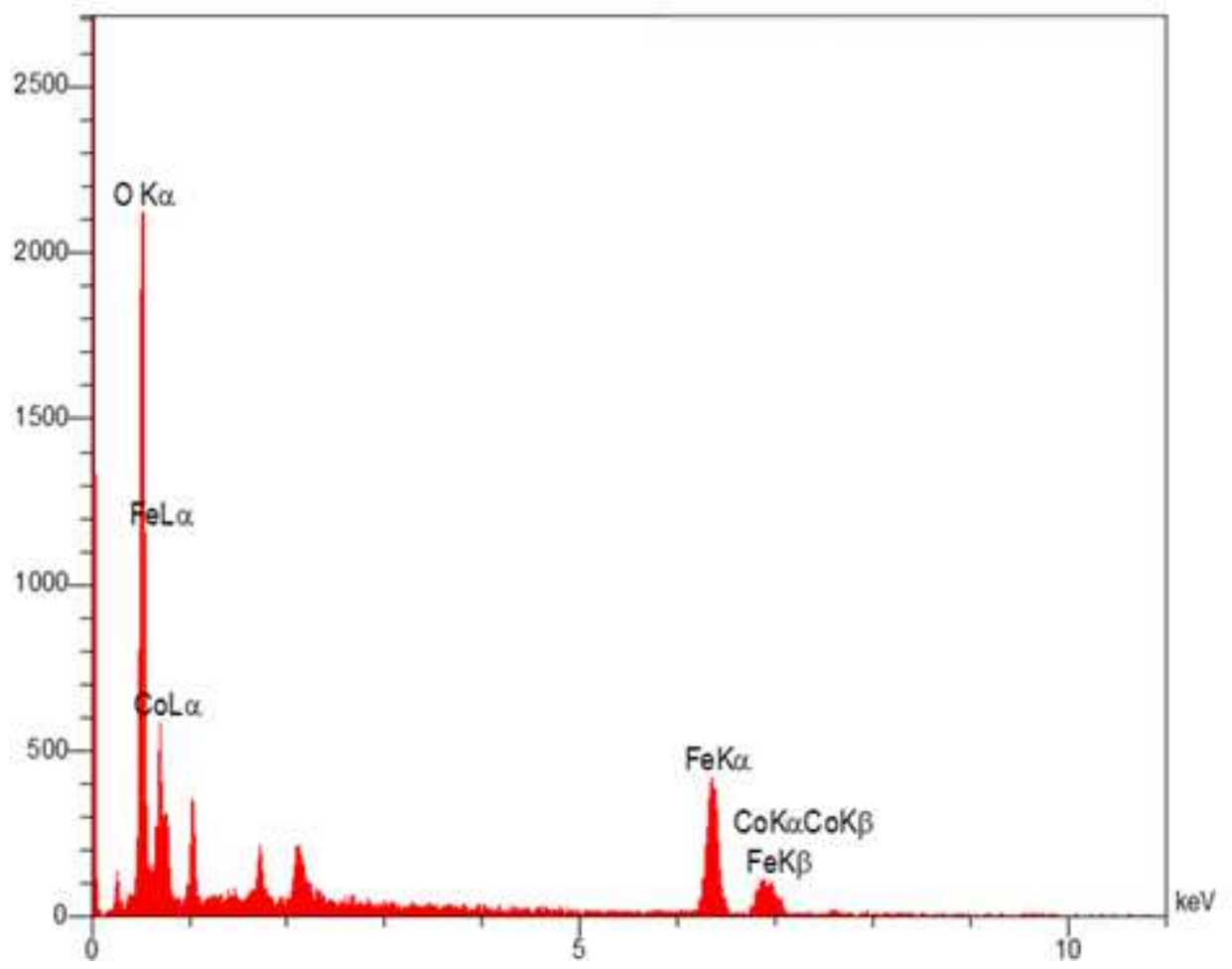

Fig. 11. EDX pattern of cobalt ferrite nanopowders. 


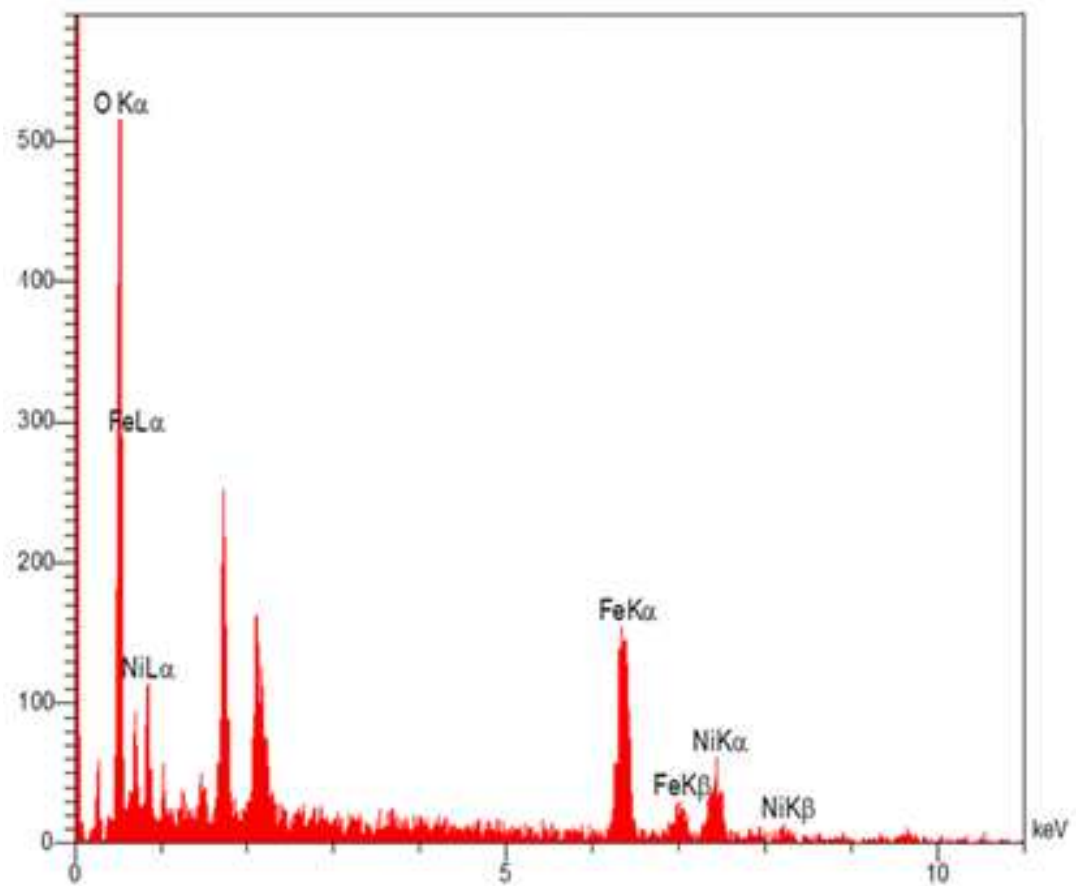

Fig. 12. EDX pattern of nickel ferrite nanopowders. 


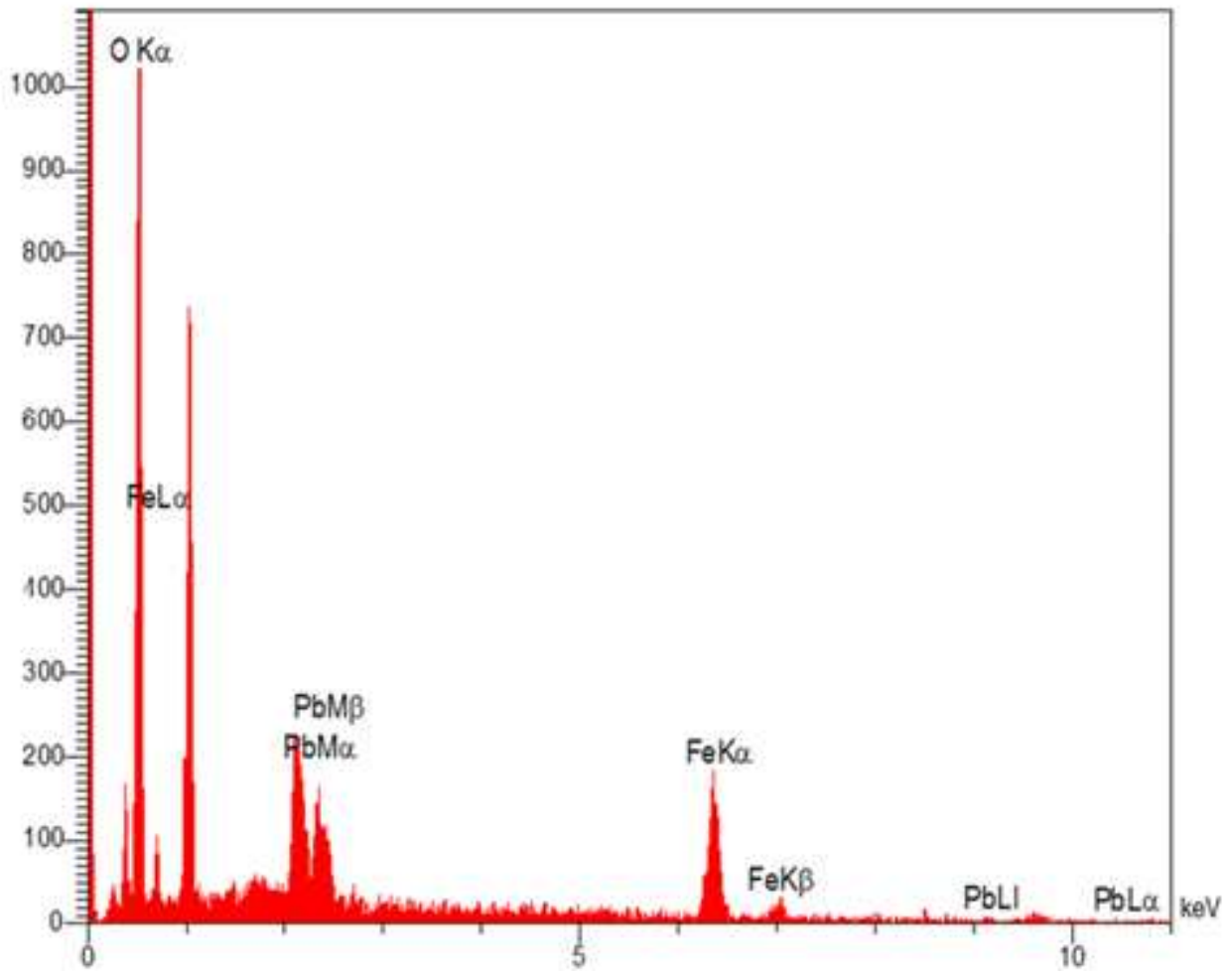

Fig. 13. EDX pattern of Lead ferrite nanopowders. 


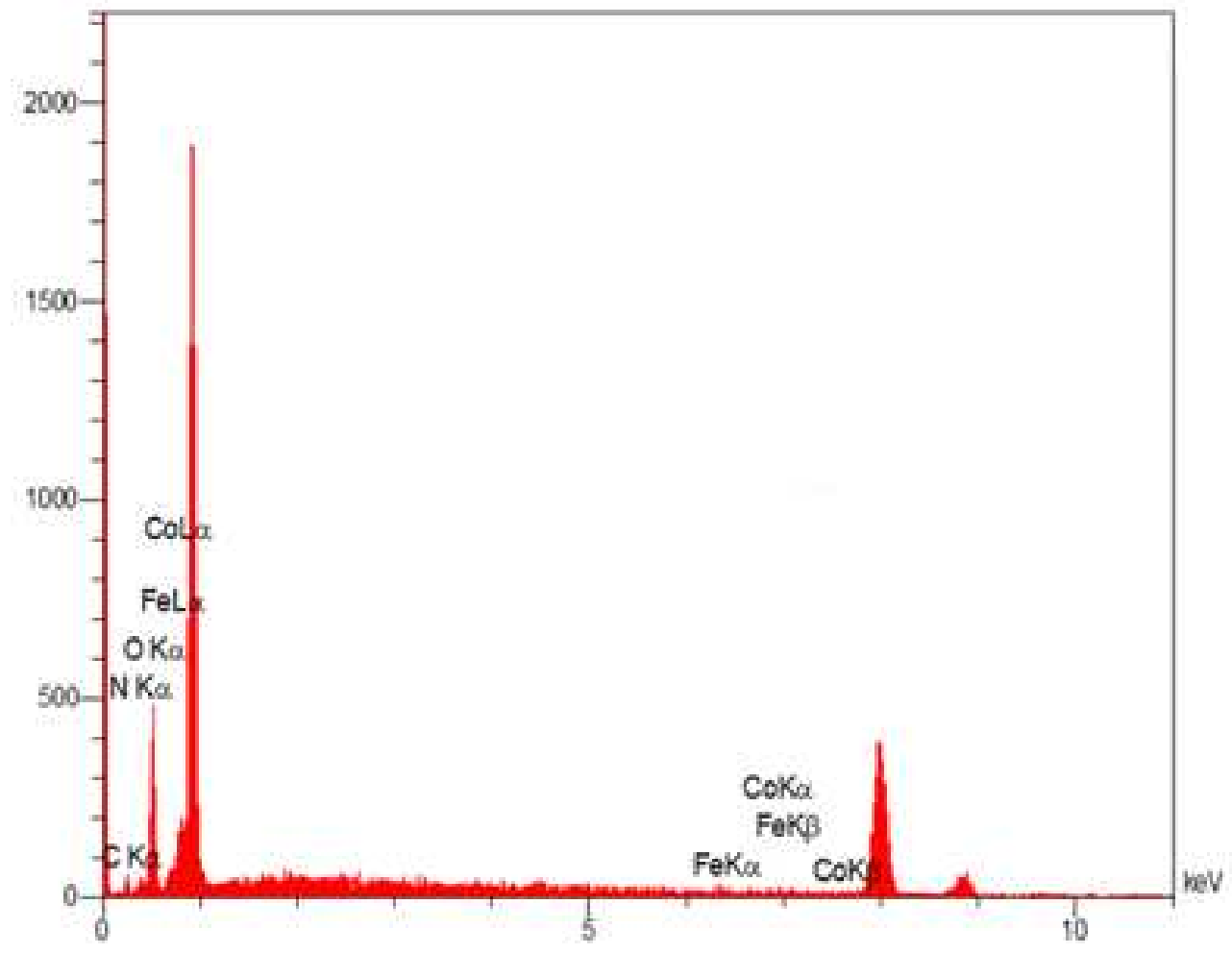

Fig.14. EDX pattern of polyaniline/ cobalt ferrite thin layer composite 


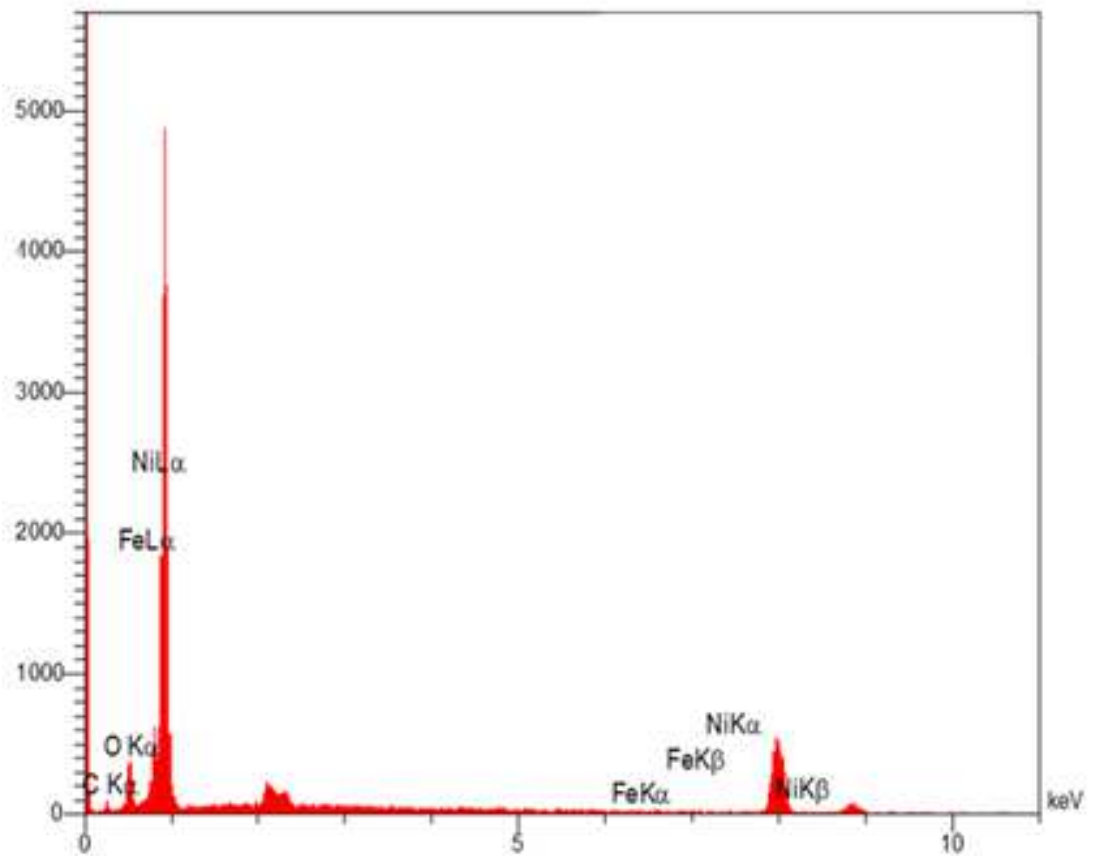

Fig.15. EDX pattern of polyaniline/ nickel ferrite thin layer composite 


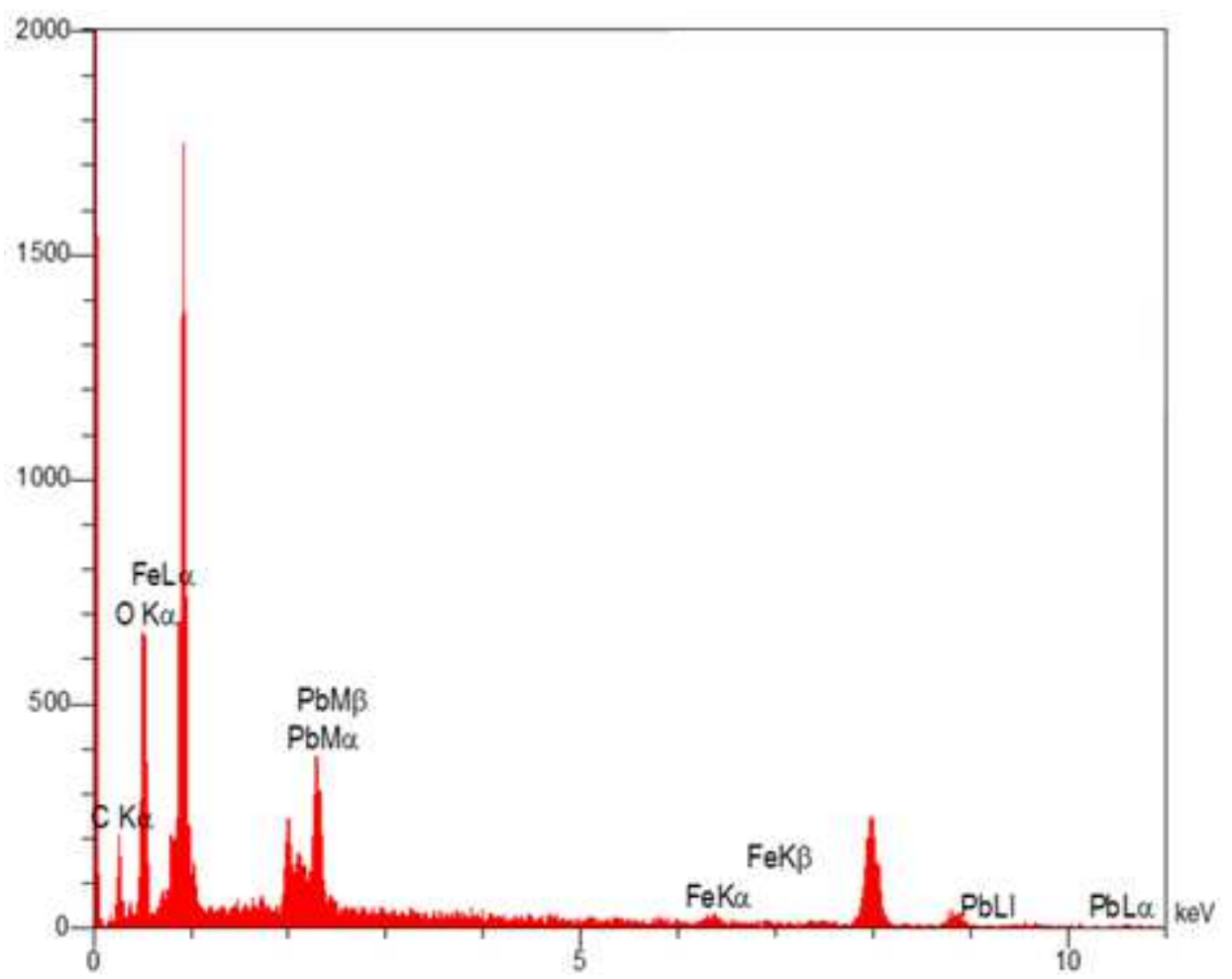

Fig.16. EDX pattern of polyaniline/ lead ferrite thin layer composite 


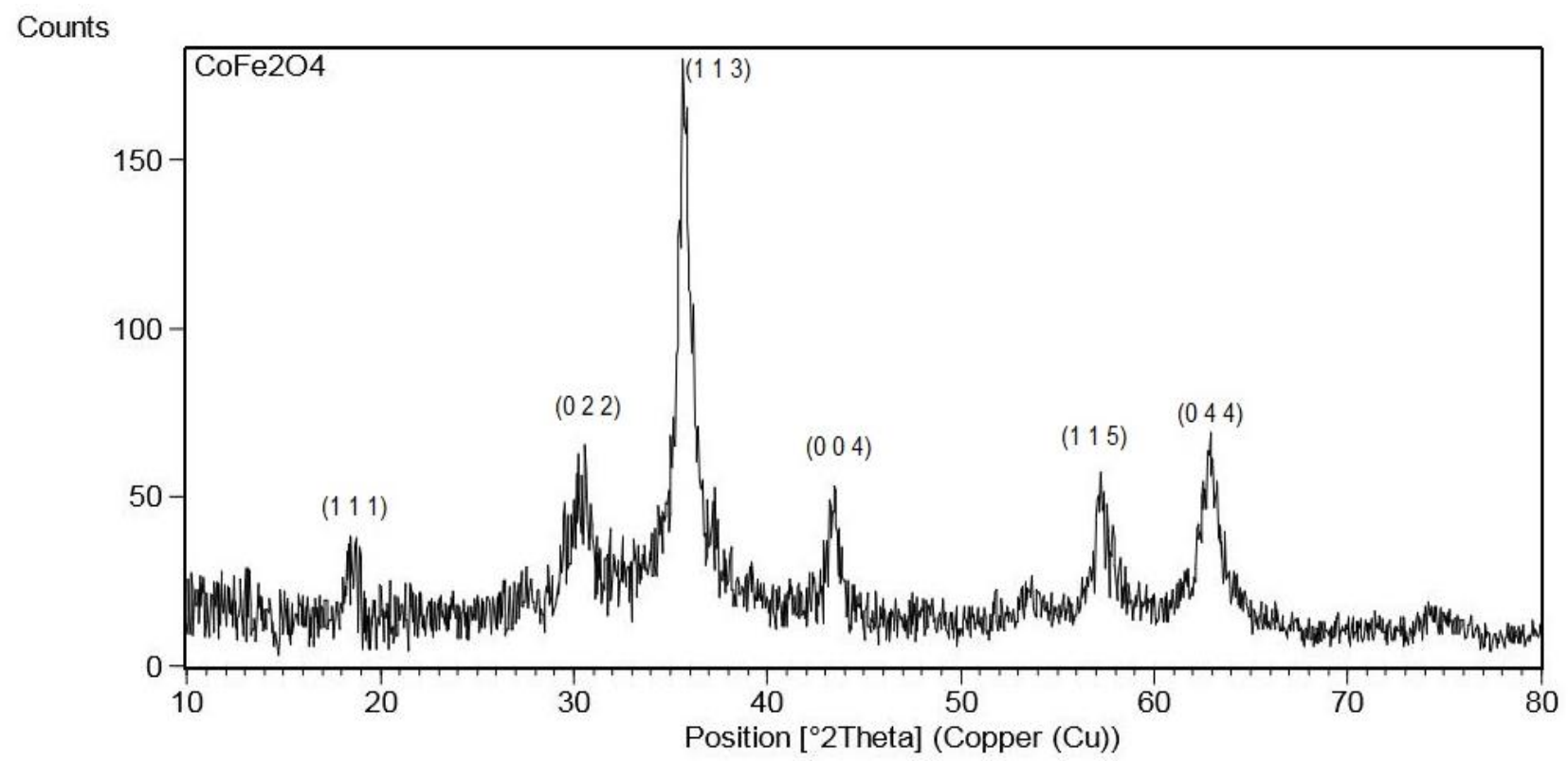

Fig. 17. XRD pattern for cobalt ferrite nanoparticles. 


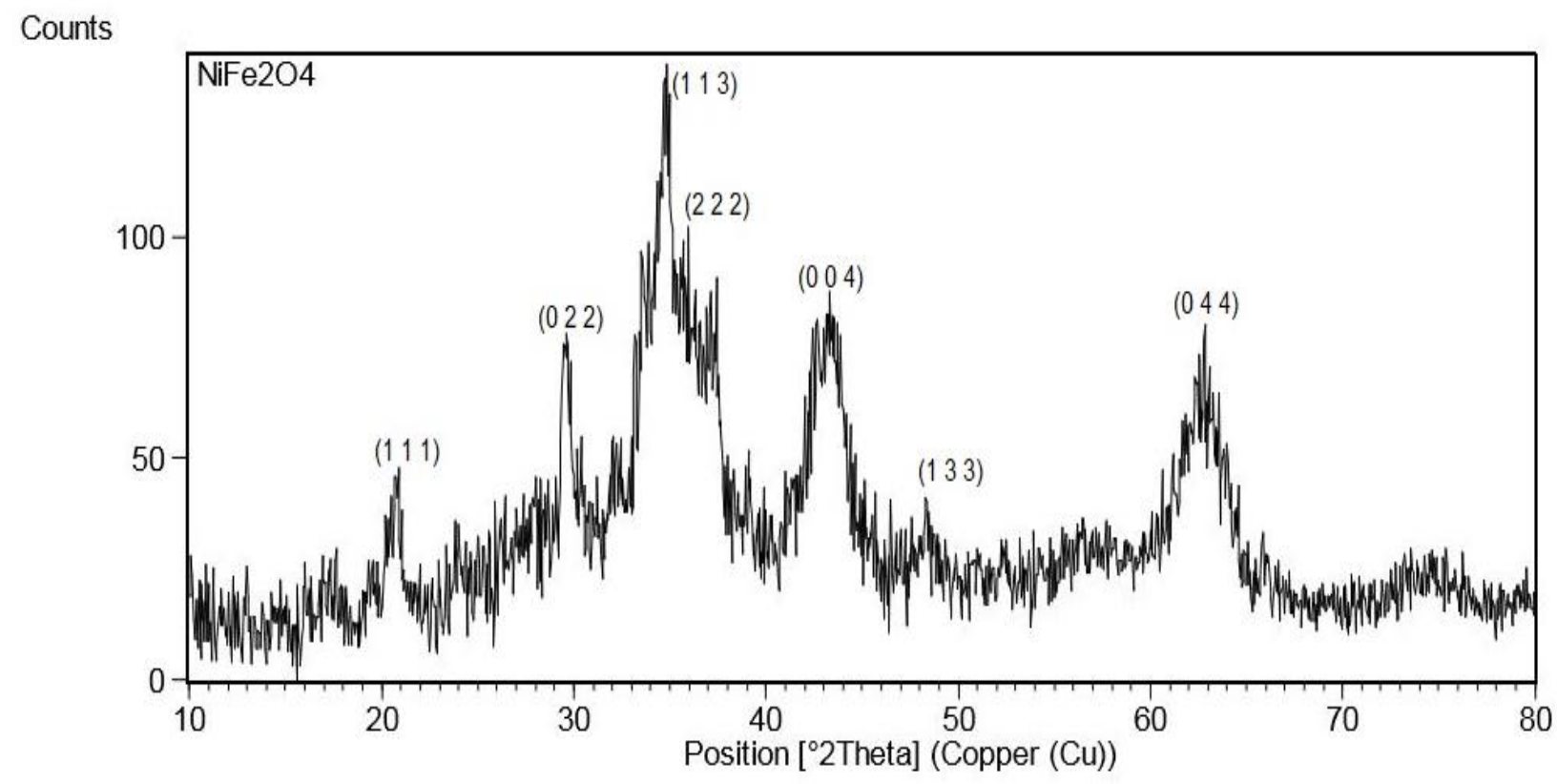

Fig. 18. XRD pattern for nickel ferrite nanoparticles. 


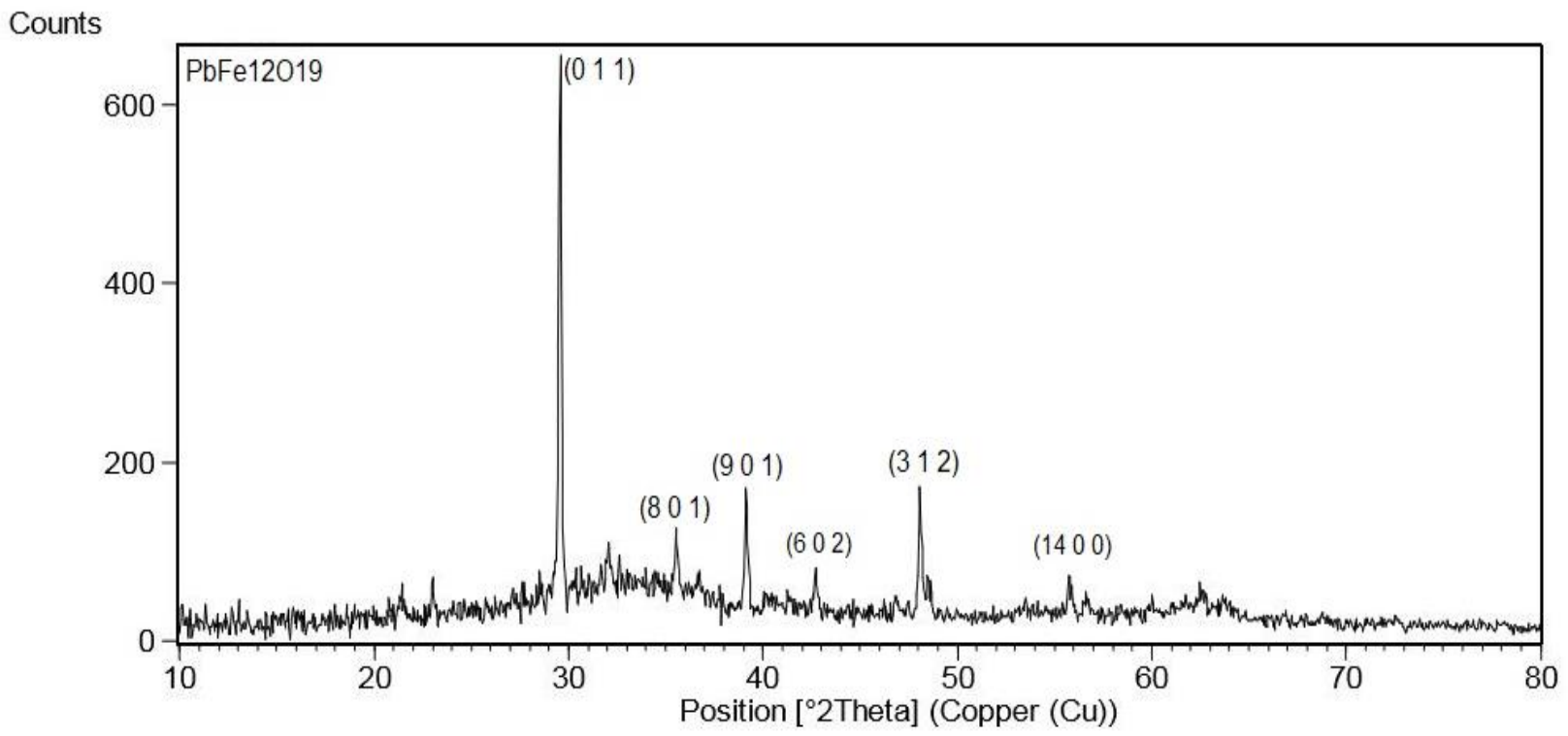

Fig. 19. XRD pattern for lead ferrite nanoparticles. 

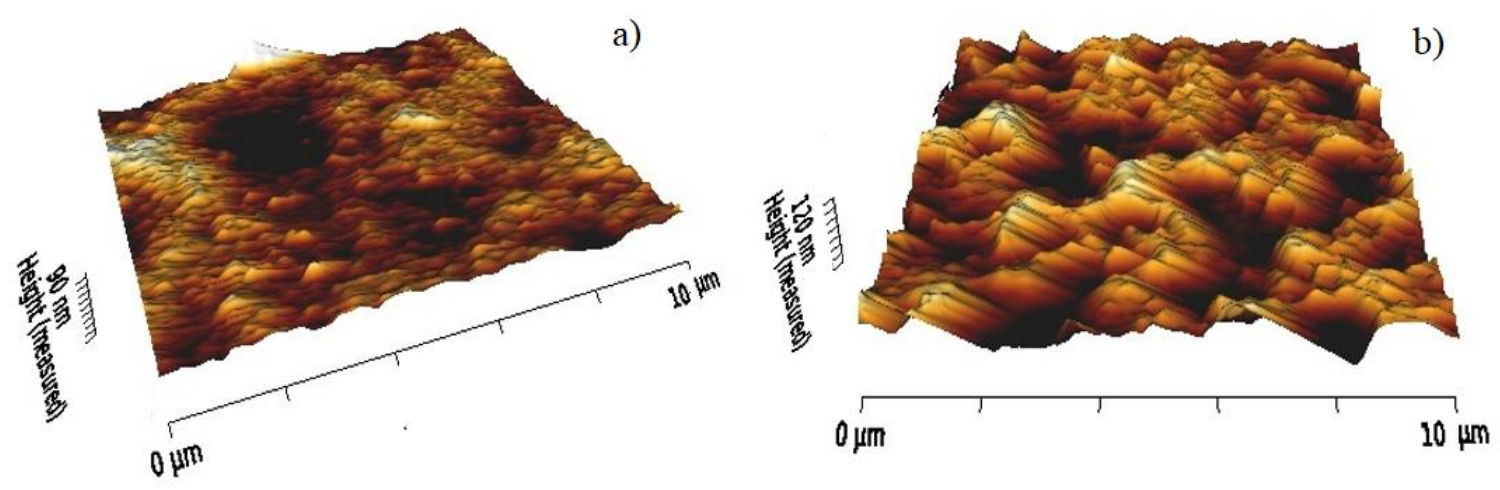

Fig. 20. AFM images of thin layer of polyaniline with a) 5 cycles and b) 10 cycles of deposition. 


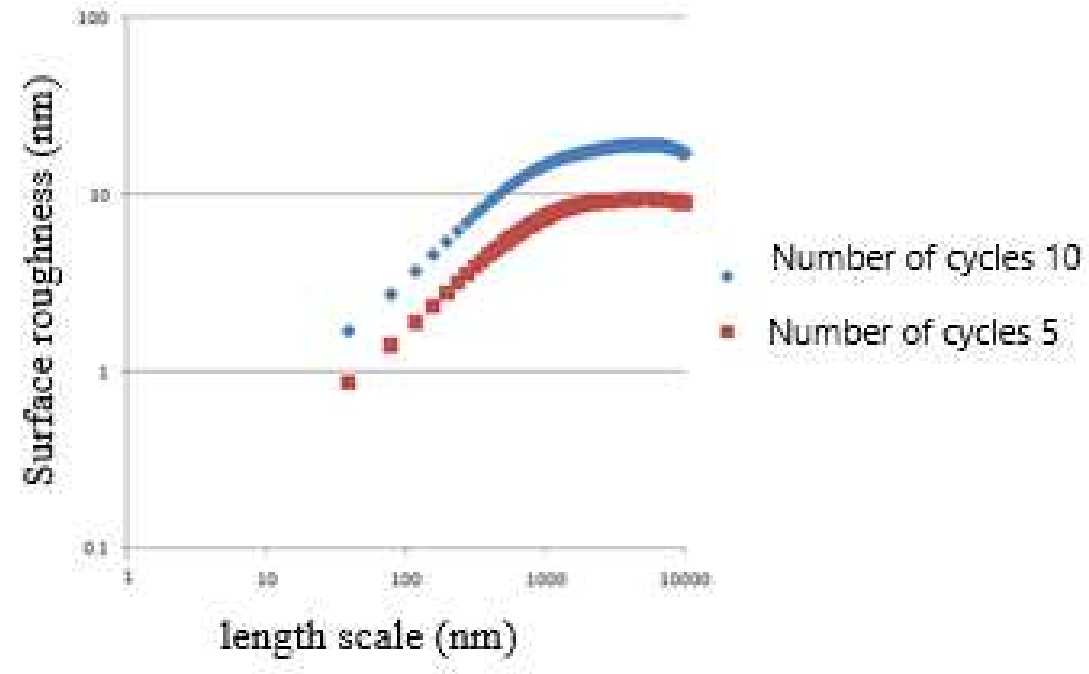

Fig .21. The roughness-scan length diagram in logarithmic scale for the thin layer of polyaniline with 5 and 10 cycles of deposition. 

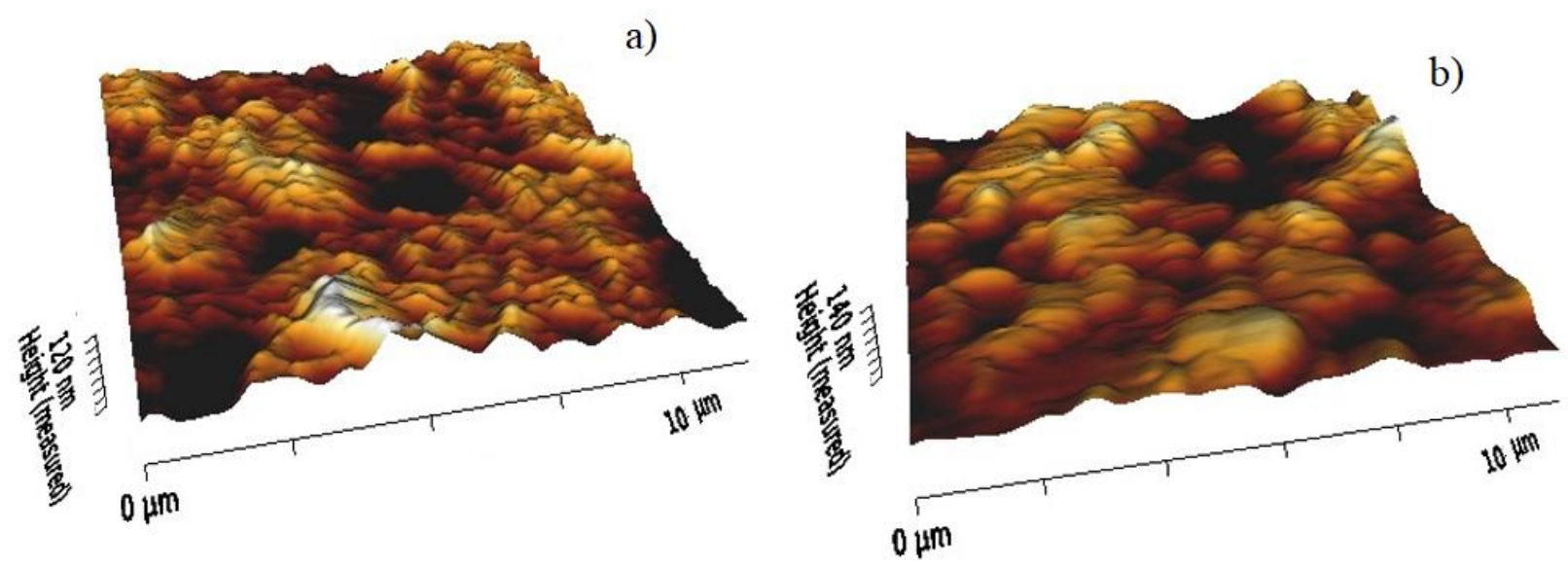

Fig. 22. AFM images of polyaniline/ cobalt ferrite thin layer composite with a) $0 / 1 \mathrm{~g}$ and b) $1 \mathrm{~g}$ cobalt ferrite. 


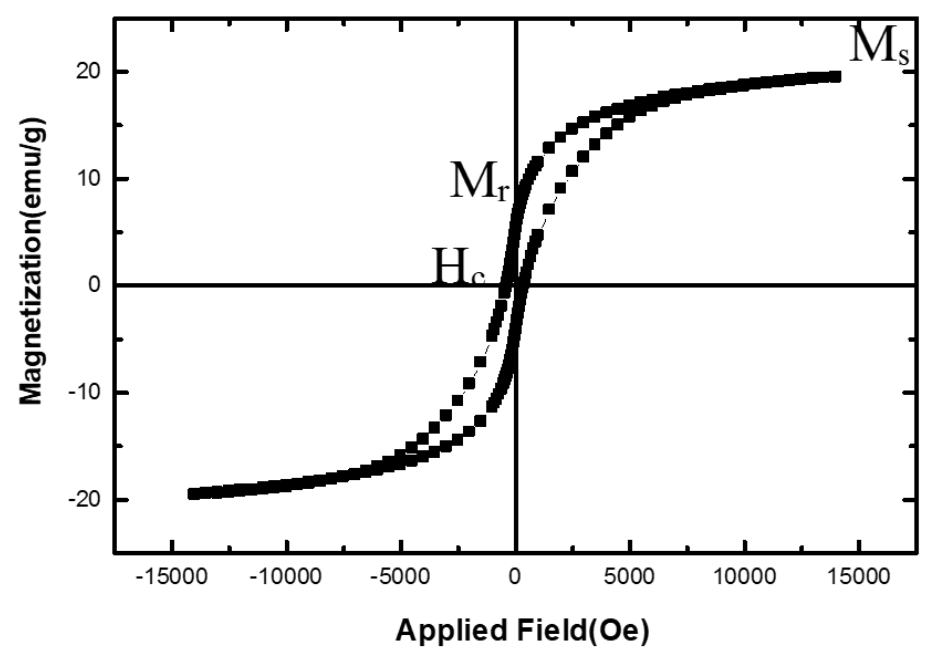

Fig. 23. Hysteresis loop for cobalt ferrite nanoparticles. 


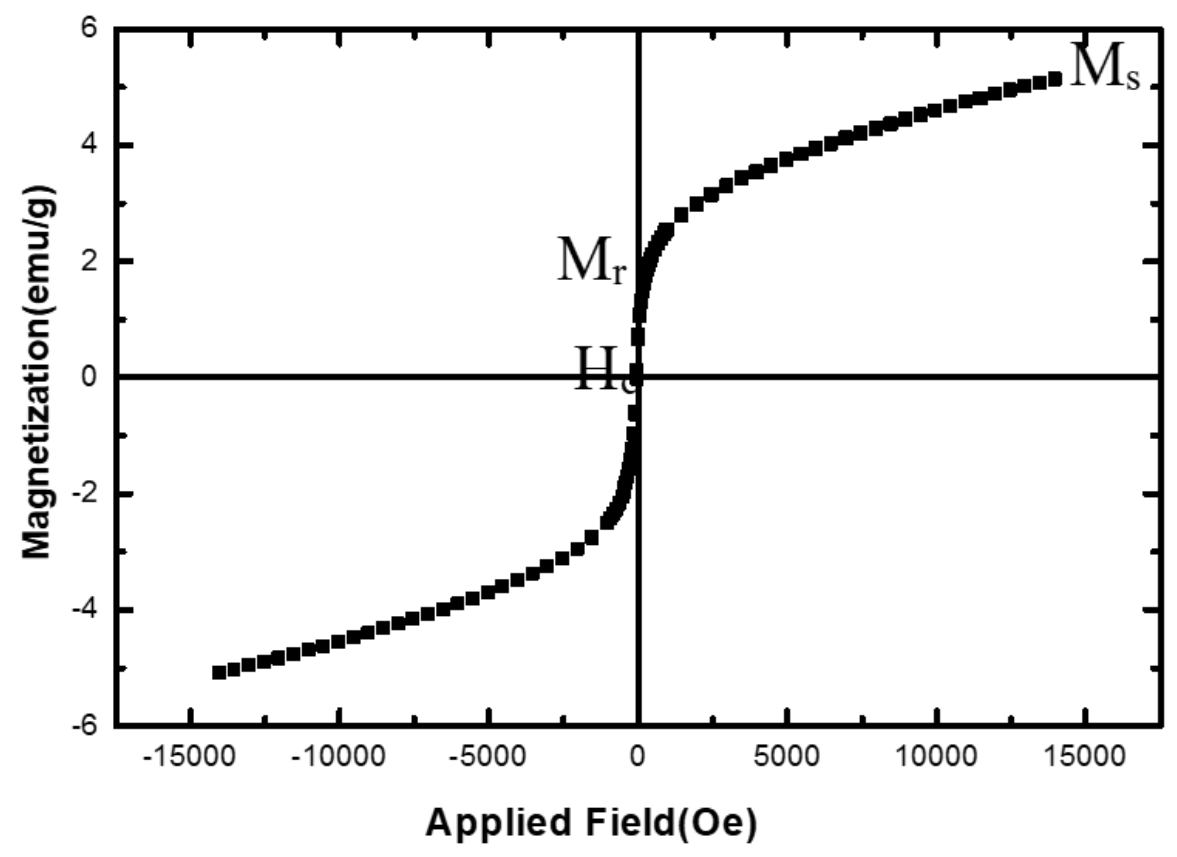

Fig. 24. Hysteresis loop for nickel ferrite nanoparticles. 


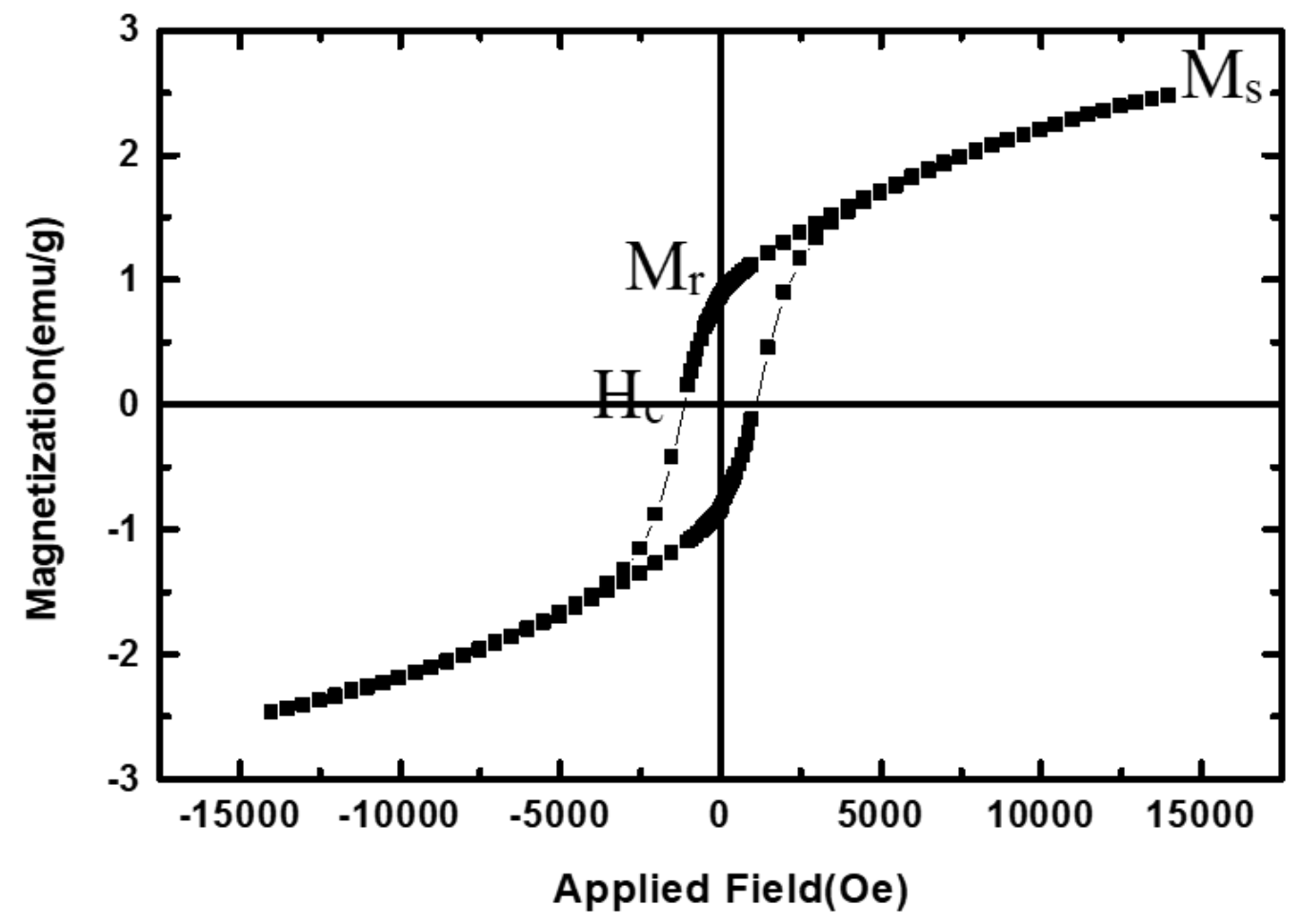

Fig. 25. Hysteresis loop for lead ferrite nanoparticles. 


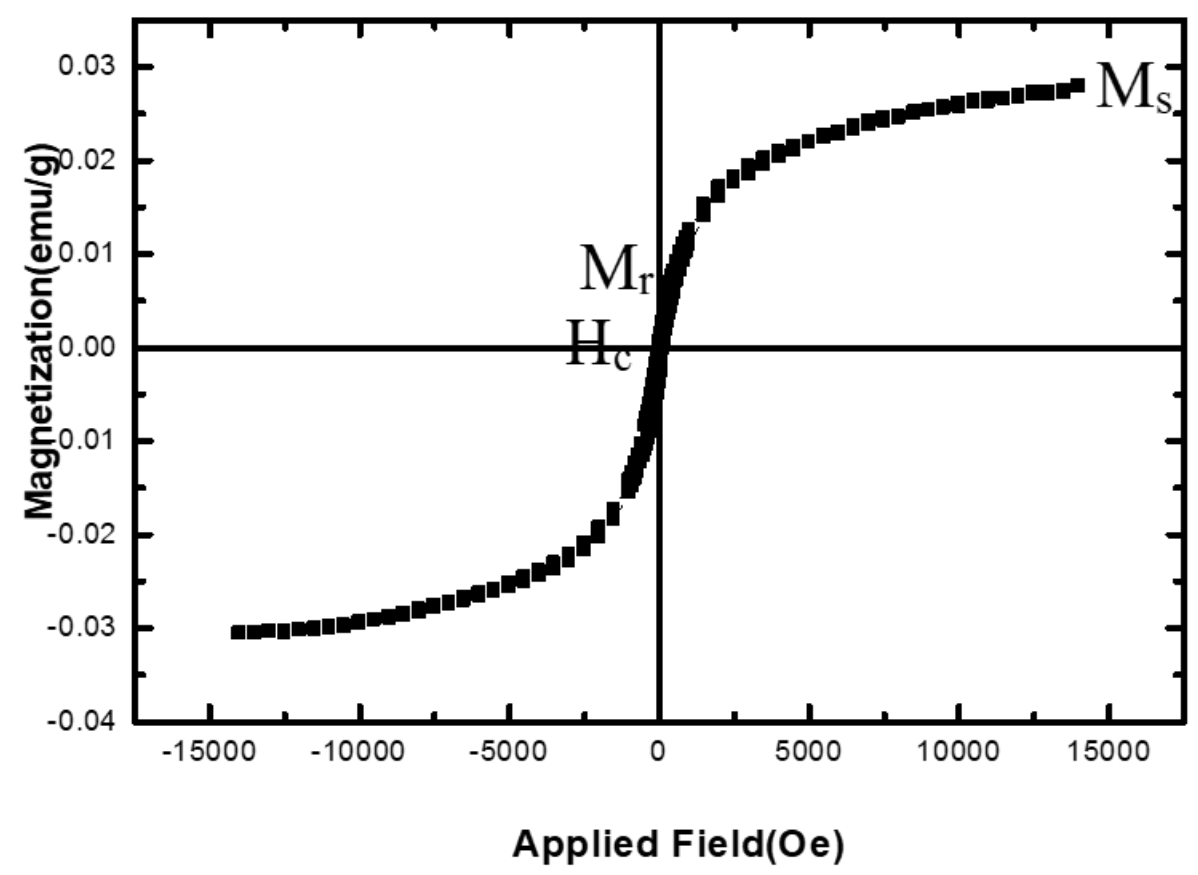

Fig. 26. Hysteresis loop for polyaniline/ cobalt ferrite thin layer composite in parallel field. 


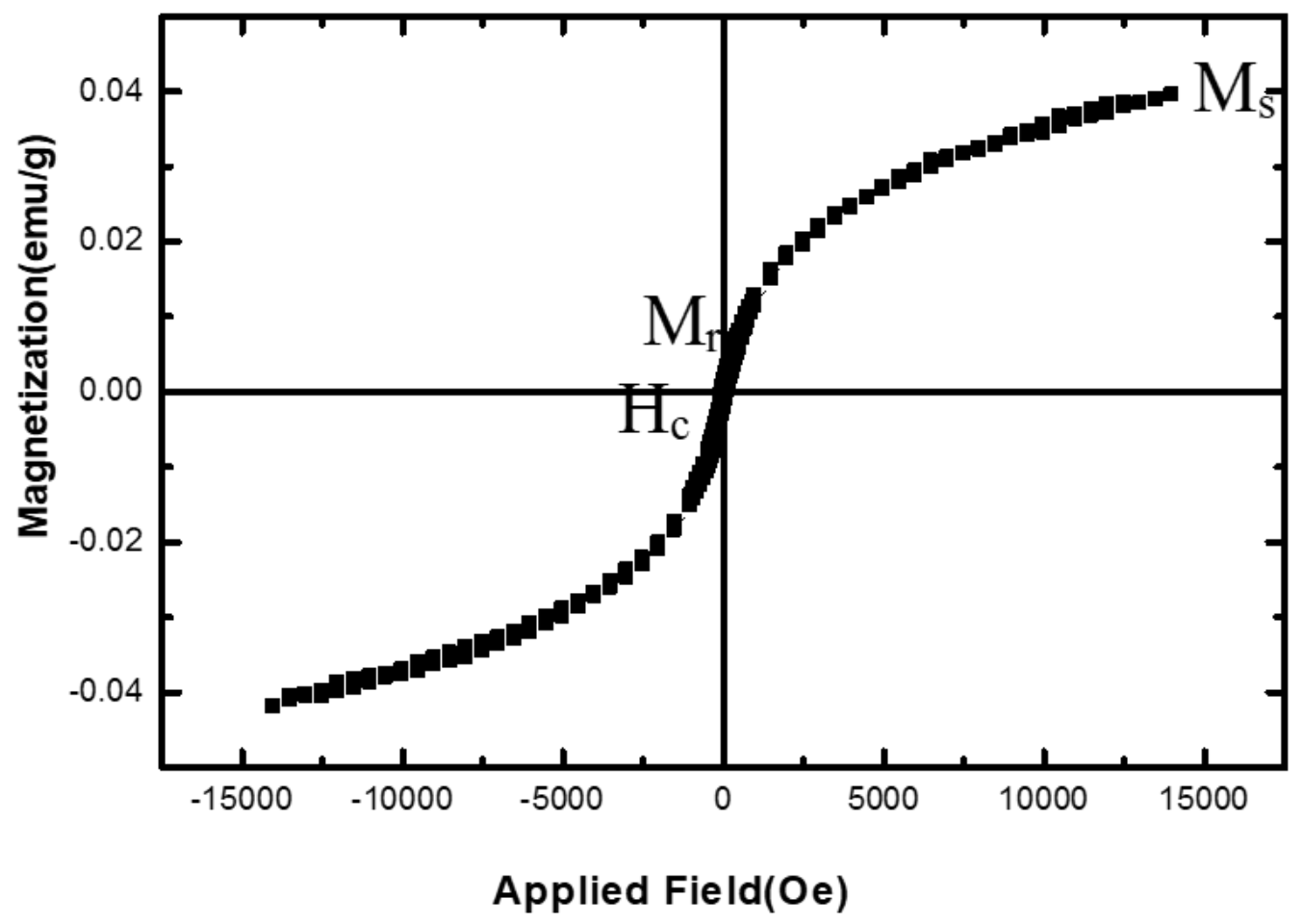

Fig. 27. Hysteresis loop for polyaniline/ cobalt ferrite thin layer composite in vertical field. 
Table $1 . \mathrm{M}_{\mathrm{r}}, \mathrm{M}_{\mathrm{s}}$ and $\mathrm{H}_{\mathrm{c}}$ for magnetic nanoparticles.

\begin{tabular}{|c|c|c|c|}
\hline Nanoparticles & $\begin{array}{c}\text { Remanence } \\
\text { magnetization } \\
(\mathrm{emu} / \mathrm{g})\end{array}$ & $\begin{array}{c}\text { Saturation } \\
\text { magnetization } \\
(\mathrm{emu} / \mathrm{g})\end{array}$ & $\begin{array}{c}\text { Coercivity } \\
(\mathrm{Oe})\end{array}$ \\
\hline Cobalt ferrite & 8.04 & 19.5 & 400 \\
\hline Nickel ferrite & 1.85 & 5.1 & 1000 \\
\hline Lead ferrite & 1 & 2.5 & 5 \\
\hline
\end{tabular}




\section{Figures}

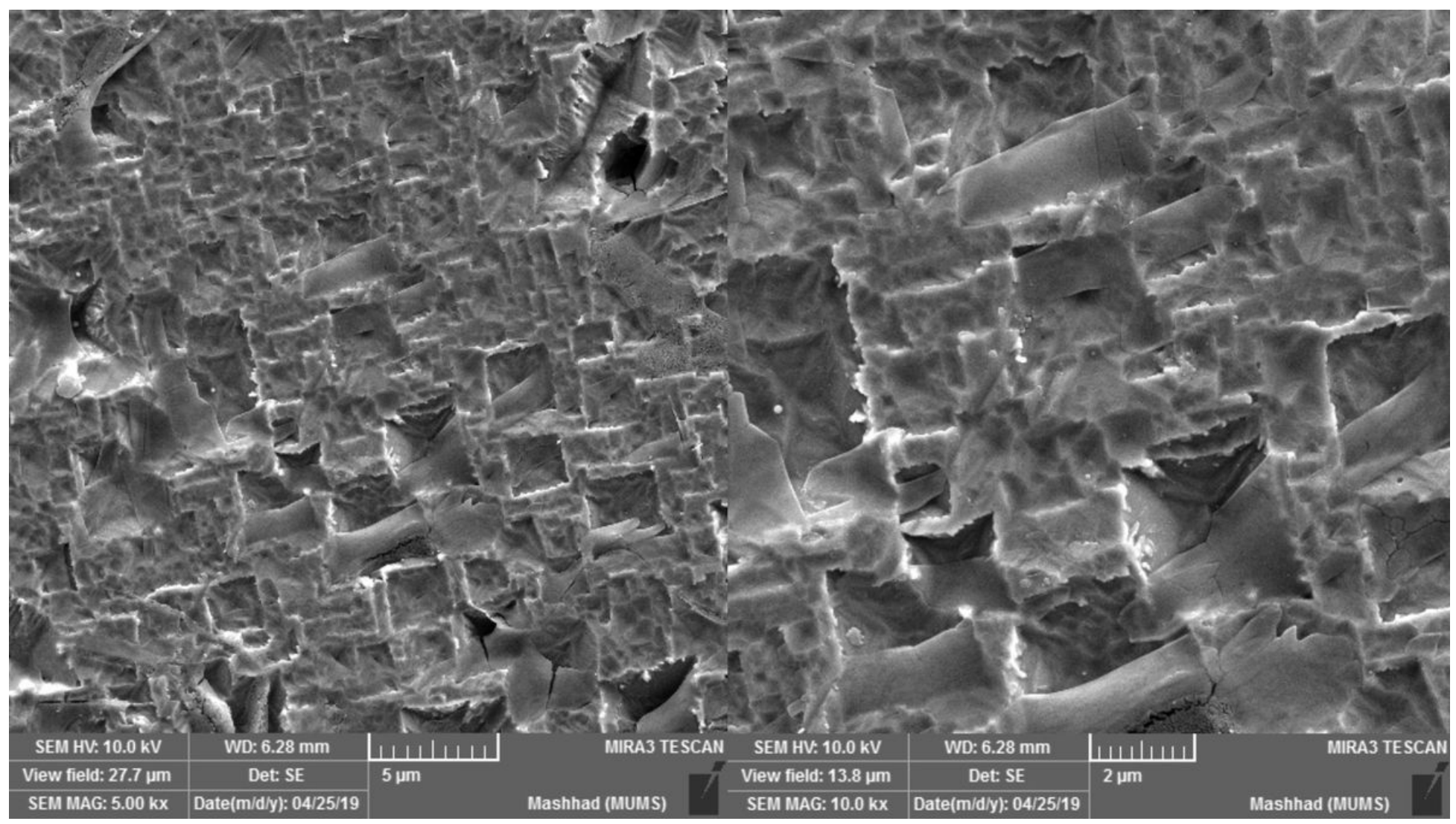

Figure 1

FESEM images of thin layer of Polyaniline with 5 cycles of electrodeposition.

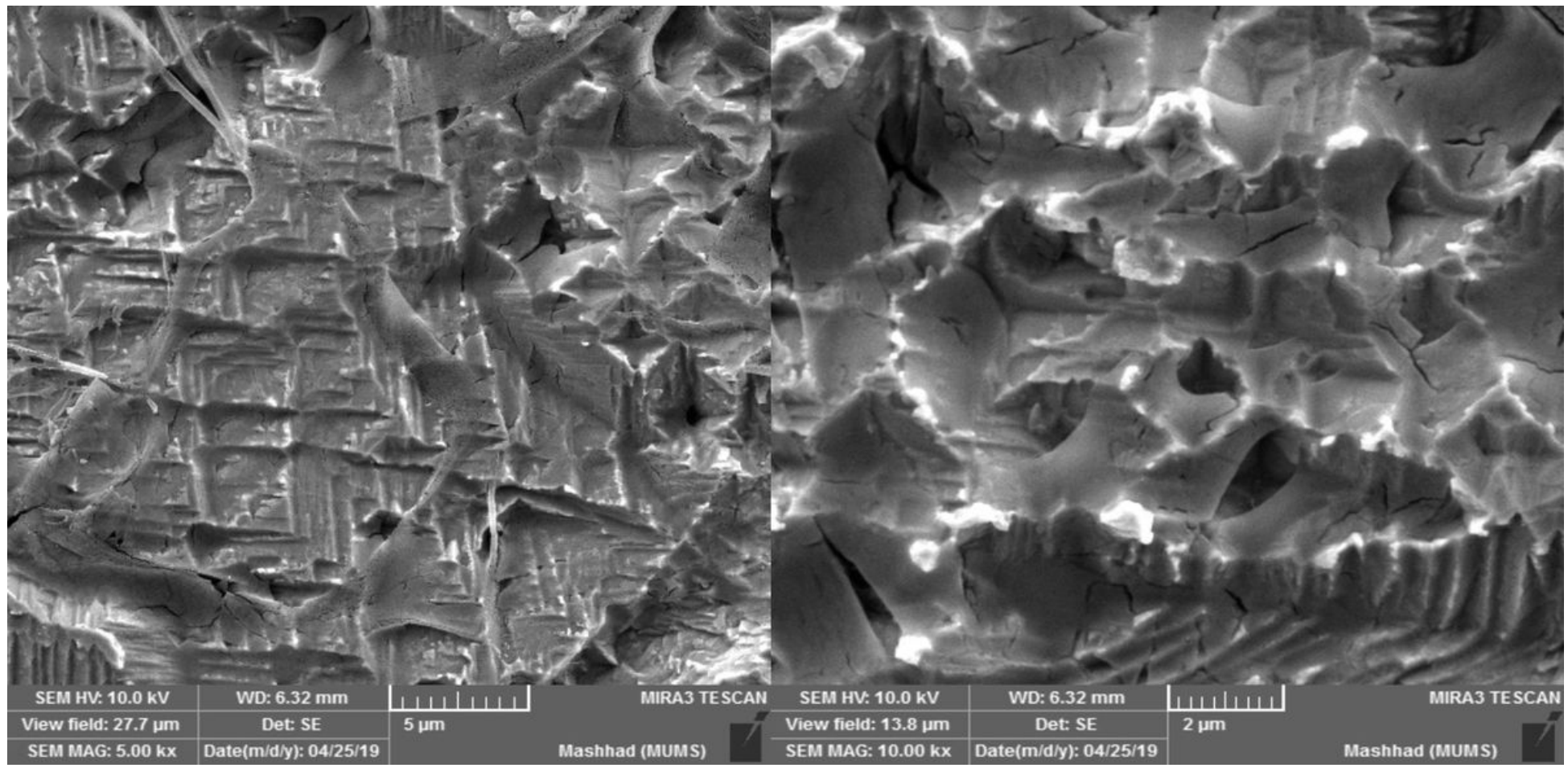

Figure 2 
SEM images of thin layer of Polyaniline with 10 cycles of electrodeposition.

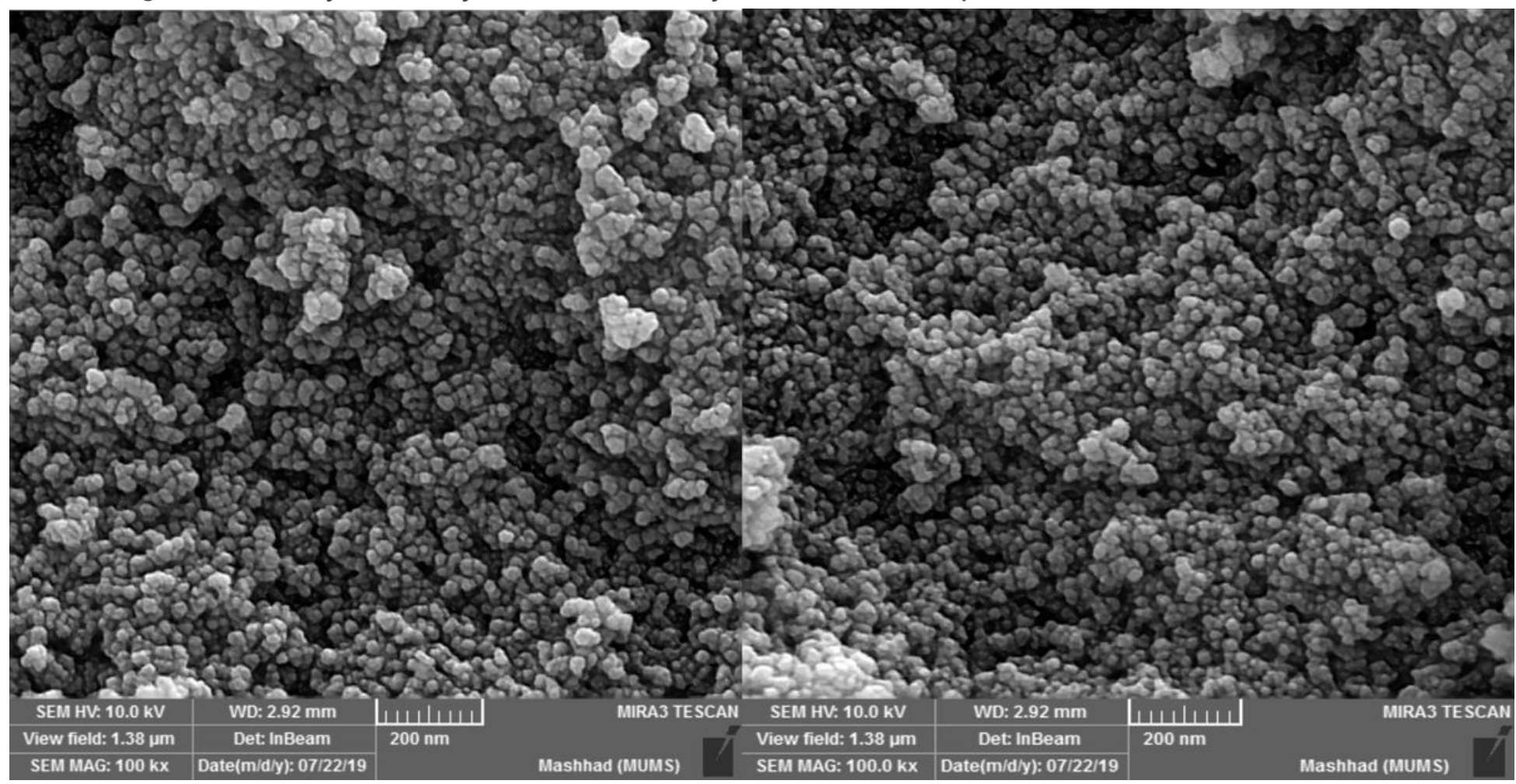

Figure 3

SEM images of cobalt ferrite nanoparticles.

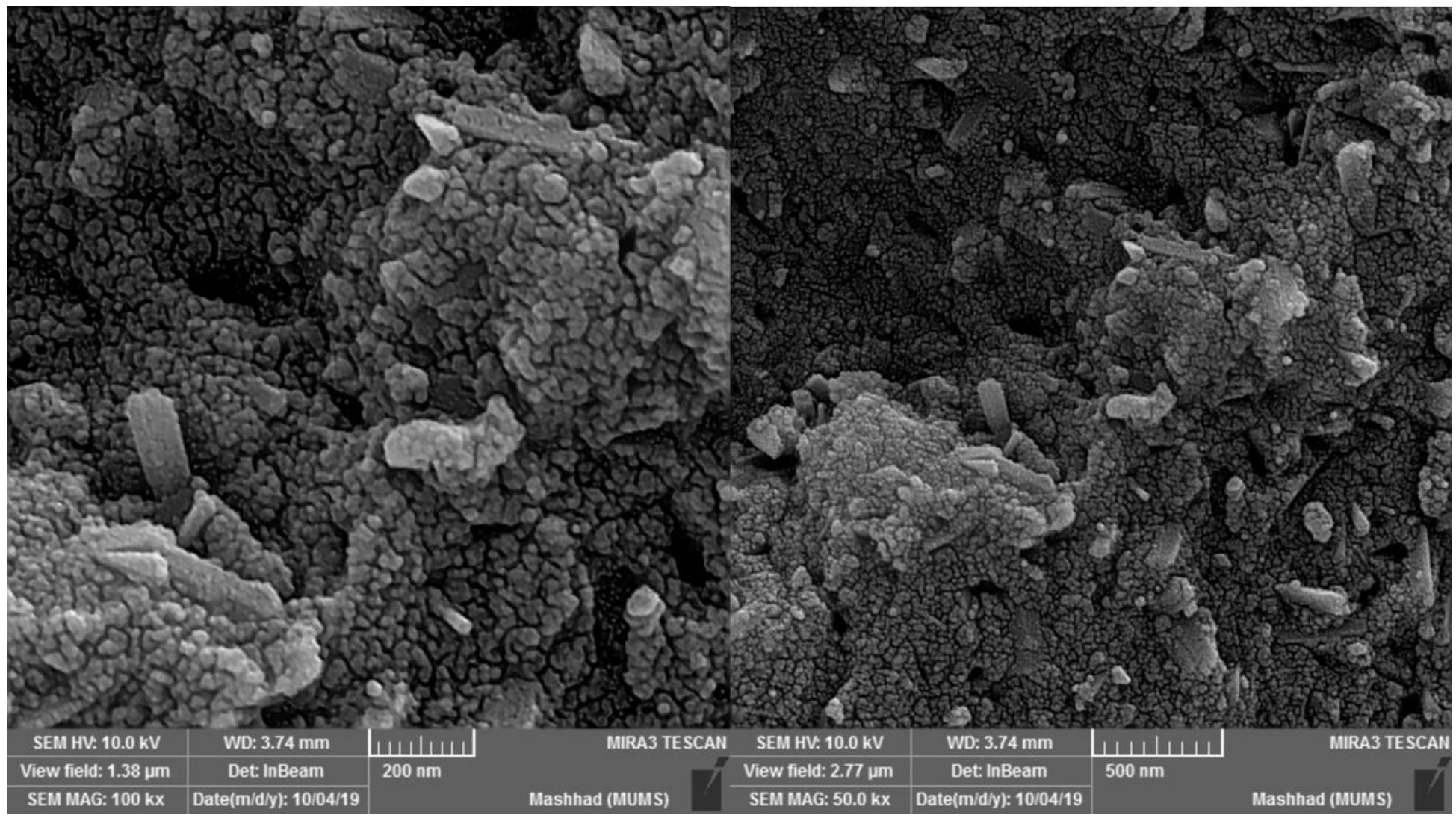

Figure 4 
SEM images of lead ferrite nanoparticles.

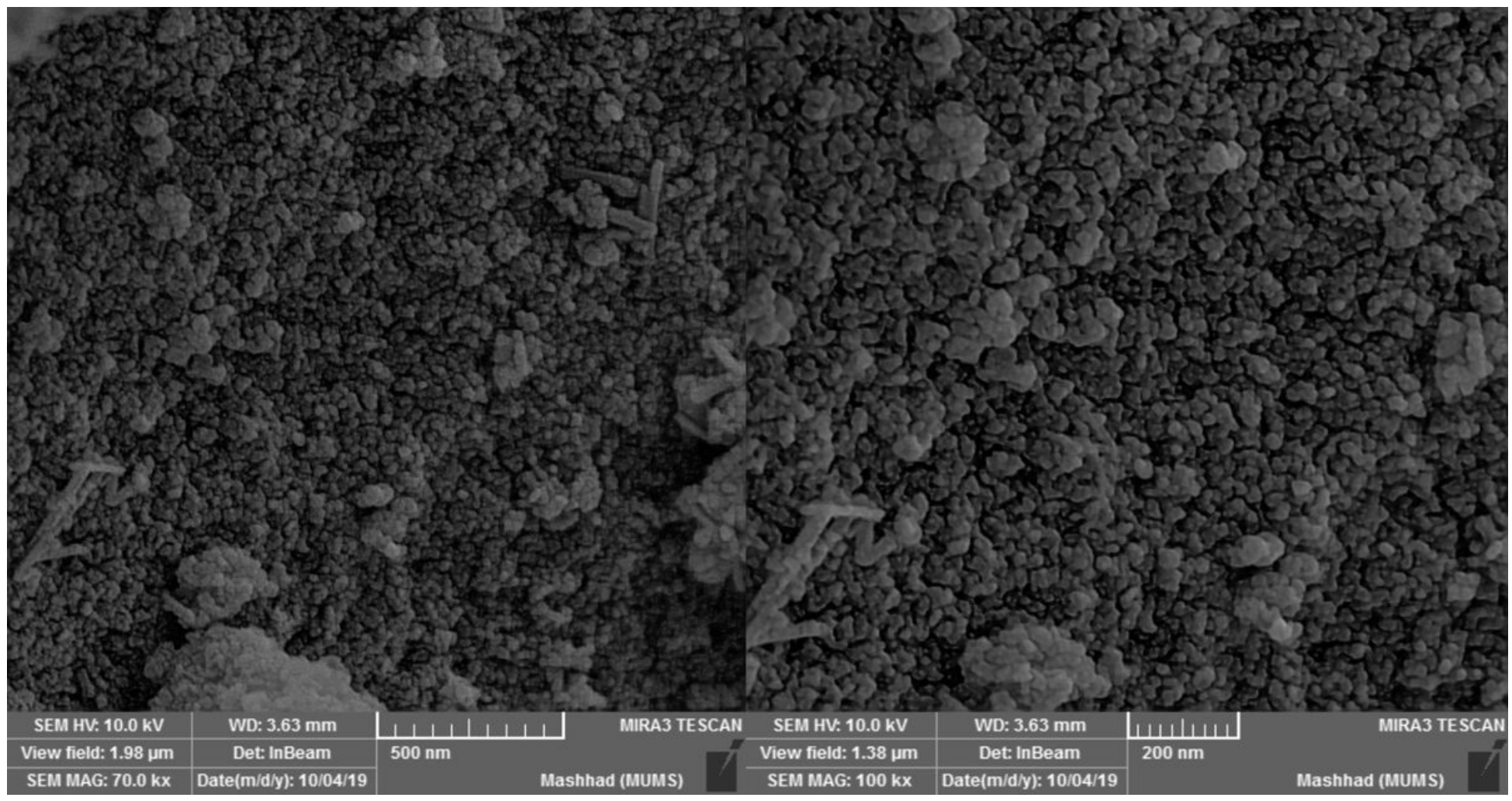

\section{Figure 5}

SEM images of nickel ferrite nanoparticles. 


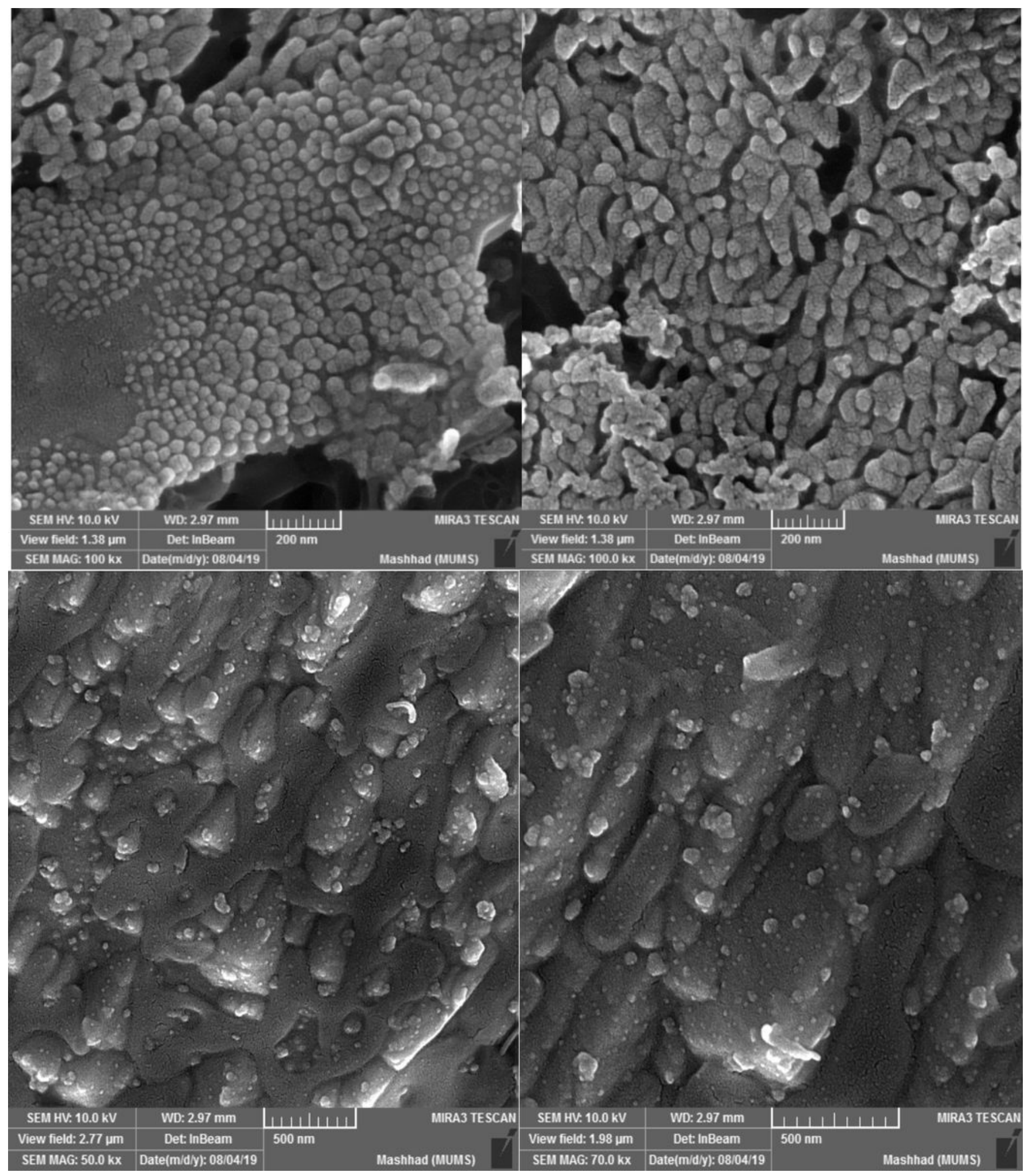

Figure 6

SEM images of polyaniline/ cobalt ferrite thin layer composite (with $0.1 \mathrm{~g}$ of cobalt ferrite). 


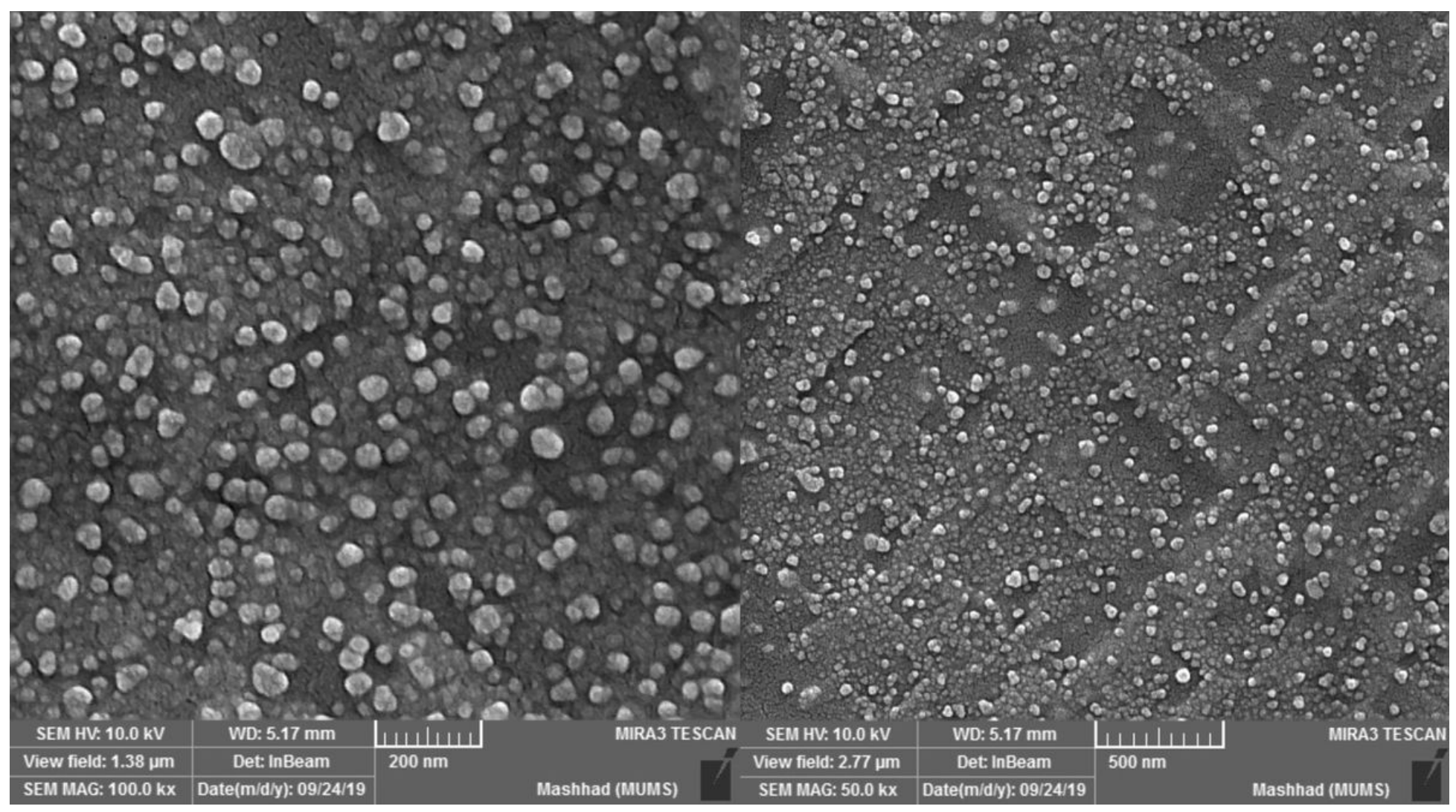

\section{Figure 7}

SEM images of polyaniline/ cobalt ferrite thin layer composite (1 $\mathrm{g}$ of cobalt ferrite )

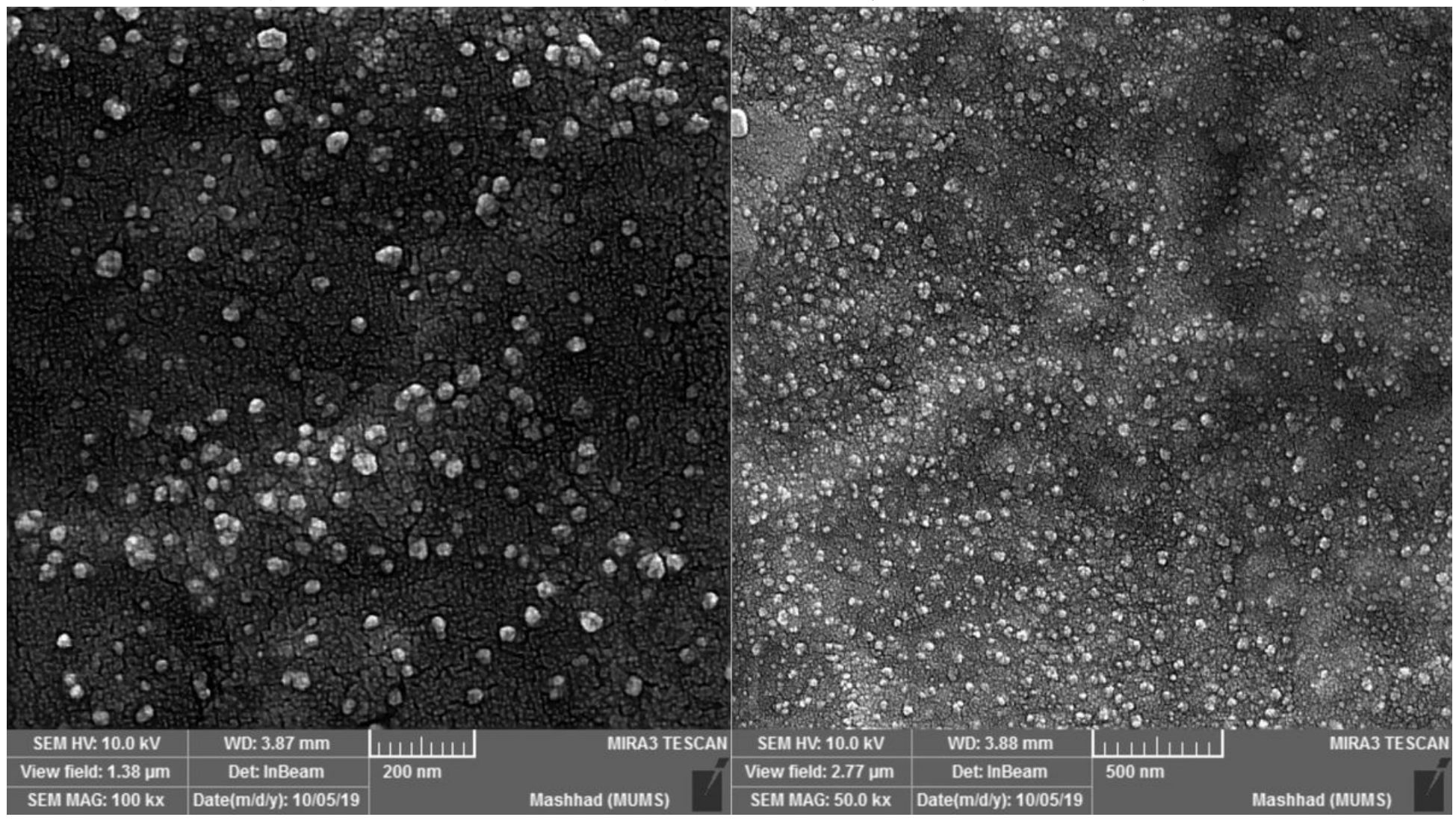

Figure 8 
SEM images of polyaniline/ lead ferrite thin layer composite (with $1 \mathrm{~g}$ of lead ferrite ).

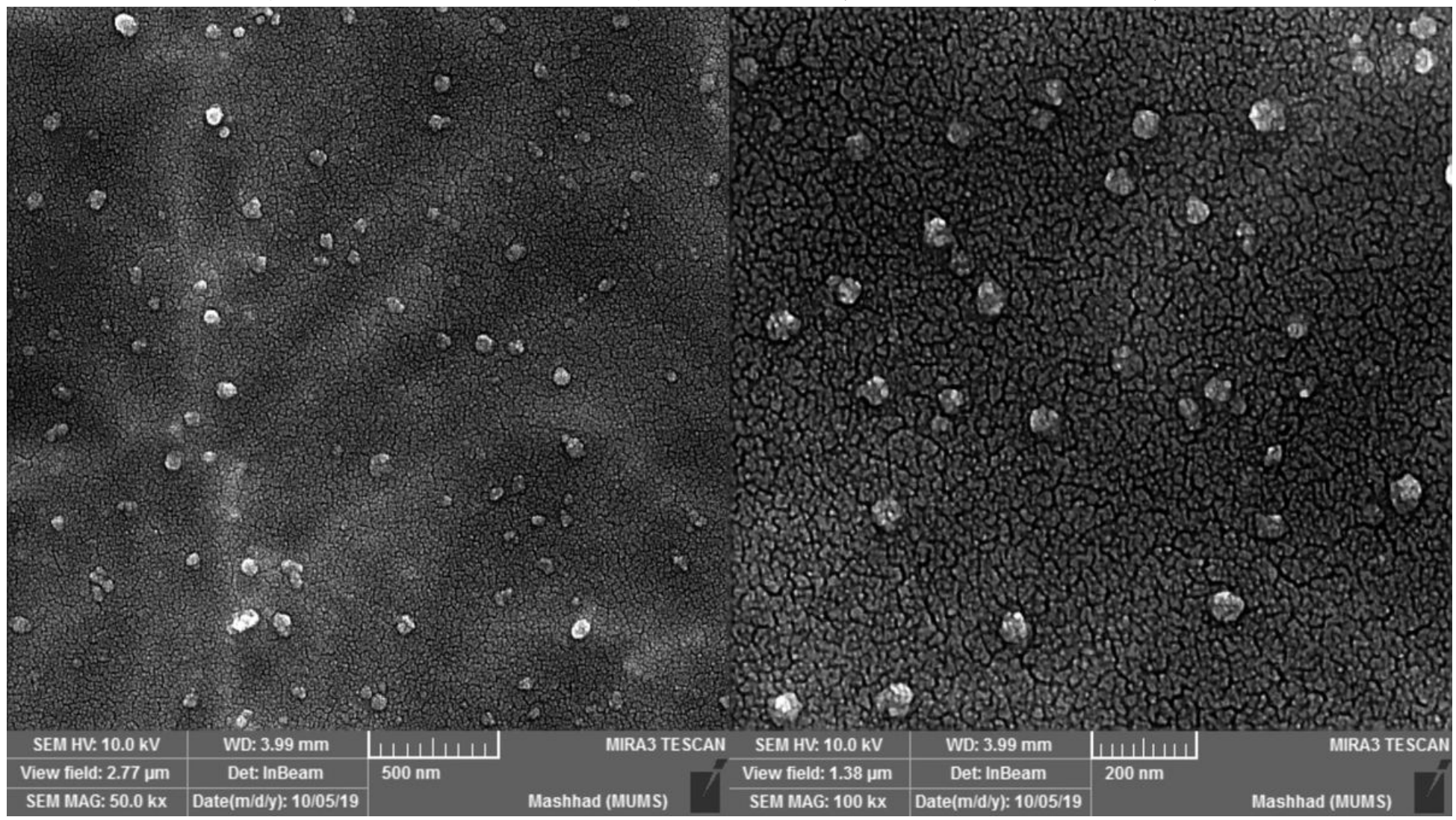

\section{Figure 9}

SEM images of polyaniline/ nickel ferrite thin layer composite (with $1 \mathrm{~g}$ of nickel ferrite ). 

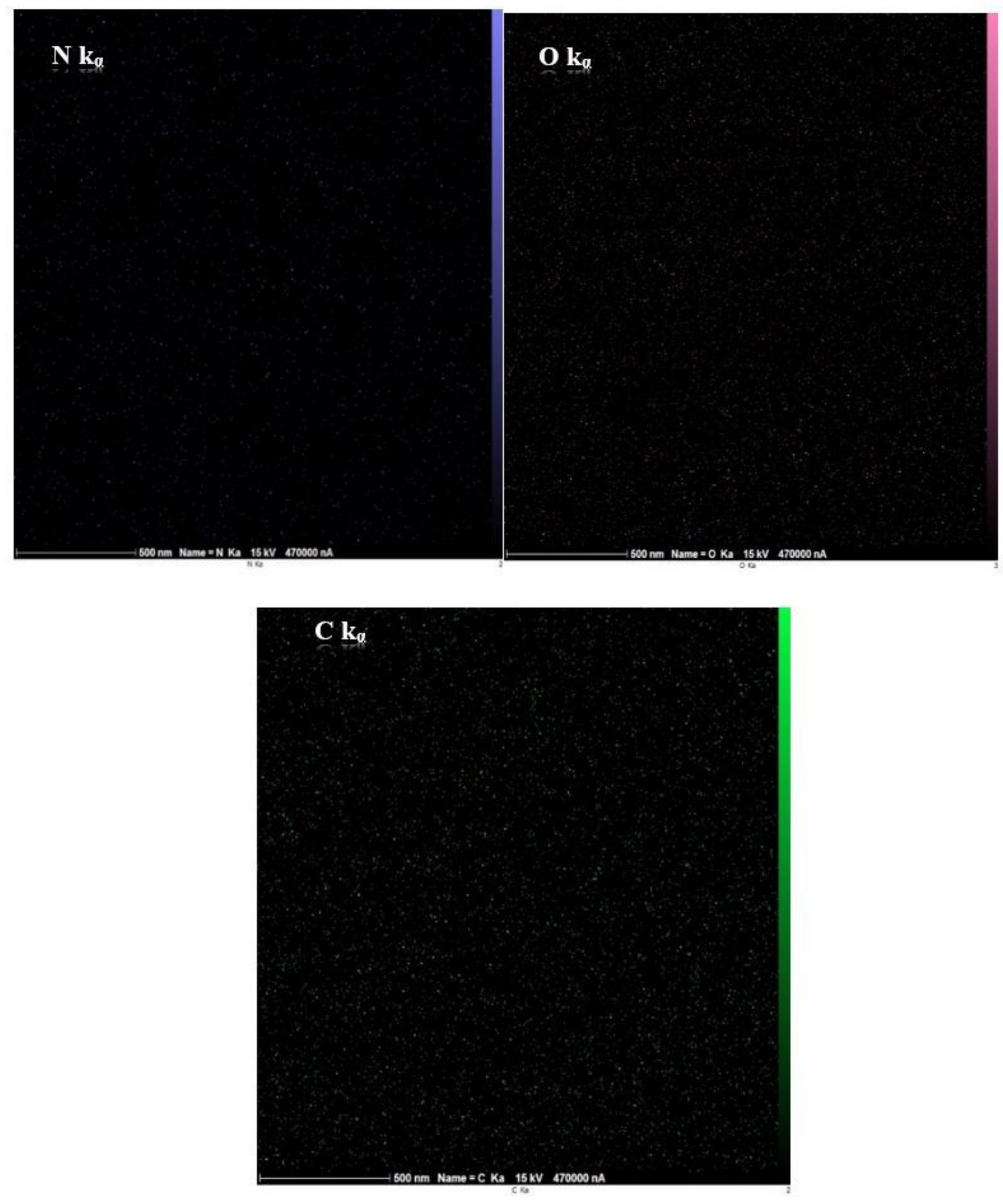

Figure 10

Elemental map of the detected elements in EDX of the polyaniline thin layer with the number of 10 deposition cycles. 


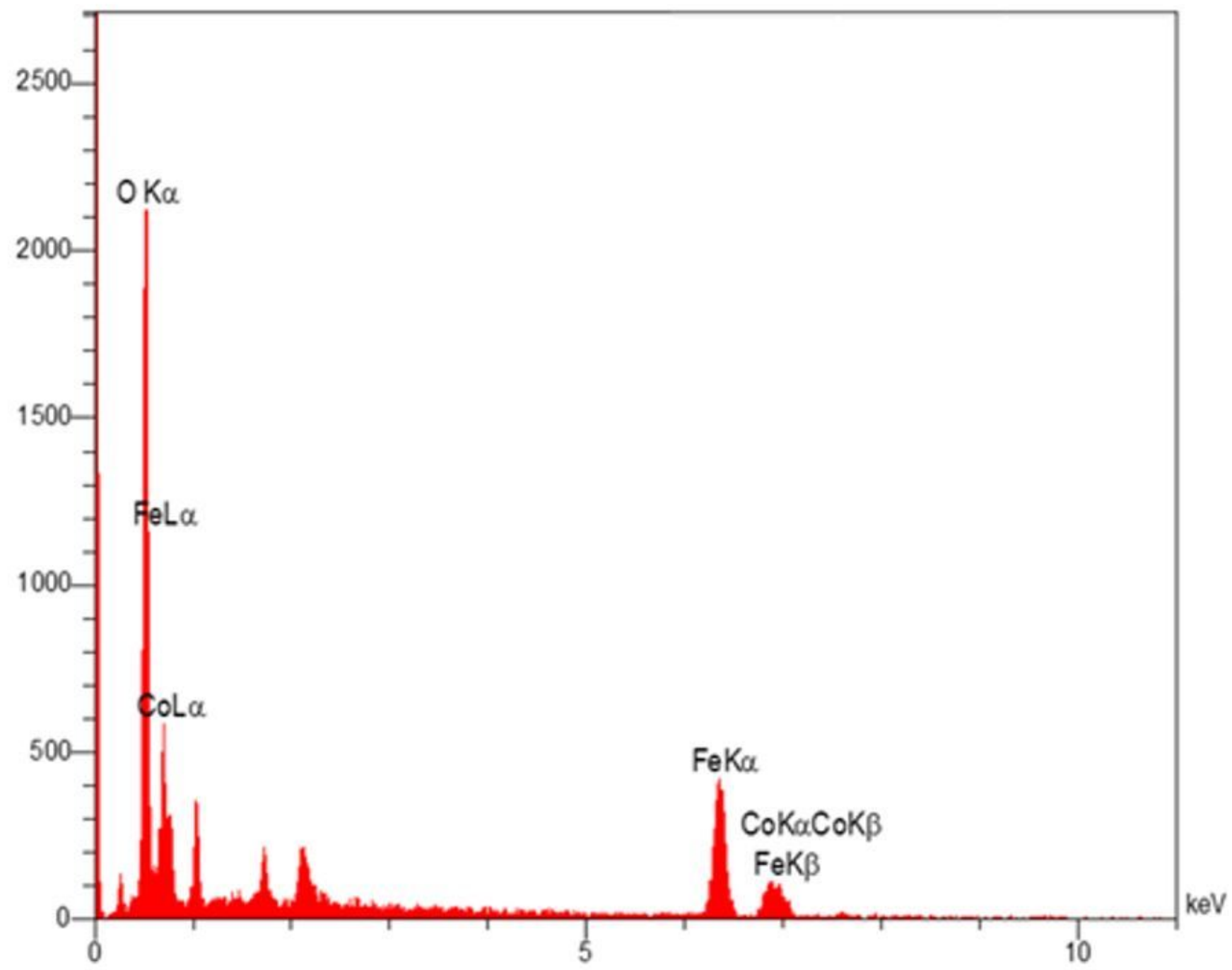

Figure 11

EDX pattern of cobalt ferrite nanopowders. 


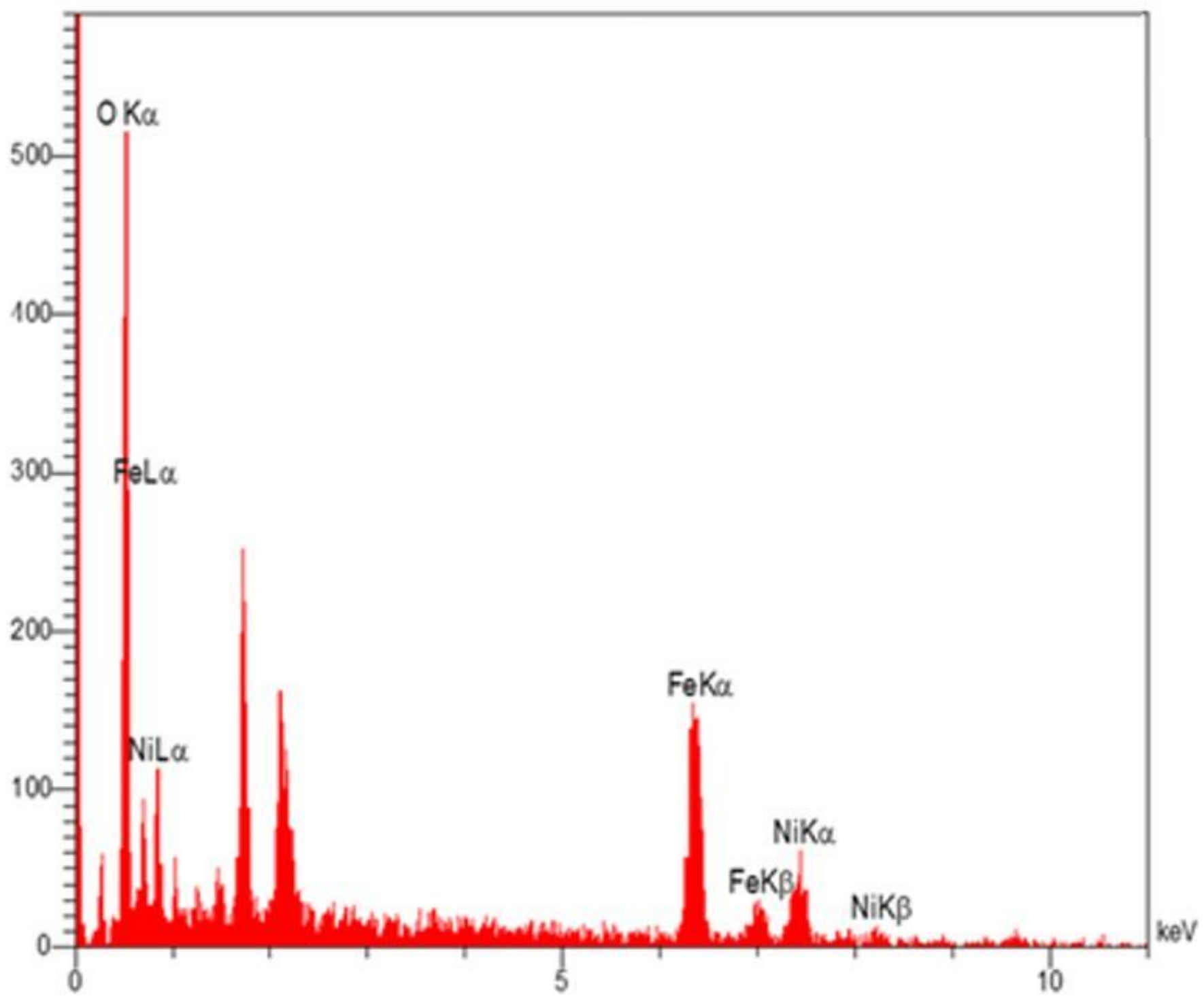

Figure 12

EDX pattern of nickel ferrite nanopowders. 


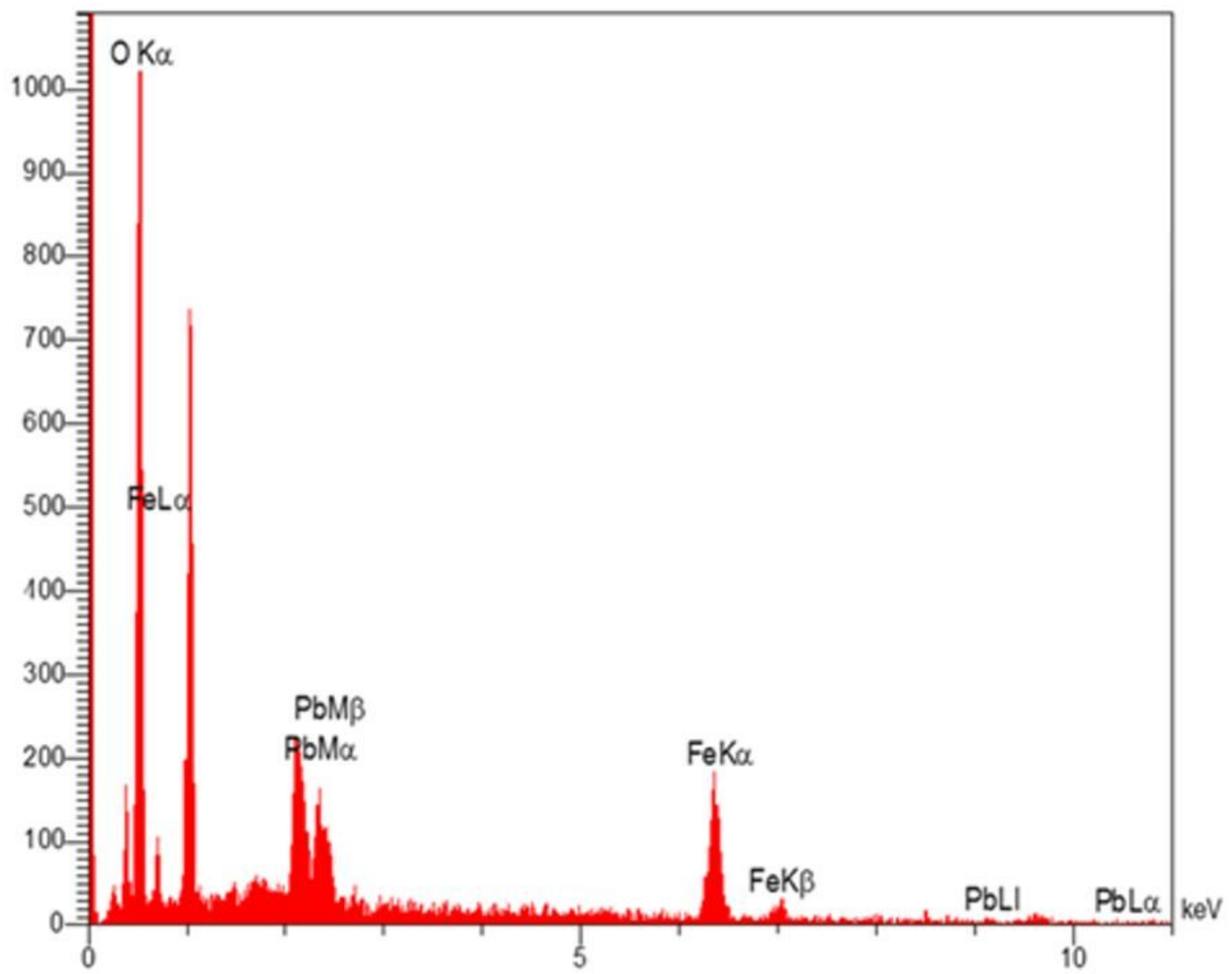

Figure 13

EDX pattern of Lead ferrite nanopowders. 


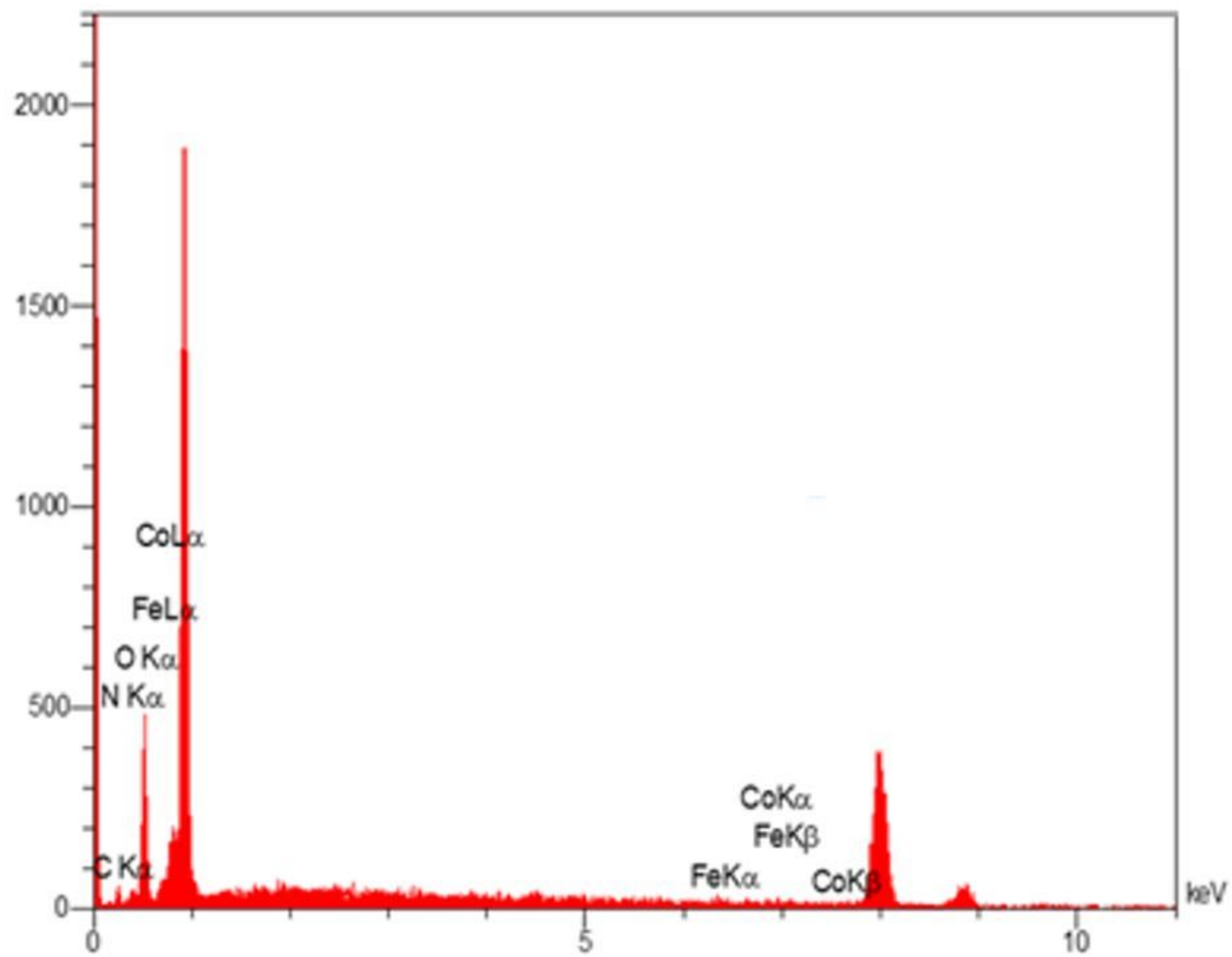

Figure 14

EDX pattern of polyaniline/ cobalt ferrite thin layer composite 


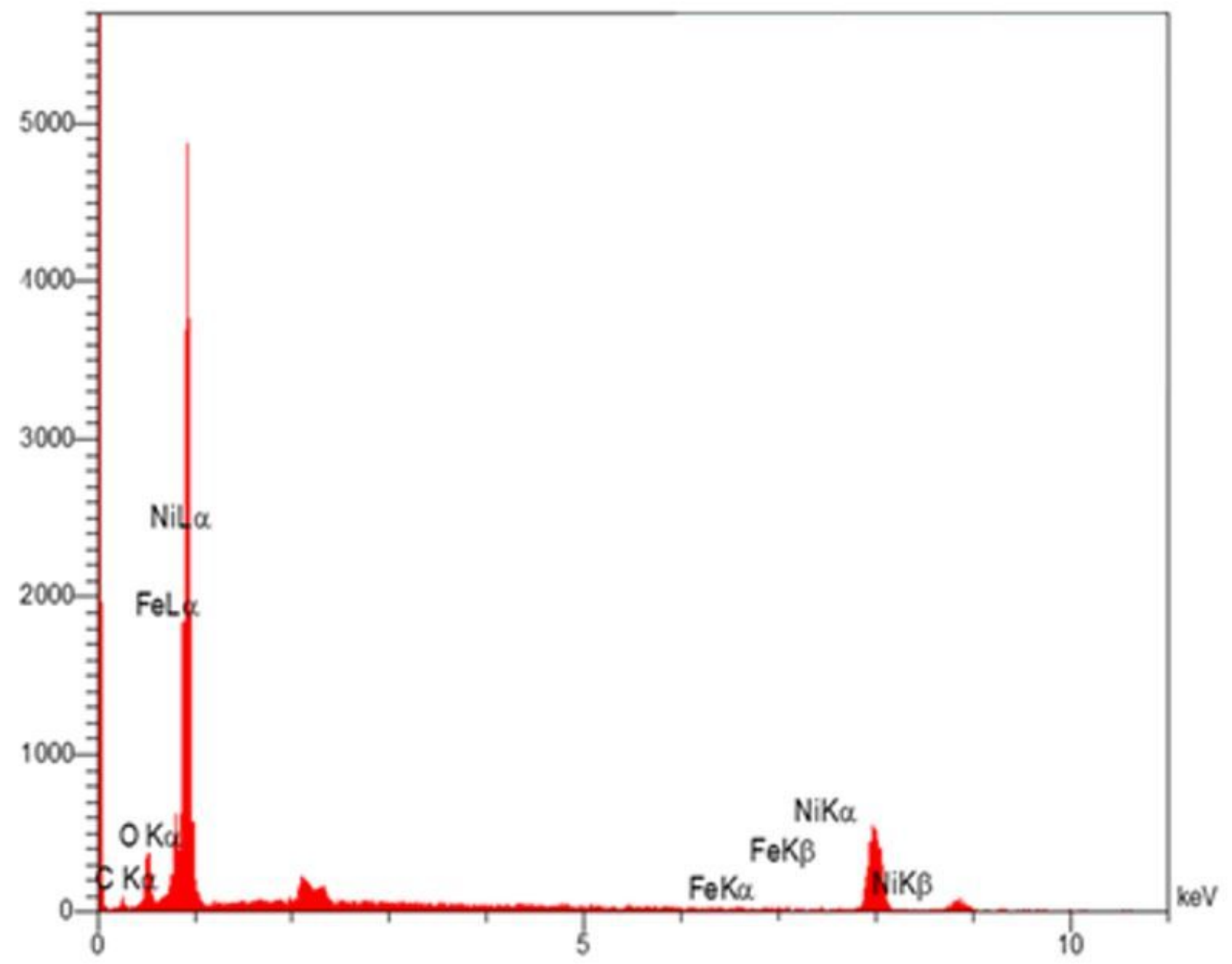

Figure 15

EDX pattern of polyaniline/ nickel ferrite thin layer composite 


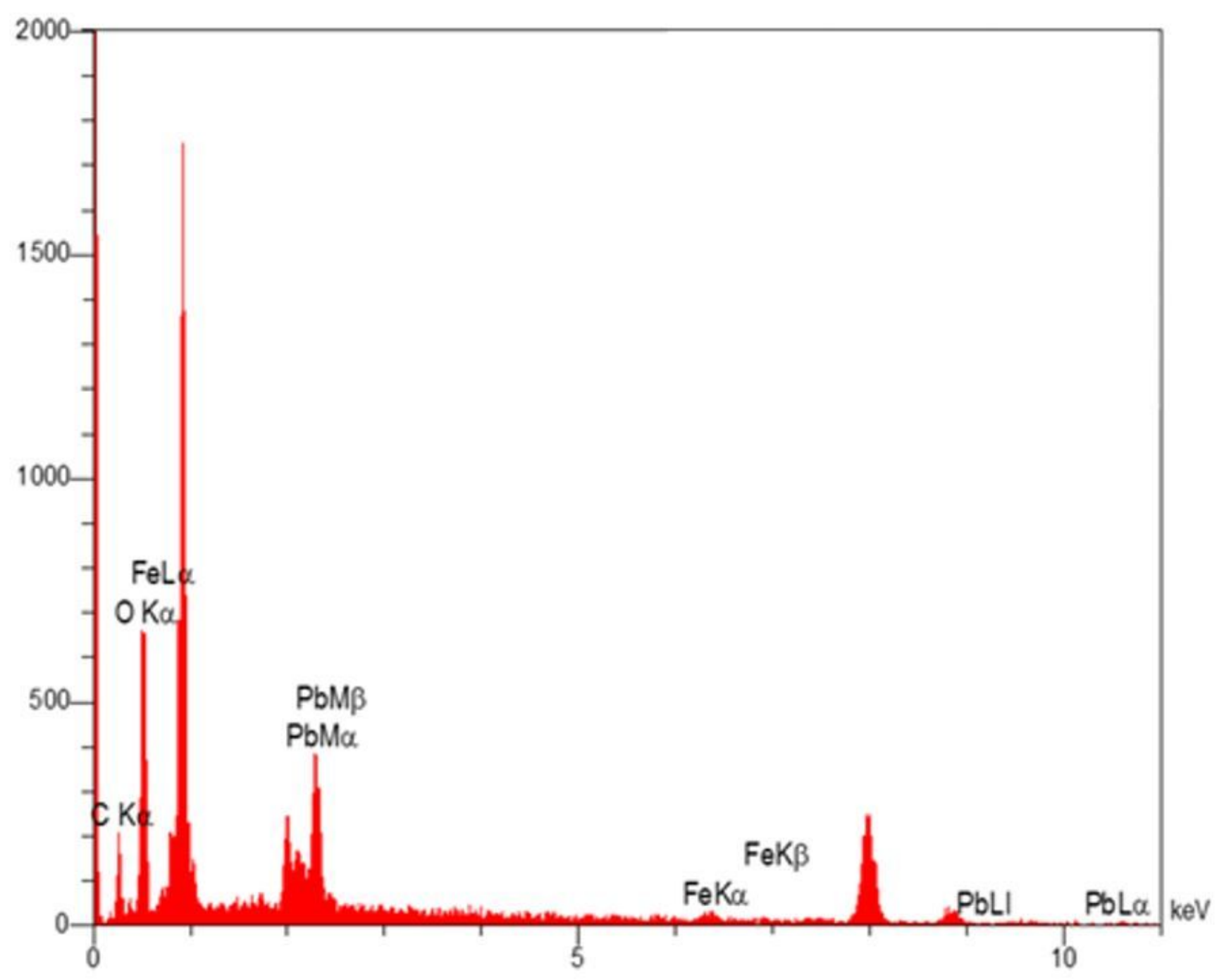

Figure 16

EDX pattern of polyaniline/ lead ferrite thin layer composite 
Counts

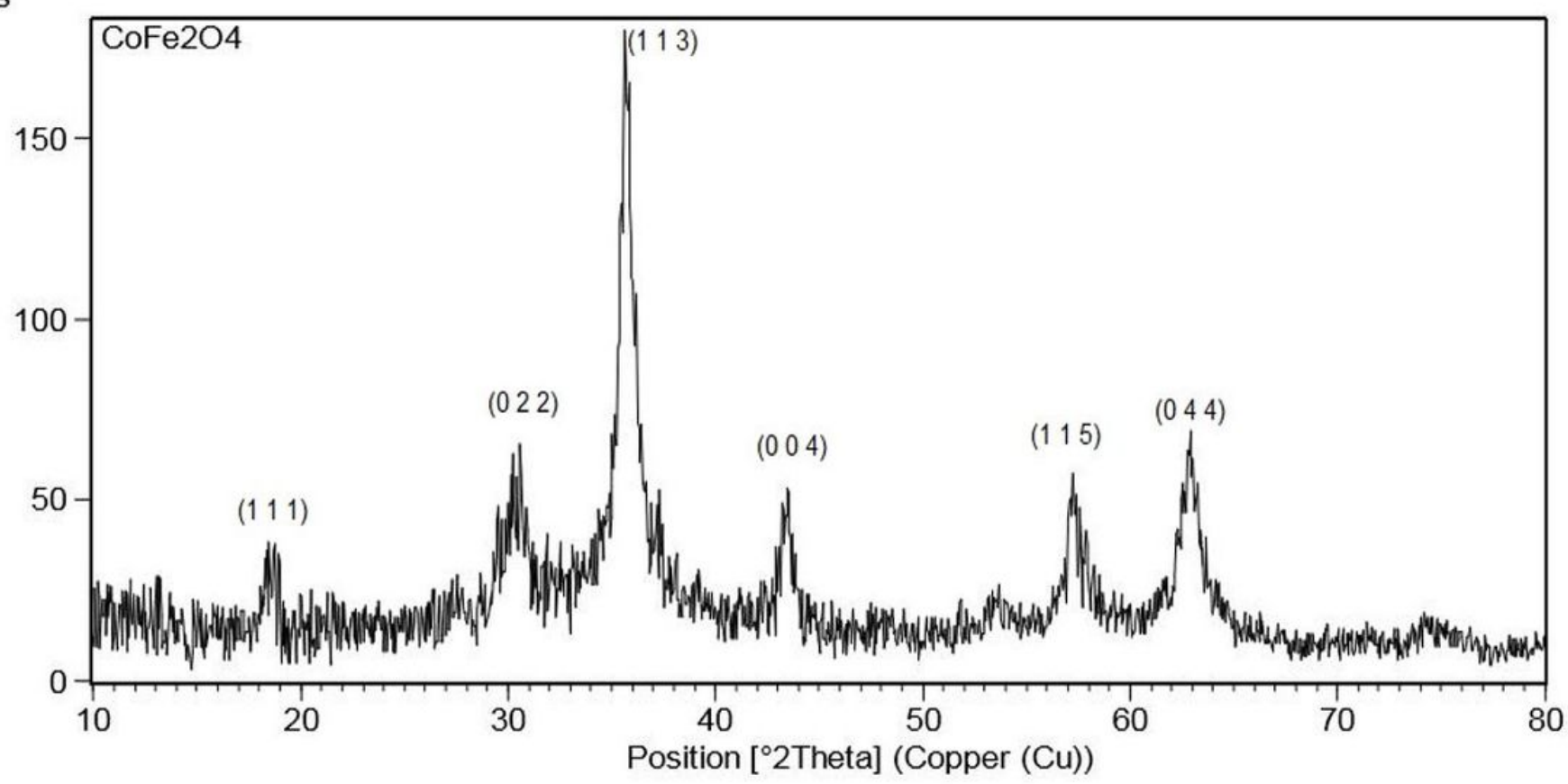

Figure 17

XRD pattern for cobalt ferrite nanoparticles.

Counts

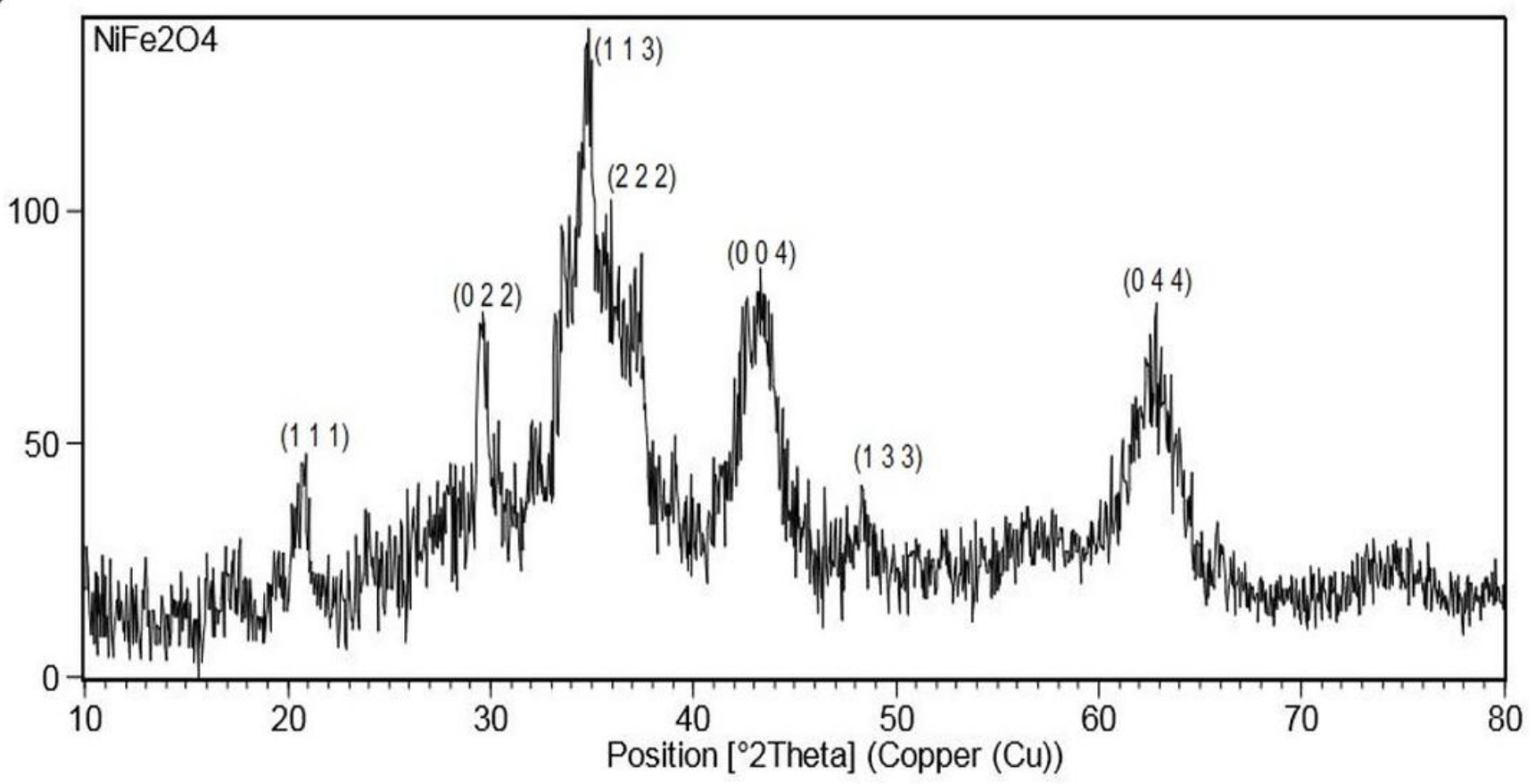

Figure 18

XRD pattern for nickel ferrite nanoparticles. 
Counts

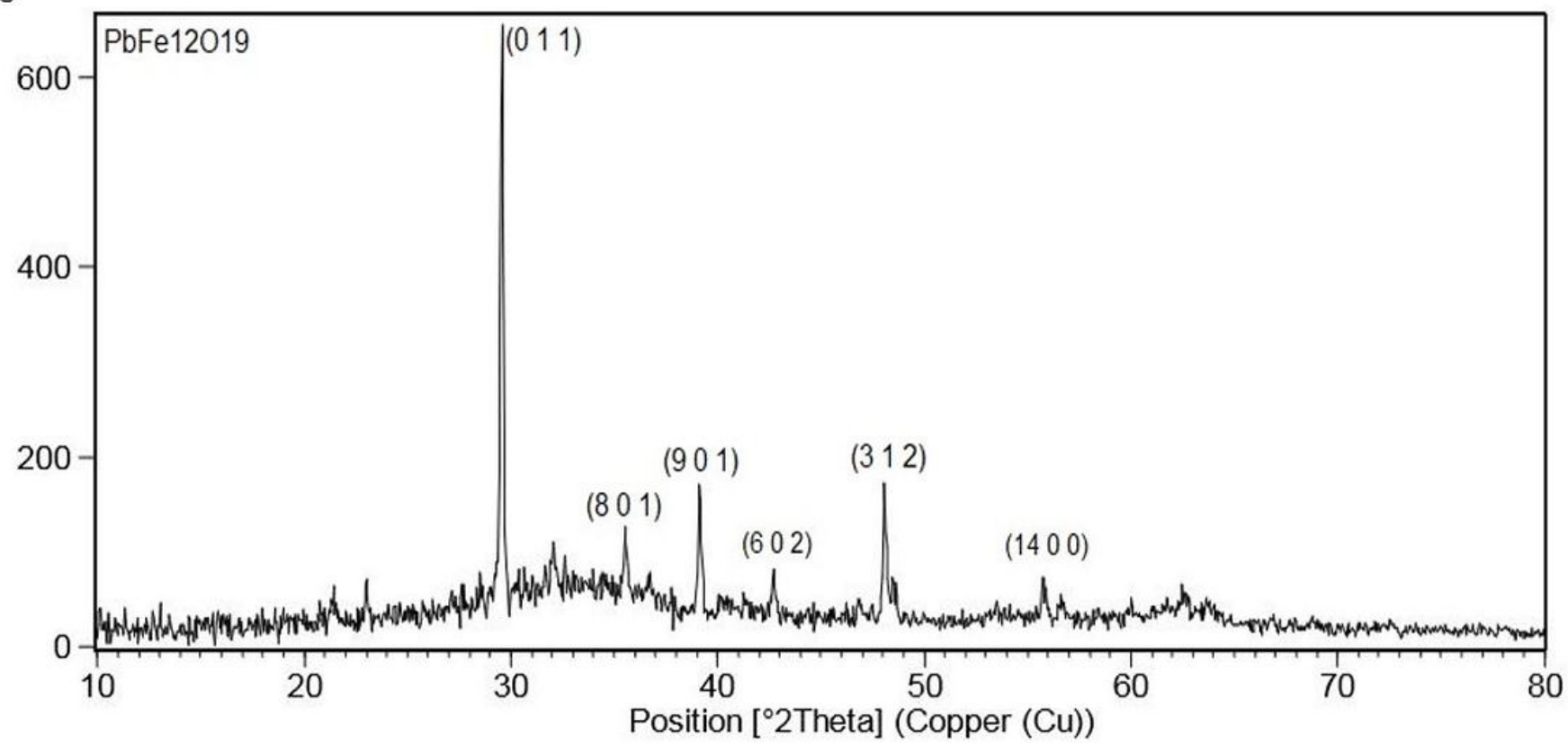

\section{Figure 19}

XRD pattern for lead ferrite nanoparticles.
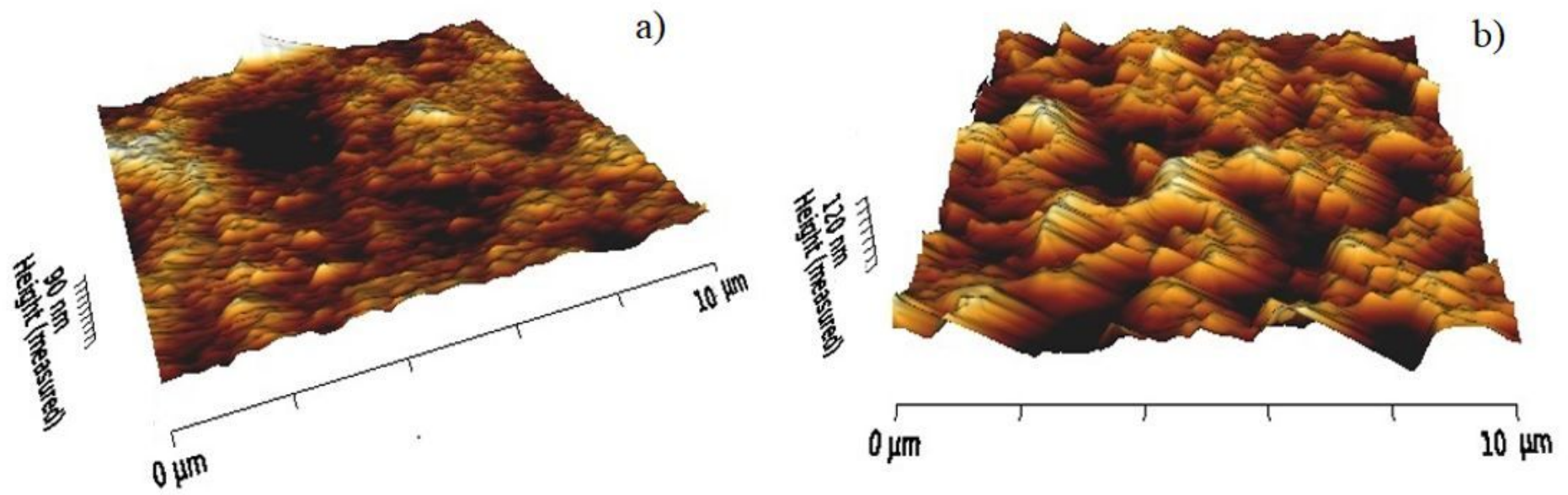

Figure 20

AFM images of thin layer of polyaniline with a) 5 cycles and b) 10 cycles of deposition. 


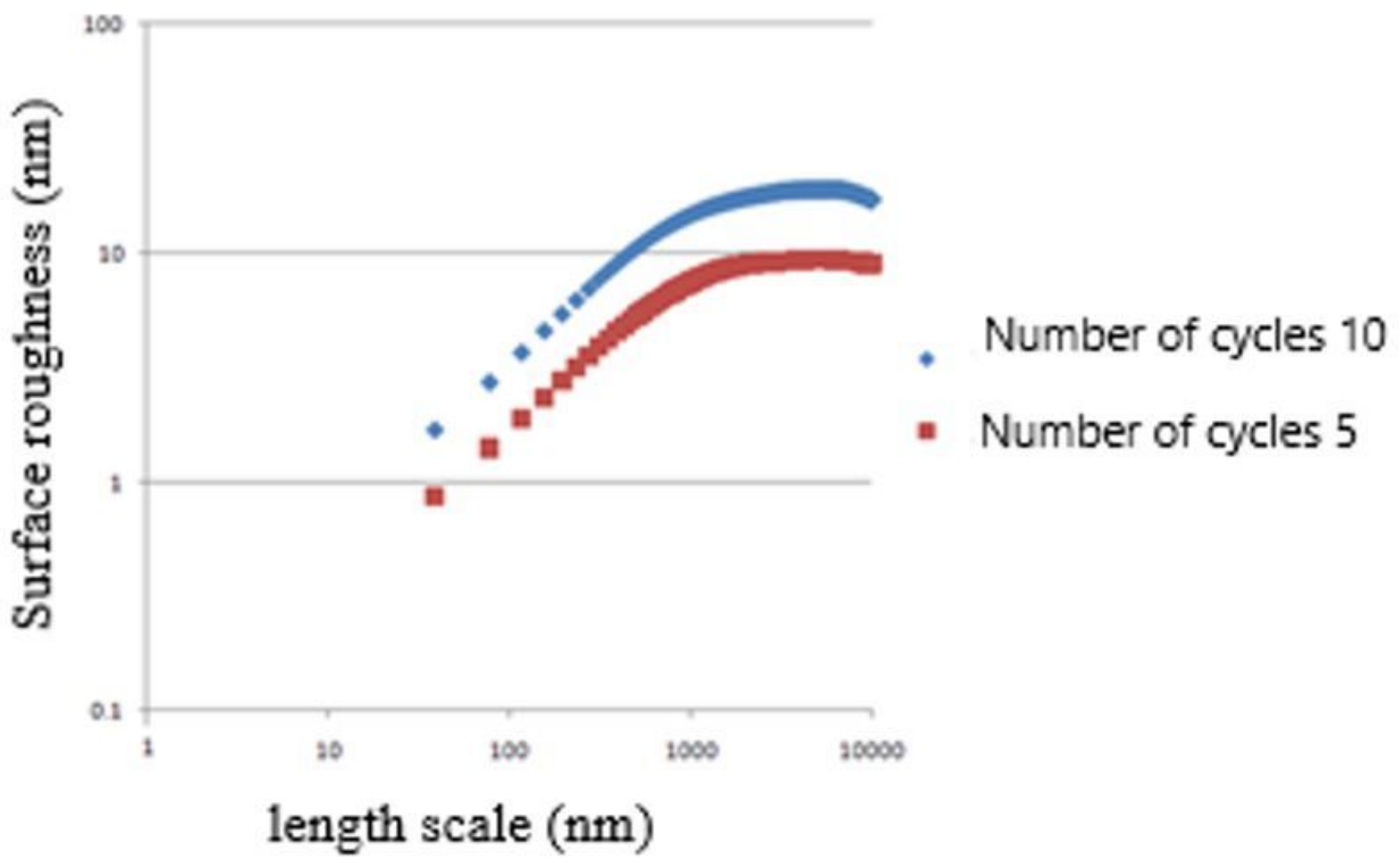

Figure 21

The roughness-scan length diagram in logarithmic scale for the thin layer of polyaniline with 5 and 10 cycles of deposition.
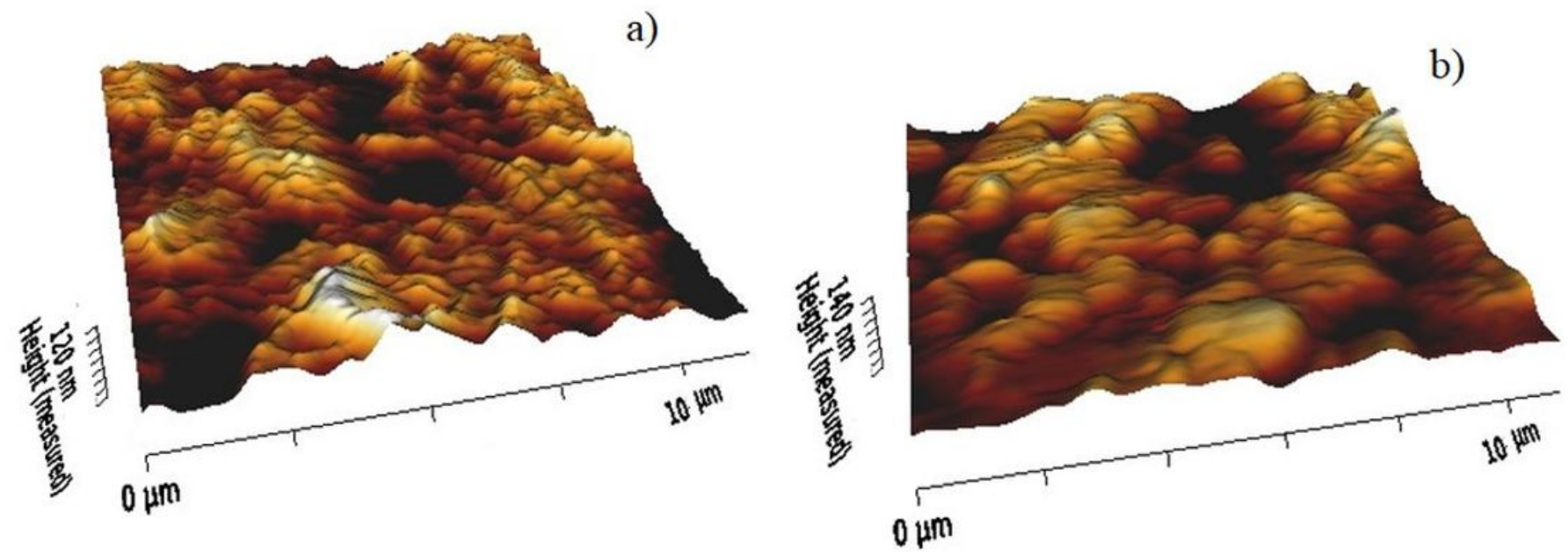

Figure 22

AFM images of polyaniline/ cobalt ferrite thin layer composite with a) $0 / 1 \mathrm{~g}$ and b) $1 \mathrm{~g}$ cobalt ferrite. 


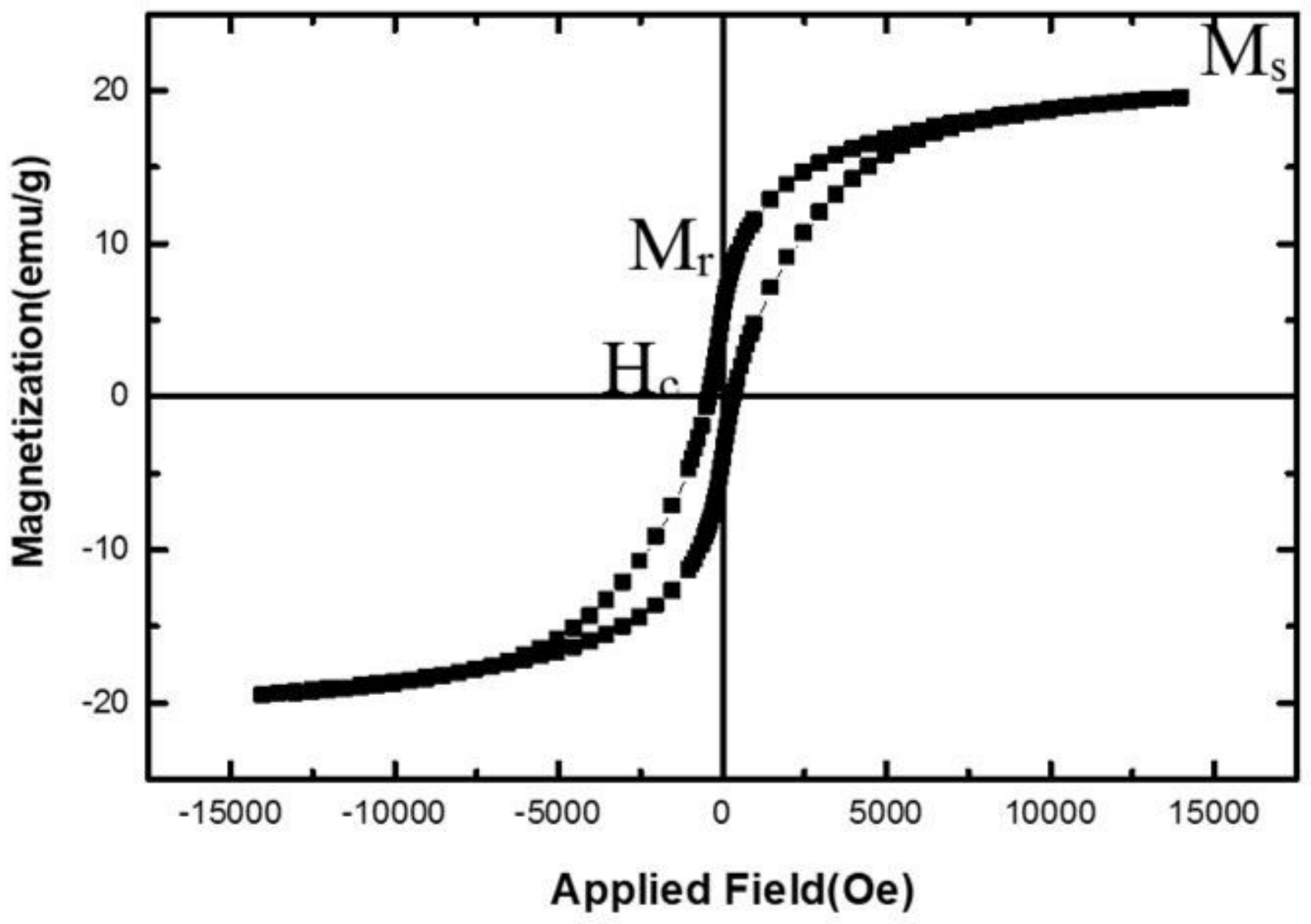

Figure 23

Hysteresis loop for cobalt ferrite nanoparticles. 


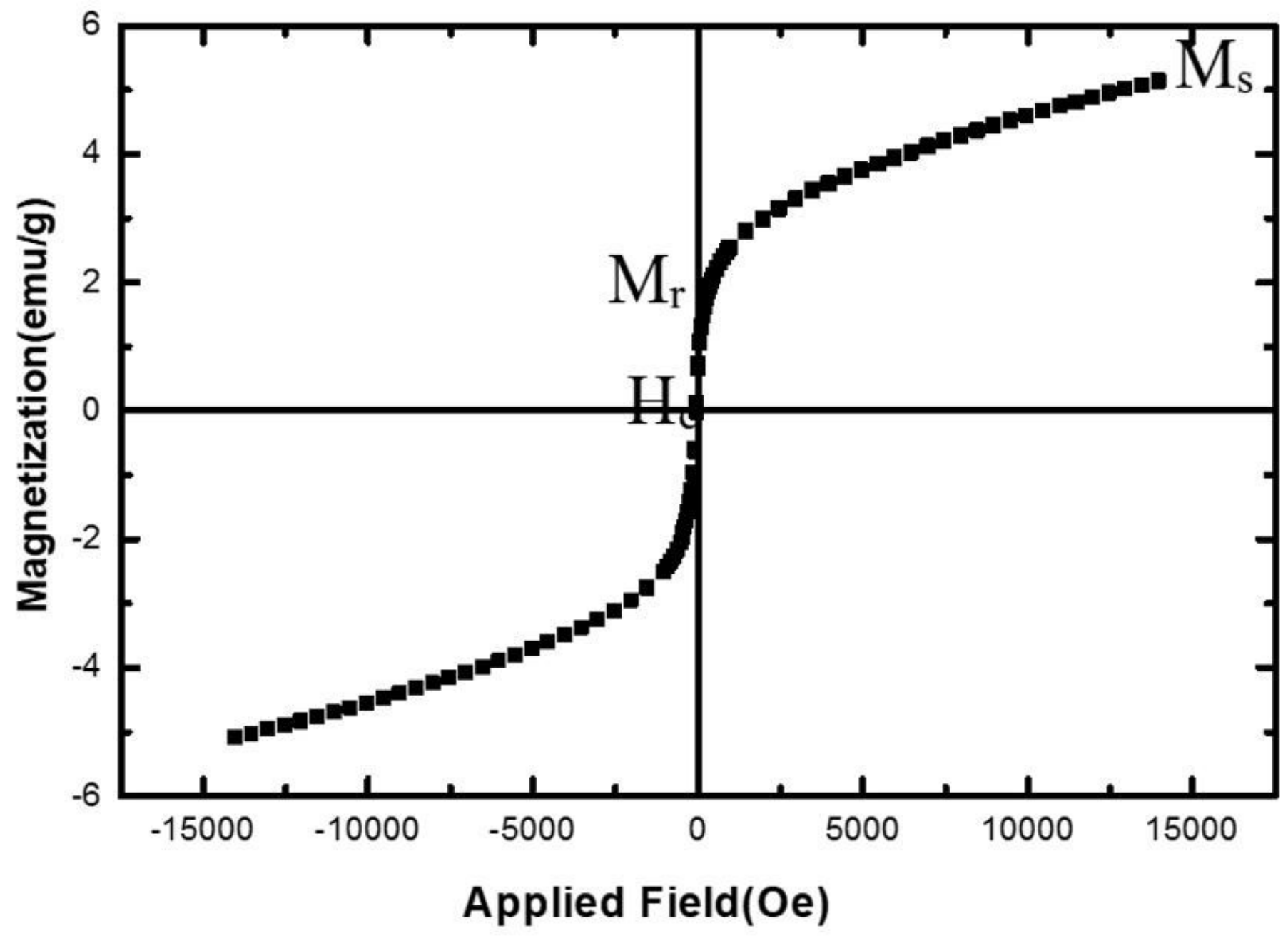

Figure 24

Hysteresis loop for nickel ferrite nanoparticles. 


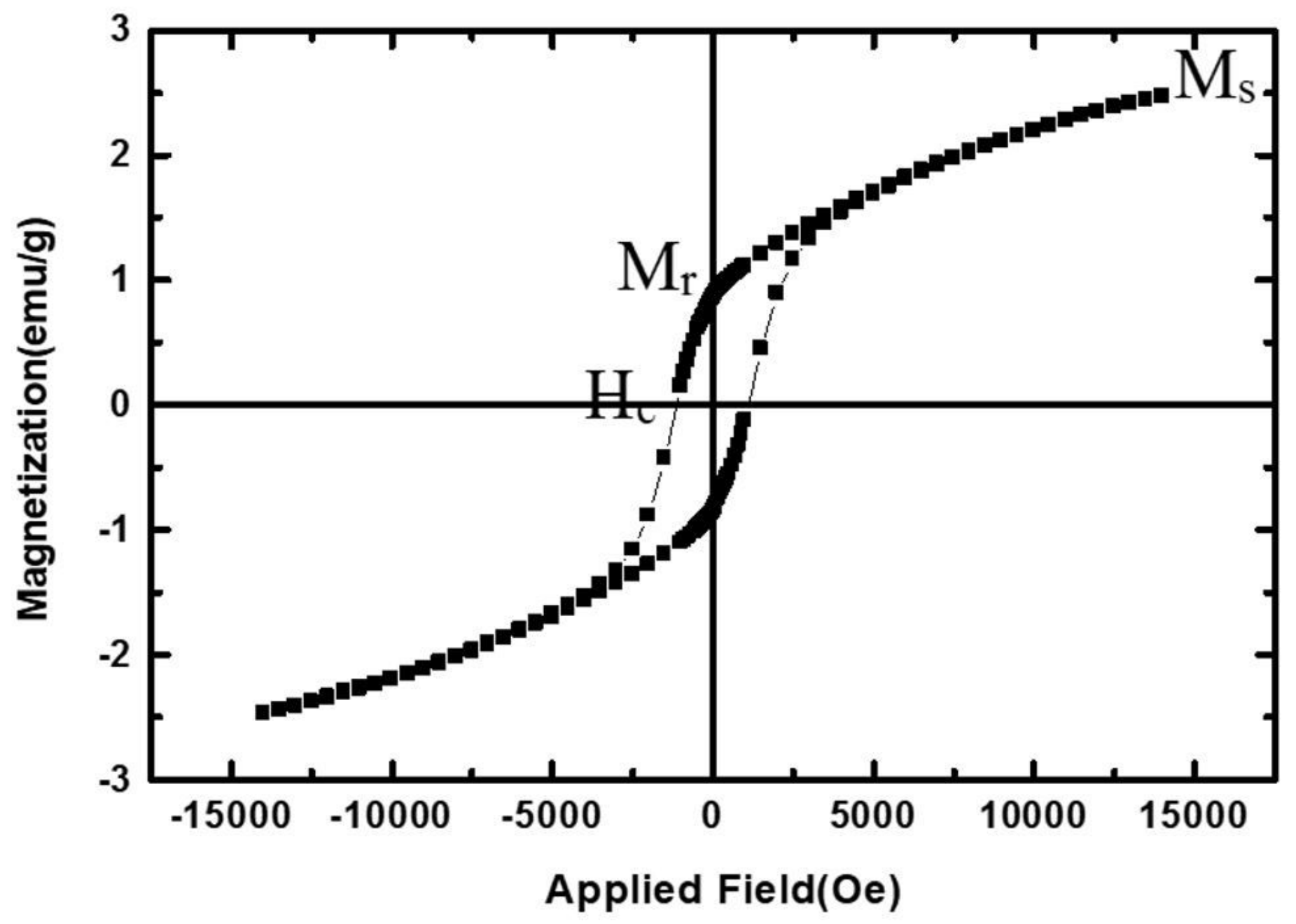

Figure 25

Hysteresis loop for lead ferrite nanoparticles. 


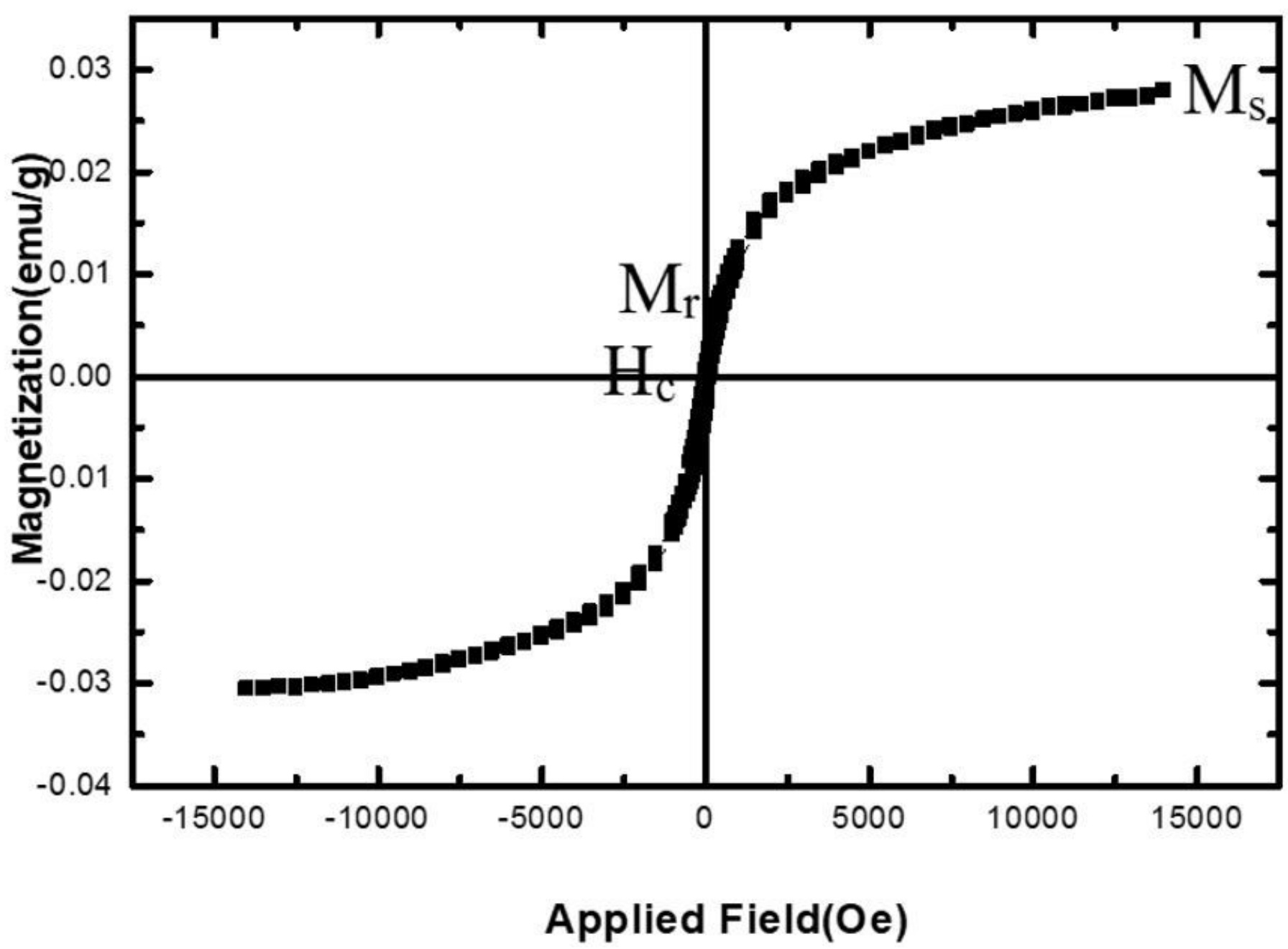

Figure 26

Hysteresis loop for polyaniline/ cobalt ferrite thin layer composite in parallel field. 


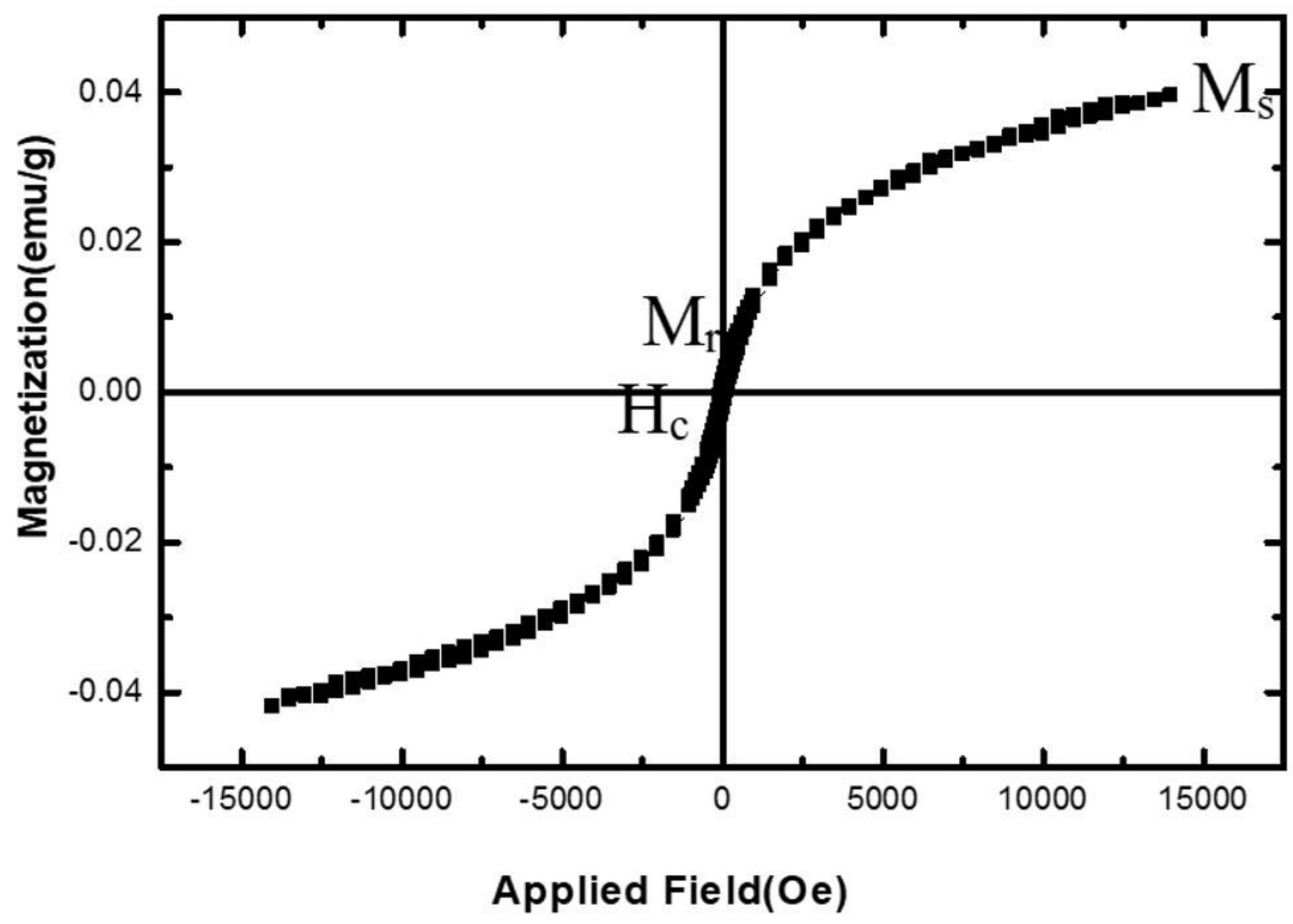

Figure 27

Hysteresis loop for polyaniline/ cobalt ferrite thin layer composite in vertical field. 